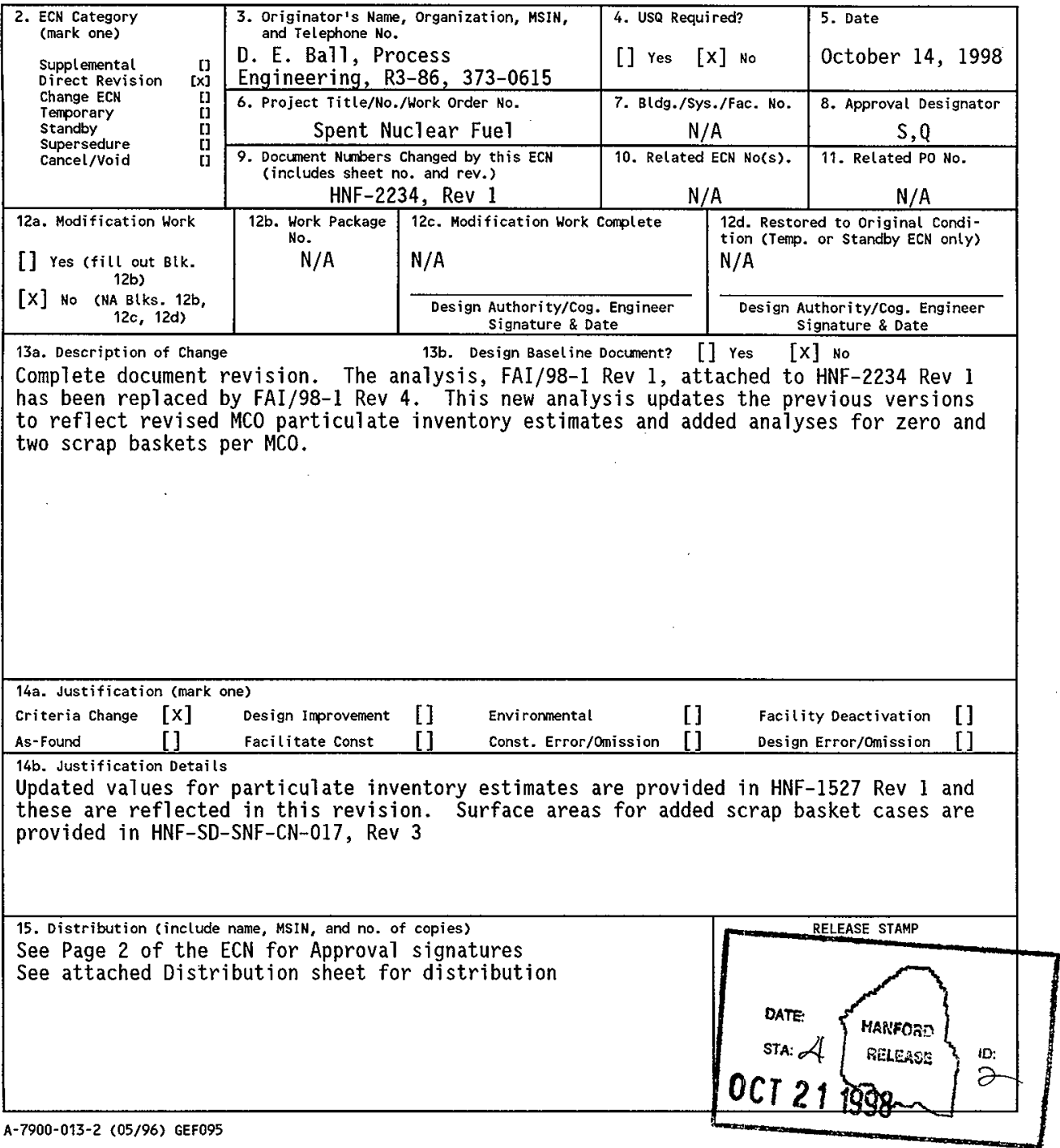




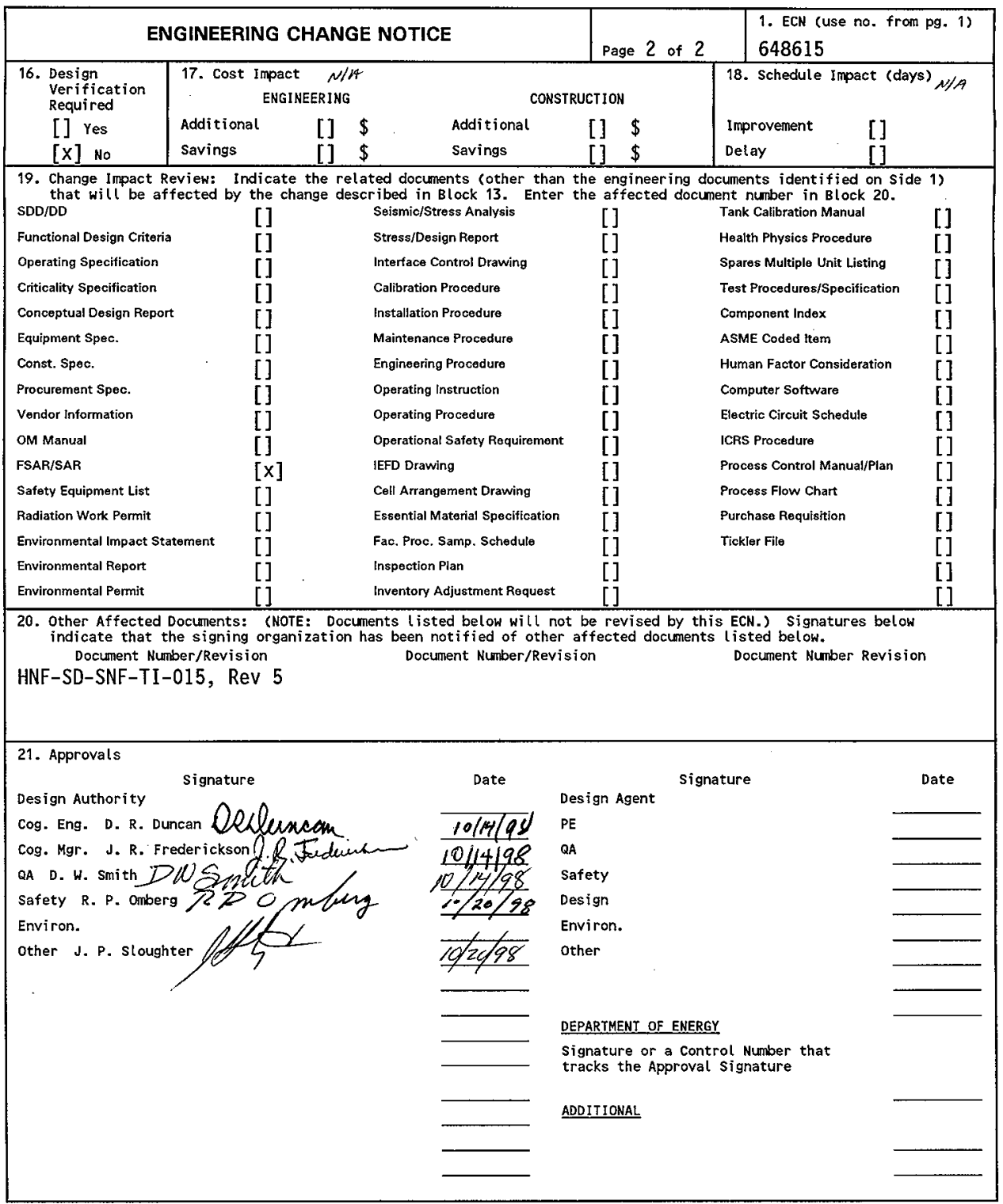


HNF-2234, Rev. 2

\section{SENSITIVITY OF PROBABILISTIC MCO WATER CONTENT ESTIMATES TO KEY ASSUMPTIONS}

D. R. Duncan, M. G. Plys*

DE\&S Hanford, Inc., Richland, WA 99352

U.S. Department of Energy Contract DE-AC06-96RL13200

EDT/ECN: 648615

Org Code: 2F300

B\&R Code: EW3135040
UC: 510

Charge Code: 105355, BA40

Total Pages: Uf $1 / 8$ percelecon $10 / 2198$

Key Words: MCO, particulate water content, cladding, damage, probabilistic

Abstract: Sensitivity of probabilistic multi-canister overpack (MCO) water content estimates to key assumptions is evaluated with emphasis on the largest non-cladding film contributors, water borne by particulates adhering to damage sites, and water borne by canister particulate. Calculations considered different choices of damage state degree of independence, different choices of percentile for reference high inputs, three types of input probability density function (pdfs): triangular, log-normal, and Weibu11, and the number of scrap baskets in an MCO.

*Fauske \& Associates, Burr Ridge, I11 inois

*MATHCAD is a registered trademark of MATHSOFT, Inc.

TRADEMARK DISCLAIMER. Reference herein to any specific comercial product, process, or service by trade name, trademark, manufacturer, or otherwise, does not necessarily constitute or imply its endorsement, recommendation, or favoring by the United States Government or any agency thereof or its contractors or subcontractors.

Printed in the United States of America. To obtain copies of this document, contact: Document Control Services, P.O. Box 950, Mailstop H6-08, Richland WA 99352, Phone (509) 372-2420;

Fax (509) 376-4989.
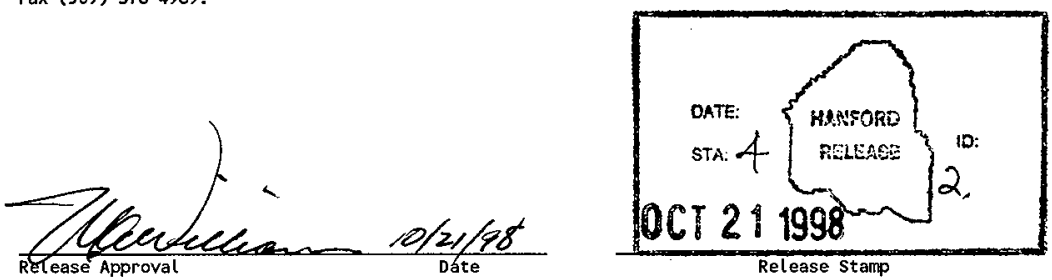

Approved for Public Release 
(2) Title

Sensitivity of Probabilistic MCO Water Content Estimates to Key Assumptions CHANGE CONTROL RECORD

\begin{tabular}{|c|c|c|c|c|}
\hline \multirow{2}{*}{ (3) } & \multirow{2}{*}{ Revision } & \multirow{2}{*}{ (4) Description of Change - Replace, Add, and Delete Pages } & \multicolumn{2}{|c|}{ Authorized for Release } \\
\hline & & & (5) Cog. Engr. & (6) Cog. Mgr. \\
\hline & 0 & (7) Released by EDT \#623987, Feb. 23, 1998 & $\begin{array}{l}\text { D. R. } \\
\text { Duncan }\end{array}$ & $\begin{array}{l}\text { J. R. } \\
\text { Frederickson }\end{array}$ \\
\hline & 1 & Released by ECN \#645071, March 23, 1998 & $\begin{array}{l}\text { D. R. } \\
\text { Duncan }\end{array}$ & $\begin{array}{l}\text { J. R. } \\
\text { Frederickson }\end{array}$ \\
\hline & $2 R S$ & $\begin{array}{l}\text { Complete document revision. The analysis, } \\
\text { FAI/98-1 Rev 1, attached to HNF-2234 Rev. I } \\
\text { has been replaced by FAI/98-1 Rev. } 4 \text {. This } \\
\text { new analysis updates the previous versions } \\
\text { to reflect revised MCO particulate } \\
\text { inventory estimates and added analyses for } \\
\text { zero and two scrap baskets per MCO. }\end{array}$ & 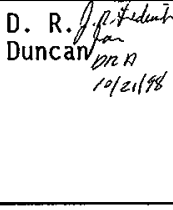 & $\begin{array}{l}\text { J. R. Mftelume } \\
\text { Fredeffickson } \\
10 / 21 / 58\end{array}$ \\
\hline & & $E C N-648615$ & & \\
\hline & & & & \\
\hline & & & & \\
\hline & & & & \\
\hline & & & & \\
\hline & & & & \\
\hline & & & & \\
\hline & & & & \\
\hline & & & & \\
\hline & & & & \\
\hline & & & & \\
\hline & & & & \\
\hline & & & & \\
\hline & & & & \\
\hline & & & & \\
\hline & & & & \\
\hline & & & & \\
\hline & & & & \\
\hline & & & & \\
\hline
\end{tabular}


HNF-2234, Rev. 2

FAI/98-1, Rev. 4

SENSITIVITY OF PROBABILISTIC MCO

WATER CONTENT ESTIMATES TO

KEY ASSUMPTIONS

Submitted To:

Duke Engineering \& Service Hanford

2355 Stevens Drive

Richland, WA 99352

Prepared By:

Martin G. Plys and Boro Malinovic

Fauske \& Associates, Inc.

16W070 West 83 rd Street

Burr Ridge, Illinois 60521

Tel: (630) 323-8750 Fax: (630) 986-5481 


\section{HNF-2234, Rev, 2 \\ Sensitivity of Probabilistic MCO Water \\ Content Estimates to Key Assumptions}

\subsection{PURPOSE}

The purpose of this document is to explore sensitivity of bounding multi-canister overpack (MCO) water inventory estimates to these three jssues: (1) Degree of independence for choice of input parameters values, (2) Percentile values of reference high input parameter values, and (3) Selection of extreme values for input parameters.

\subsection{SUMMARY}

Sensitivity of probabilistic MCO water content estimates to key assumptions is evaluated with emphasis on the largest non-cladding film contributors, water borne by particulate adhering to damage sites and water borne by canister particulate. Previous documents present "high" values for MCO particulate and water content found by applying high estimates for damage state and water fraction to all fuel elements in an MCO, Sloughter, 1998a. That procedure is known to be conservative and this document presents calculations to quantify the degree of conservatism and sensitivity to underlying assumptions. The analyses concludes that the high, or bounding, values are conservative.

It should be noted that values used for canister particulate and bound water do not reflect the latest issued values, Sloughter, 1998b. The results from using the values given in Sloughter, 1998a for this analyses is the introduction of a small degree of conservatism since they are slighter lower than those in Sloughter, 1998b.

\subsection{REFERENCES}

Sloughter, J.P., 1998a, "Estimates of Particulate Mass in Multi-Canister Overpacks," HNF-1527 Rev 1, Duke Engineering \& Services Hanford, Richland, Washington.

Sloughter, J. P., 1998b, "Estimates of Particulate Mass in Multi-Canister Overpacks," HNF-1527, Rev 2, Duke Engineering \& Services Hanford, Richland, Washington. 
HNF-2234, Rev. 2

TABLE OF CONTENTS

Page

LIST OF FIGURES $\ldots \ldots \ldots \ldots \ldots \ldots \ldots \ldots \ldots \ldots \ldots \ldots \ldots \ldots \ldots \ldots \ldots$

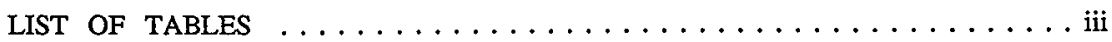

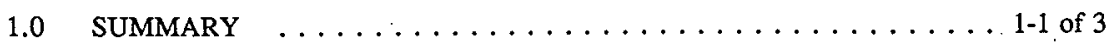

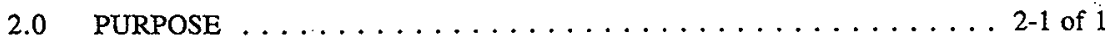

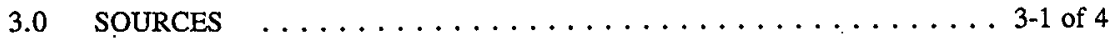

4.0 TECHNICAL BASES $\ldots \ldots \ldots \ldots \ldots \ldots \ldots \ldots \ldots \ldots \ldots$ 4 1 of 2

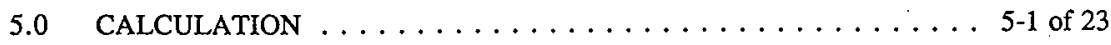

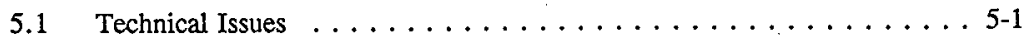

5.2 Model Equations and Method . . . . . . . . . . . 5-2

5.3 Probability Density Function and Case Inputs $\ldots \ldots \ldots \ldots \ldots \ldots$ 5-5

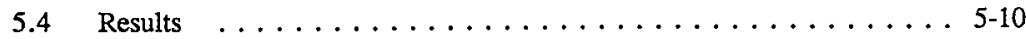

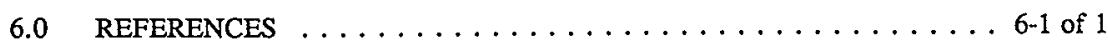

APPENDIX A Triangular Input Distributions $\ldots \ldots \ldots \ldots \ldots \ldots$ A-1 of 14 APPENDIX B Log-Normal Input Distributions ............ B-1 of 11

APPENDIX $\mathrm{C} \quad$ Weibull Input Distributions ................. APPENDIX D Validation of Monte Carlo Calculations . . . . . . D D-1 of 12 APPENDIX E Detailed Results for Monte Carlo Validation . . . . . E E-1 of 2 APPENDIX $F \quad$ Complete Results for Total Water Content ......... F-1 of 10 APPENDIX $\mathrm{G}$ Total Water Content Distribution Functions . . . . . . G-1 of 10 APPENDIX $\mathrm{H}$ Anderson-Darling Statistic Significance Levels $\ldots \ldots \ldots H$ H-1 of 1 APPENDIX I Water Content Using Final Value for Canister Particulate

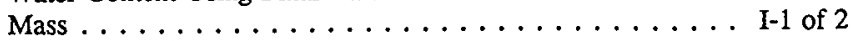
APPENDIX $\mathrm{J}$ Quality Assurance Documents $\ldots \ldots \ldots \ldots \ldots \ldots \ldots$ J-1 of 4 
HNF-2234, Rev. 2

\section{LIST OF FIGURES}

5-1 Output Water Content Curve Fit for Case 8 and 4 Groups, Log-Normal

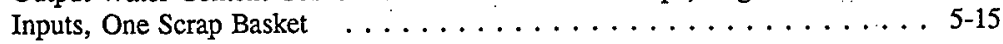

5-2 Output Water Content Curve Fit for Case 8 and 18 Groups, Log-Normal Input, One Scrap Basket $\ldots \ldots \ldots \ldots \ldots \ldots \ldots \ldots \ldots \ldots \ldots \ldots \ldots \ldots .16$

A-1 Derivation of New Triangular Distribution Maximum $\ldots \ldots \ldots \ldots \ldots$ A $\ldots$. . . 
HNF-2234, Rev. 2

\section{LIST OF TABLES}

\section{Table}

3-1 Summary of Reference Water Mass Categories $\ldots \ldots \ldots \ldots$ 3-2

3-2 Calculation of Particulate Water Mass $\ldots \ldots \ldots \ldots \ldots \ldots$ 3-3

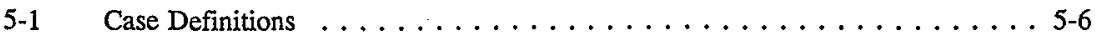

5-2 Parameters For Triangular Distributions . . . . . . . . . . . . 5-7

5-3 Parameters For $\log -$ Normal Distributions $\ldots \ldots \ldots \ldots \ldots$ 5-9 . . . . .

5-4 Parameters For Weibull Distributions $\ldots \ldots \ldots \ldots \ldots \ldots$ 5-11

5-5 Triangular Results Summary: No Scrap Basket $\ldots \ldots \ldots \ldots \ldots \ldots$. . . . . . .

5-6 Triangular Results Summary: One Scrap Basket . . . . . . . . . . 5-18

5-7 Triangular Results Summary: Two Scrap Baskets f . . . . . . . . . . 5-19

5-8 Log-Normal Results Summary: No Scrap Basket . . . . . . . . . . . 5-19

5-9 Log-Normal Results Summary: One Scrap Basket . . . . . . . . . . . . . 5-20

5-10 Log-Normal Results Summary: Two Scrap Baskets . . . . . . . . . 5 5-20

5-11 Weibull Resuits Summary: No Scrap Basket $\ldots \ldots \ldots \ldots \ldots$. . . . . . 21

5-12 Weibull Results Summary: One Scrap Basket $\ldots \ldots \ldots \ldots \ldots$. . . . . .

5-13 Weibull Results Summary: Two Scrap Baskets . . . . . . . . . . . . 5 5-22

$H-1 \quad$ Anderson-Darling Statistic Distribution $\ldots \ldots \ldots \ldots \ldots \ldots \ldots \ldots \ldots$

I-1 Comparison of Results Using Draft and Final Inputs for Canister Particulate Mass per Assembly. . . . . . . . . . . . . . . . I-2 


\subsection{SUMMARY}

Sensitivity of probabilistic multi-canister overpack $(\mathrm{MCO})$ water content estimates to key assumptions is evaluated here with emphasis on the largest non-cladding film contributors, water borne by particulate adhering to damage sites, and water borne by canister particulate. Previous documents present "high" values for MCO particulate and water content found by applying high estimates for damage state and water fraction to all fuel elements in an MCO [Sloughter, et al., 1998; and Duncan and Ball, 1998]. That procedure is known to be conservative, and this document presents calculations to quantify the degree of conservatism and sensitivity to underlying assumptions. Cladding surface films are discussed in [Sloughter, et al., 1998].

Key technical issues addressed in this calculation note are:

1. Damage State Degree of Independence. Because an $\mathrm{MCO}$ is comprised of fuel from about 18 canister pairs, and the number of damaged fuel assemblies and the state of damage vary from canister to canister, the degree of independence, or number of independent choices of damage state in an $\mathrm{MCO}$, must be considered.

2. $\quad$ Percentile of Reference High Inputs. The percentile assigned to reference high inputs [Sloughter, et al., 1998; and Duncan and Ball, 1998] must be explored. The reference definition of a high input value is one that is exceeded occasionally, but is an unreasonable representation of an entire MCO.

3. Extreme Input Values. Reasonable extrema must be chosen for input parameters, if the previously used high values are to be exceeded.

Probabilistic calculations were performed to determine distributions for total water borne by particulate adhering to damage sites and canister particulate adhering to any part of a fuel assembly. In all, one hundred eighty (180) calculations were performed to explore the three issues described above. Calculations considered different choices of damage state degree of independence, different choices of percentile for reference high inputs, three types of input probability density functions (pdfs): triangular, log-normal, and Weibull, and the number of 
scrap baskets in an MCO. The number of independent damage state choices was varied between 4 and 18 , where 4 corresponds to each fuel basket plus associated scrap having independent damage states, and 18 corresponds to each canister pair (14 assemblies) having independent $=$ : damage states. A degree of independence of at least 10 is judged to be realistic based on observations [Pitner, 1995]. For triangular distributions, percentile values for reference high input parameters were $100 \%, 97.5 \%, 95 \%$, and $90 \%$. For log-normal and Weibull distributions, these percentiles were $99.9 \%, 97.5 \%, 95 \%$, and $90 \%$. A percentile of at least $95 \%$ is judged to represent the reference choice of high values. Cases were replicated to consider MCO configurations with zero, one, and two scrap baskets:

Results of probabilistic calculations show the following trends:

- the calculated mean particulate mass and water content increase as the percentile of reference bounding input parameters decreases,

- the calculated particulate mass and water content standard deviation decrease as the number of independent damage states increases,

- output distributions are generally well-approximated as log-normal,

- the "incredible value" (the value with an exceedance probability of $1 \mathrm{x}$ $10^{-6}$ ) of particulate and water mass decreases as the number of independent damage state choices increases, and

- incredible values are comparable for cases with triangular, log-normal, and Weibull input pdfs.

Calculated mean values for water content depend on the number of scrap baskets, damage state independence, and percentile applied to reference high input parameters, but may be summarized as follows:

- For no scrap baskets, the mean value for water content was between 0.1 and $0.4 \mathrm{~kg}$,

- For a single scrap basket, the mean value for water content was between 0.2 and $0.5 \mathrm{~kg}$, and 
- $\quad$ For two scrap baskets, the mean value for water content was between 0.2 and $0.6 \mathrm{~kg}$.

Reference high water content values were only exceeded for extreme combinations of the $90^{\text {th }}$ percentile assigned to reference input high quantities, and a low degree of damage state independence, less than 10 independent selections. For the case of reference high inputs representing the $95^{\text {th }}$ percentile, and at least $\mathrm{n}=10$ for independent choices of damage level, incredible values are calculated to be roughly $2 / 3$ the reference high water contents:

- For zero scrap baskets, about $0.8 \mathrm{~kg}$ are calculated to be incredible, versus the reference value of $1.2 \mathrm{~kg}$,

- For one scrap basket, 0.75 to $0.83 \mathrm{~kg}$ are calculated to be incredible, versus the reference value of $1.37 \mathrm{~kg}$, and

- For two scrap baskets, about $1.0 \mathrm{~kg}$ is calculated to be incredible, versus the reference value of $1.55 \mathrm{~kg}$. 
HNF-2234, Rev. 2

\subsection{PURPOSE}

The purpose of this work is to explore sensitivity of bounding multi-canister overpack (MCO) water inventory estimates to these three issues: (1) Degree of independence for choice of input parameter values, (2) Percentile values of reference high input parameter values, and (3) Selection of extreme values for input parameters. This calculation focuses on the most important two line item contributors to the MCO water inventory, excluding cladding surface films, water associated with particulate clinging to fuel assemblies.at damage sites and water associated with canister particulate adhering to assembly surfaces after fuel cleaning. Cladding film inventory is discussed by [Sloughter, et al., 1998] and its water content is discussed by [Duncan and Ball, 1998]. 
HNF-2234, Rev. 2

\subsection{SOURCES}

High, nominal, and low values for the post-cold vacuum drying (CVD) MCO particulate inventory are provided by [Sloughter, et al., 1998], and similar values for the post-CVD MCO water inventory are provided by [Duncan and Ball, 1998]. Both documents used a framework with seven basic particulate/water source categories, as shown in Table 3-1. Cladding film, oxide film, and adhering particulate may be further broken down into scrap basket and fuel basket line item contributions. The largest contribution to water inventory is from a cladding film composed of aluminum oxide hydrates for those fuel assemblies stored in aluminum containers at $\mathrm{K}$ West; this contribution is considered by [Sloughter, et al., 1998].

The largest contributors remaining are water associated with particulate adhering to fuel assemblies at damage sites for an MCO with no scrap baskets, and water associated with canister particulate for an MCO with two scrap baskets. The particulate masses per assembly and water mass fractions were assigned values as shown in Table 3-2.

Canister particulate water was calculated by multiplying high, nominal, and low values for particulate per fuel element by the number of fuel elements in fuel baskets in an $\mathrm{MCO}$, and multiplying the result by corresponding high, nominal, and low water fractions:

$$
\mathrm{m}_{\mathrm{wcp}}=\mathrm{n}_{\mathrm{f}} \mathrm{n}_{\mathrm{af}} \mathrm{m}_{\mathrm{cpf}} \mathrm{f}_{\mathrm{wcp}}
$$

where $\mathrm{m}_{\mathrm{wcp}}=$ mass of canister particulate water in an $\mathrm{MCO}$,

$n_{\mathbf{f}}=$ number of fuel baskets in an $\mathrm{MCO}$,

$\mathrm{n}_{\mathrm{af}}=$ number of fuel assemblies in a fuel basket, 54 ,

$\mathrm{m}_{\mathrm{cpf}}=$ mass of canister particulate per fuel assembly, and

$f_{w c p}=$ water fraction of canister particulate.

Note that canister particulate is only associated with assemblies in fuel baskets. Table 3-2 contains the high, nominal, and low values for the evaluation. For example, the nominal water 
Table 3-1: Summary of Reference Water Mass Categories and Values Rounded From [Plys, et al., 1998 ].

\begin{tabular}{|c|c|c|c|c|c|c|c|c|c|}
\hline \multirow{2}{*}{ Source } & \multicolumn{3}{|c|}{$\begin{array}{l}\text { Zero Scrap, } \\
\text { Five Fuel Baskets }\end{array}$} & \multicolumn{3}{|c|}{$\begin{array}{l}\text { One Scrap, } \\
\text { Four Fuel Baskets }\end{array}$} & \multicolumn{3}{|c|}{$\begin{array}{c}\text { Two Scrap, } \\
\text { Three Fuel Baskets }\end{array}$} \\
\hline & High & Nominal & Low & High & Nominal & Low & High & Nominal & Low \\
\hline $\mathrm{A} \ell(\mathrm{OH})_{3}$ Cladding Film & 3.72 & 0.931 & 0 & 3.52 & 0.88 & 0 & 3.31 & 0.83 & 0 \\
\hline $\begin{array}{l}\text { Uranium Oxide Hydrate } \\
\text { Cladding Film }\end{array}$ & 0 & 0.04 & 0.06 & 0 & 0.04 & 0.05 & 0 & 0.03 & 0.05 \\
\hline Oxide Film & 0.02 & $<0.001$ & $<0.001$ & 0.04 & 0.002 & $<0.001$ & 0.06 & 0.004 & 0.001 \\
\hline Adhering Particulate & 0.30 & 0.08 & 0.005 & 0.67 & 0.10 & 0.008 & 1.0 & 0.11 & 0.01 \\
\hline Canister Particulate & 0.91 & 0.049 & 0 & 0.73 & 0.039 & 0 & 0.55 & 0.029 & 0 \\
\hline Generated Particulate & 0.03 & 0 & 0 & 0.05 & 0 & 0 & 0.08 & 0 & 0 \\
\hline Free Water & 0.20 & 0.20 & 0.20 & 0.20 & 0.20 & 0.20 & 0.20 & 0.20 & 0.20 \\
\hline TOTAL & 5.2 & 1.30 & 0.26 & 5.2 & 1.25 & 0.26 & 5.2 & 1.20 & 0.26 \\
\hline
\end{tabular}


HNF-2234, Rev. 2

\begin{tabular}{|c|c|c|c|}
\hline Source & Low & Nominal & High \\
\hline Adhering Particulate Mass per Assembly, Scrap, gram & 6 & 20 & 200 \\
\hline Adhering Particle Mass per Assembly, Fuel, gram & 1.3 & 7.6 & 20 \\
\hline Adhering Particulate Water Content & $1.5 \%$ & $4 . \%$ & $5.5 \%$ \\
\hline Canister Particulate Mass per Fuel Assembly, gram & 0 & $2.22(1)$ & 13.0 \\
\hline Canister Particulate Water Content & $2 . \%$ & $7.5 \%$ & $26 . \%$ \\
\hline \multicolumn{4}{|l|}{ Example for MCO With One Scrap Basket: } \\
\hline Canister Particulate Water Mass, kg & 0 & 0.036 & 0.73 \\
\hline Adhering Particulate Water Mass, Scrap (2), kg & 0.004 & 0.031 & 0.43 \\
\hline Adhering Particulate Water Mass, Fuel (2), kg & 0.004 & 0.066 & 0.24 \\
\hline \multicolumn{4}{|c|}{$\begin{array}{l}\text { (1) This value is } 2.41 \text { grams in the final yersion of [Sloughter, et al, } 1998 \text { ] For the } \\
\text { methodology to follow, the difference between the draft and final values is negligible } \\
\text { (2) 39, assemblies for scrap, } 216 \text { assemblies for fuel. }\end{array}$} \\
\hline
\end{tabular}

mass borne by canister particulate in an MCO with one scrap basket is $\mathrm{m}_{\mathrm{wcp}}=4 * 54 *$ $0.00241 * 0.075=0.039 \mathrm{~kg}$. Note that the nominal canister particulate mass changed slightly between draft and final versions of [Sloughter, et al., 1998]. The draft value in Table 3-2 was used for analyses in Section 5, and Appendix I contains calculations with the final value, and demonstrates that there is no impact on conclusions.

Adhering particulate water was calculated by summing contributions from fuel and scrap basket assemblies, where each contribution again is a product of mass and water content values assigned to all fuel assemblies of each basket type:

$$
m_{\text {wap }}=n_{f} n_{a f} m_{\text {apf }} f_{\text {wap }}+n_{s} n_{\text {as }} m_{\text {aps }} f_{\text {wap }}
$$

where $m_{\text {wap }}=$ mass of adhering particulate water in an $\mathrm{MCO}$,

$\mathrm{m}_{\text {apf }}=$ mass of adhering particulate per fuel assembly,

$\mathrm{m}_{\text {aps }}=$ mass of adhering particulate per scrap assembly, 


$$
\begin{aligned}
& \mathrm{f}_{\text {wap }}=\text { water fraction of adhering particulate, } \\
& \mathrm{n}_{\mathrm{s}}=\text { number of scrap baskets, and } \\
& \mathrm{n}_{\mathrm{as}}=\text { number of equivalent fuel assemblies in a scrap basket, 39.1. }
\end{aligned}
$$

Table 3-2 also contains values needed to calculate the adhering particulate water mass. For example, the nominal water mass borne by adhering particulate in an MCO with one scrap basket is $\mathrm{m}_{\text {wap }}=(4 * 54 * 0.0076 * 0.04)+(1 * 39.1 * 0.02 * 0.04)=0.066+0.031=$ $0.097 \mathrm{~kg}$.

The technique described above is conservative because high values for each input parameter are combined and assumed to apply to all fuel elements. Clearly, it is improbable to load an MCO with fuel assemblies that are all at extreme damage levels and whose corrosion product contains the highest water content. Calculations in this report are motivated by these concerns. 
HNF-2234, Rev. 2

\subsection{TECHNICAL BASES}

This assessment explores sensitivity to the degree of independence of key input parameter values and the shape and extrema of their probability density functions (pdfs).

A best judgement of the degree of independence of damage states is based on the K-East top view fuel survey which assigned damage states to every fuel assembly inner and outer element in every canister [Pitner, 1995]. As a technical basis for conclusions, the degree of independence of fuel damage levels is expected to be close to the canister pair level, i.e., the damage level will vary randomly from canister pair to canister pair, or for groups of a few canister pairs. In contrast, it is not expected that the degree of independence exists at the fuel basket level (a fuel basket holds 54 assemblies, or about 4 canister pairs), and it is certainly inappropriate to assume that all fuel assemblies in an MCO can have the same damage level. Note that this assumption applies to fuel damage levels and not to the cladding film; it is possible to construct an MCO comprising assemblies which all have or all lack an aluminum oxide hydrate cladding film.

Reference particulate [Sloughter, et al., 1998] and water content [Duncan and Ball, 1998] documents provide technical bases for bounding input parameter values. High values are such that they may be occasionally exceeded, but are not a realistic value for an entire MCO. Here, percentiles are assigned to these values. For example, the 95 -th percentile implies a $5 \%$ chance that the bound may be locally exceeded. The 95 -th percentile is judged to represent the intent of the references.

The reference documents provide three points: low, nominal, and high values for input parameters. These values form the technical basis for selection of pdf's used here. The chosen pdf's, triangular, log-normal, and Weibull, capture the reference data and provide a detailed pdf shape not explicitly given by the references. Obviously, a triangular distribution can be created from the three reference points. A log-normal distribution has the advantage of allowing a longer tail for extreme values, which is useful for sensitivity analysis. The Weibull distribution 
provides an alternative to the log-normal for additional sensitivity analysis. Other probability distributions can be used to describe the results noted in Tables 3-1 and 3-2, but with little realistic gain. 


\subsection{CALCULATION}

\subsection{Technical Issues}

Probabilistic calculations were performed to calculate the particulate mass and water content associated with particulate clinging to fuel assemblies of a single MCO. These calculations use a range of input parameter values selected to address three key issues of a probabilistic assessment.

1. Damage State Degree of Independence. An MCO is loaded with fuel assemblies from about 18 canister pairs (assuming each pair contains 14 full assemblies). High estimates of particulate mass [Sloughter, et al., 1998] were previously made by applying bounding values per assembly simultaneously to all assemblies loaded into an MCO. In practice, the damage state is variable from canister pair to canister pair, so as many as 18 independent choices of damage state are implicitly made as an MCO is loaded. This implies a very low probability that all loaded assemblies have damage states near the high value.

Thus the first key issue for a probabilistic assessment is the number of times a given damage state is independently chosen when loading an MCO. This issue is addressed by varying the number of independent damage state choices from 4 to 18 with an equal number of assemblies per choice.

2. Probability of Exceeding High Input Parameter Values. Input parameters required to estimate the particulate inventory and water content were assigned low, nominal, and high values in references. The stated interpretation of the high values is: The high value may occasionally be locally exceeded, but it would be inappropriate to apply this value for an entire MCO. From this statement, particulate and water content estimates were implicitly defined as incredible because high input parameter values were indeed applied to the entire contents of an MCO. Authors of the particulate and water content estimates did not have a good knowledge base to assign a probability that the selected high value might be locally exceeded.

Hence, the second key issue for a probabilistic assessment is to explore the impact of various probability levels that the high value for input parameters might be locally exceeded, in essence, to assign a percentile 
value in a cumulative pdf to the previously used high parameter values. This issue is addressed by assigning percentile values of $100 \%(99.9 \%$ in the case of a log-normal or Weibull), $97.5 \%, 95 \%$, and $90 \%$.

3. Extreme Values of Input Parameters. When probability density functions (pdf's) are chosen for input parameter values, a key issue is the physical meaning of the highest values that are implied by the distribution. On one hand, it is physically necessary that a meaningful upper limit be used to define the distribution or be implied by the distribution; for example, the amount of particulate on a fuel assembly cannot physically exceed some fraction of the assembly mass. On the other hand, in the absence of a large number of measurements, a physical upper bound can be argued to be somewhat subjective. Expanding the previous example, the maximum fraction of an assembly that is particulate should not exceed a value at which the assembly would no longer have structural integrity -- but selection of the fraction is somewhat subjective.

Hence, the third key issue for a probabilistic assessment is the selection of physically possible extrema for input parameter pdf's. This issue is addressed by considering triangular, log-normal, and . Weibull distributions. The log-normal and Weibull are useful for sensitivity because they exhibit long tails and allow large values.

Note that the issues are framed to resolve the question of high bounding results. If the concern were shifted to the expected range of particulate during normal operation, issues such as the choice of pdf for input parameters would also become important. However, the three issues described above suffice for exploration of bounding results.

\subsection{Model Equations and Method}

The mass of particulate adhering to damage sites in a single MCO can be found from:

$$
m_{a p}=\sum_{i=1}^{n} \frac{n_{s} n_{a s}}{n} m_{a p s i}+\frac{n_{f} n_{a f}}{n} m_{a p f i}
$$

where $\mathrm{m}_{\mathrm{ap}}=$, mass of adhering particulate in an $\mathrm{MCO}$,

$\mathrm{n}=$ degree of independence,

$\mathrm{n}_{\mathrm{s}}=$ number of scrap baskets, 


$$
\begin{aligned}
& \mathrm{n}_{\mathrm{as}}=\text { number of assemblies per scrap basket, } \\
& \mathrm{m}_{\text {apsi }}=\quad \text { mass of adhering particulate per scrap assembly, random sample } \mathrm{i}, \\
& \mathrm{n}_{\mathrm{f}}=\text { number of fuel baskets, } \\
& \ddot{\mathrm{n}}_{\mathrm{af}}=\quad \text { number of assemblies per fuel basket, and } \\
& \mathrm{m}_{\mathrm{apfi}}=\quad \text { mass of adhering particulate per fuel assembly, random sample } \mathrm{i} .
\end{aligned}
$$

This equation is an extension of the reference calculations (see Section 3, Sources) to allow $n$ independent damage level choices among 39.1 scrap and 216 fuel assemblies. If there is no independence between canister pairs, $n=1$. If canister pairs are completely independent, $n=$ 18. Calculations were performed here with $n=4,7,10,14$, and 18 to span the range of interest and demonstrate the impact of variation in this parameter. Each independent group of assemblies is of equal size because the point is to illustrate the impact of having $n>1$.

Similarly, water content can be found from:

$$
m_{\text {wap }}=\sum_{i=1}^{n}\left(\frac{n_{s} n_{a s}}{n} m_{a p s i}+\frac{n_{f} n_{a f}}{n} m_{a p r i}\right) x_{\text {wapi }}
$$

where $\mathrm{x}_{\text {wapi }}=$ water fraction of adhering particulate on random sample $\mathrm{i}$.

Similarly, the mass of canister particulate and the mass of water borne by canister particulate are given by

$$
\begin{aligned}
& \mathrm{m}_{\mathrm{cp}}=\sum_{\mathrm{i}=1}^{\mathrm{n}} \frac{\mathrm{n}_{\mathrm{f}} \mathrm{n}_{\mathrm{af}}}{\mathrm{n}} \mathrm{m}_{\mathrm{cpfi}} \\
& \mathrm{m}_{\mathrm{wcp}}=\sum_{\mathrm{i}=1}^{\mathrm{n}} \frac{\mathrm{n}_{\mathrm{f}} \mathrm{n}_{\mathrm{af}}}{\mathrm{n}} \mathrm{m}_{\mathrm{cpfi}} \mathrm{x}_{\mathrm{wcpi}}
\end{aligned}
$$

where $\mathrm{m}_{\mathrm{cp}}=$ mass of canister particulate in an $\mathrm{MCO}$,

$\mathrm{m}_{\mathrm{cpfi}}=$ mass of canister particulate per fuel assembly, random sample $\mathrm{i}$, and

$x_{\text {wcpi }}=$ water fraction of canister particulate, random sample $i$. 
Total water in an MCO for a particular trial is therefore

$$
\mathrm{m}_{\mathrm{w}}=\mathrm{m}_{\mathrm{wap}}+\mathrm{m}_{\mathrm{wcp}}
$$

A Monte Carlo method was employed using various probability density functions (pdf's) for inputs, described in Section 5.3, to generate pdf's for particle masses and water contents. Simulations using Crystal Ball ${ }^{\text {tw }}$ [Decisioneering, 1996] generated thousands of random samples for the five random variables $m_{\text {apsi }}, m_{\text {apfi }}, x_{\text {wapi }}, m_{c p f i}$, and $x_{w c p i}$. (equations (5-1) and (5-4) above), then evaluated $m_{c p}, m_{w c p}, m_{a p}, m_{w a p}$, and $m_{w}$, and lastly, tallied the output.

Probability density functions used for the five random variables can be described as follows:

Triangular

Parameters: Minimum, Likeliest, and Maximum.

Formula: $\quad f(x)= \begin{cases}\frac{h(x-\text { Min })}{\text { Likeliest }- \text { Min }} & \text { if Min }<x<\text { Likeliest } \\ \frac{h(x-\text { Likeliest })}{\text { Likeliest }- \text { Max }}+h & \text { if Likeliest }<x<\text { Max } \\ 0 & \text { otherwise }\end{cases}$

$$
\text { where } h=\frac{2}{\operatorname{Max}-\operatorname{Min}}
$$

\section{Weibull}

Parameters: Location (L), Scale $(\alpha)$, and Shape $(\beta)$.

$$
\text { Formula: } \quad \begin{aligned}
\mathrm{f}(\mathrm{x}) & =\frac{\beta}{\alpha}\left(\frac{\mathrm{x}-\mathrm{L}}{\alpha}\right)^{\beta-1} \mathrm{e}^{-\left(\frac{\mathrm{x}-\mathrm{L}}{\alpha}\right)^{\beta}} & & \text { if } \mathrm{x}>\mathrm{L} \\
& =0 & & \text { if } \mathrm{x}<\mathrm{L}
\end{aligned}
$$


HNF-2234, Rev. 2

\section{$\underline{\text { Log-Normal }}$}

Parameters: Log mean $(\mu)$, and Log Standard Deviation $(\sigma)$.

Formula: $\quad f(x)=\frac{1}{x \sqrt{2 \pi} \sigma} e^{-\frac{(\ell n(x)-\mu)^{2}}{2 \sigma^{2}}} \quad$ for $0<x<\infty$

As discussed in Section 5.4, generated output distributions require curve-fitting to evaluate the incredible $\left(10^{-6}\right.$ probability of exceeding) water content. For log-normally distributed results, the sample mean $\mu_{\mathrm{s}}$ and standard deviation $\sigma_{\mathrm{s}}$ are related to the log-normal parameters for $\log$ mean $\mu$ and $\log$ deviation $\sigma$ via [Miller and Freund, 1997]:

$$
\begin{aligned}
& \sigma^{2}=\ln \left[\left(\frac{\sigma_{s}}{\mu_{s}}\right)^{2}+1\right] \\
& \mu=\ln \mu_{s}-\frac{1}{2} \sigma^{2}
\end{aligned}
$$

\subsection{Probability Density Function and Case Inputs}

Probability distributions for the five random variables of equations (5-1) to (5-4) and discrete values for the number of independent choices $n$ were selected as described here. Three sets of calculations were performed: (1) a set using triangular distributions for the particulate masses and water percentages, (2) a set using log-normal distributions instead, and (3) a set using Weibull distributions instead. For each type of distribution, four cases were defined by assuming a different percentile for the bounding values. In all, twelve cases were defined. For each case, five values of the degree of independence $(n=4,7,10,14$, and 18) were explored. Each case was repeated for configurations with zero, one, and two scrap baskets.

As shown in Table 5-1, the first four cases used triangular distributions for the particulate mass per assembly and water content. In Case 1, the high value from the references is the maximum value of each distribution. In Cases 2,3 , and 4 , the reference high values are the 
HNF-2234, Rev. 2

\begin{tabular}{|c|c|c|c||}
\hline \multicolumn{5}{|c|}{ Table 5-1: Case Definitions } \\
\hline Case No. & Distribution Shape & $\begin{array}{c}\text { Percentile of Reference } \\
\text { High Value }\end{array}$ & Degree of Independence \\
\hline 1 & Triangular & $100 \%$ & $4,7,10,14,18$ \\
\hline 2 & Triangular & $97.50 \%$ & $4,7,10,14,18$ \\
\hline 3 & Triangular & $95.00 \%$ & $4,7,10,14,18$ \\
\hline 4 & Triangular & $90.00 \%$ & $4,7,10,14,18$ \\
\hline 5 & Log-Normal & $99.9 \%$ & $4,7,10,14,18$ \\
\hline 6 & Log-Normal & $97.50 \%$ & $4,7,10,14,18$ \\
\hline 7 & Log-Normal & $95.00 \%$ & $4,7,10,14,18$ \\
\hline 8 & Log-Normal & $90.00 \%$ & $4,7,10,14,18$ \\
\hline 9 & Weibull & $99.9 \%$ & $4,7,10,14,18$ \\
\hline 10 & Weibull & $97.5 \%$ & $4,7,10,14,18$ \\
\hline 11 & Weibull & $95.00 \%$ & $4,7,10,14,18$ \\
\hline 12 & Weibull & $90.00 \%$ & $4,7,10,14,18$ \\
\hline
\end{tabular}

$97.5 \%, 95.0 \%$, and $90.0 \%$ values of the input pdf's, respectively. Another way of looking at it is that the exceedance probabilities for the reference high values are $0.0 \%, 2.5 \%, 5.0 \%$, and $10.0 \%$, respectively, in Cases 1 through 4 .

Table 5-2 lists triangular distribution parameters in Cases 1 through 4. Appendix A illustrates the triangular distributions. The triangular distribution for Case 1 has the following interpretation: (1) the minimum is the "low" value from the references, (2) the likeliest value is the "nominal" value, and (3) the reference high value is the maximum. In all four cases, the minima and likeliest values were preserved. For cases 2,3 , and 4 , the reference high values have the listed percentiles, and the pdf maxima are shifter higher as a consequence. Derivation of maxima is explained in Appendix A. 
HNF-2234, Rev. 2

\begin{tabular}{|c|c|c|c|c|c|}
\hline \multicolumn{6}{|c|}{ Table 5-2: Parameters For Triangular Distributions } \\
\hline $\begin{array}{l}\text { Case } \\
\text { No. }\end{array}$ & Low (1) & $\begin{array}{l}\text { Most Likely } \\
\text { (1) }\end{array}$ & High (1) & $\begin{array}{c}\text { Percentile of } \\
\text { Reference Bound (2) }\end{array}$ & Maximum (3) \\
\hline \multicolumn{6}{|c|}{ Adhering Particulate, Scrap: Mass/Assy., kg } \\
\hline 1 & 0.006 & 0.02 & 0.2 & $100 \%$ & 0.200 \\
\hline 2 & 0.006 & 0.02 & 0.2 & $97.50 \%$ & 0.235 \\
\hline 3 & 0.006 & 0.02 & 0.2 & $95 \%$ & 0.254 \\
\hline 4 & 0.006 & 0.02 & 0.2 & $90 \%$ & 0.286 \\
\hline \multicolumn{6}{|c|}{ (Adhering Particulate, Fuel: Mass/Assy., kg } \\
\hline 1 & $1.30 \mathrm{E}-03$ & $7.60 \mathrm{E}-03$ & $2.00 \mathrm{E}-02$ & $100 \%$ & 0.020 \\
\hline 2 & $1.30 \mathrm{E}-03$ & $7.60 \mathrm{E}-03$ & $2.00 \mathrm{E}-02$ & $97.50 \%$ & 0.023 \\
\hline 3 & $1.30 \mathrm{E}-03$ & $7.60 \mathrm{E}-03$ & $2.00 \mathrm{E}-02$ & $95 \%$ & 0.024 \\
\hline 4 & $1.30 \mathrm{E}-03$ & $7.60 \mathrm{E}-03$ & $2.00 \mathrm{E}-02$ & $90 \%$ & 0.027 \\
\hline \multicolumn{6}{|c|}{ Adhering Particulate Water Content, $\%$} \\
\hline 1 & 1.5 & 4 & 5.5 & $100 \%$ & 5.500 \\
\hline 2 & 1.5 & 4 & 5.5 & $97.50 \%$ & 5.969 \\
\hline 3 & 1.5 & 4 & 5.5 & $95 \%$ & 6.225 \\
\hline 4 & 1.5 & 4 & 5.5 & $90 \%$ & 6.677 \\
\hline \multicolumn{6}{|c|}{ (1) Canister Particulate: Mass/Assy., kg } \\
\hline 1 & 0.0 & $2.20 \mathrm{E}-03(4)$ & $1.30 \mathrm{E}-02$ & $100 \%$ & $1.3 \mathrm{E}-2$ \\
\hline 2 & 0.0 & $2.20 \mathrm{E}-03(4)$ & $1.30 \mathrm{E}-02$ & $97.50 \%$ & $1.52 \mathrm{E}-2$ \\
\hline 3 & 0.0 & $2.20 \mathrm{E}-03(4)$ & $1.30 \mathrm{E}-02$ & $95 \%$ & $1.63 \mathrm{E}-2$ \\
\hline 4 & 0.0 & $2.20 \mathrm{E}-03(4)$ & $1.30 \mathrm{E}-02$ & $90 \%$ & $1.84 \mathrm{E}-2$ \\
\hline \multicolumn{6}{|c|}{ Canister Particulate Water Content, \% } \\
\hline 1 & 2.0 & 7.5 & 26.0 & $100 \%$ & 26.00 \\
\hline 2 & 2.0 & 7.5 & 26.0 & $97.50 \%$ & 29.97 \\
\hline 3 & 2.0 & 7.5 & 26.0 & $95 \%$ & 32.08 \\
\hline 4 & 2.0 & 7.5 & 26.0 & $90 \%$ & 35.0 \\
\hline \multicolumn{6}{|c|}{$\begin{array}{l}\text { (1) Values from [Sloughter, et al., 1998] for mass/assy. and from [Duncan and Ball } \\
1998 \text { ] for water content. }\end{array}$} \\
\hline \multicolumn{6}{|c|}{ (2) Probability of a value less than the listed bound. } \\
\hline \multicolumn{6}{|c|}{ (3) Value used for the triangular distribution. } \\
\hline (4) & $241 \mathrm{E}-3$ in $\mathrm{f}$ & version of [S] & ughter, et a & 1998]. & \\
\hline
\end{tabular}


Cases 5 through 8 used the log-normal distributions shown in Table 5-3 and Appendix B. Log-normal distributions do not have a practical maximum, and a 99.9 percentile value is used for Case 5 as the reference high value. Similarly, reference low values were assigned $a=$ : probability of $0.1 \%$. In Cases 6,7 , and 8 , the high values are the $97.5 \%, 95.0 \%$, and $90.0 \%$. values, respectively; i.e., the exceedance probabilities for the high values are $2.5 \%, 5.0 \%$, and $10.0 \%$, respectively, in Cases 6 through 8 .

For adhering particulate mass, log-normal distribution parameters were selected to preserve the minimum value (at the $0.1 \%$ percentile) and to ensure the desired percentile for the reference high value. The mean of the resulting distributions (see Table 5-3) shifted to successively higher values compared to the reference nominal value. This approach allows the goal - a test of sensitivity to the assumed distribution - to be attained in a conservative manner.

For adhering particulate water content, a different approach was required to avoid physically unrealistic values above $11 \%$ water. Here, the reference nominal was preserved as the median of the input pdf, and values for the standard deviation were chosen to recover the desired percentile for the reference high value. As seen in Table 5-3, input pdf's resulting from this method had only trivial probability of unphysically large values.

For canister particulate mass, log-normal parameters were selected to preserve the reference nominal values as the median, and to match the desired percentile for the reference high value. This is because following the method used for adhering particulate resulted in mean and median values below the reference nominal. With these assumptions, final results are relatively insensitive to minor variations in the nominal values. If the nominal value (the median) changes from the draft value of 2.22 grams/assembly to the final value of 2.41 grams/assembly, the mean of the log-normal distribution changes from 3.93 grams to 4.05 grams, for a 3\% increase. Of course, the canister particulate mass is but one part of the calculation for total water. For cases with one or two scrap baskets, the adhering particulate contributes the preponderance of water mass. Considering the random variations associated with a limited number of Monte Carlo trails, such variations in input are not significant. 


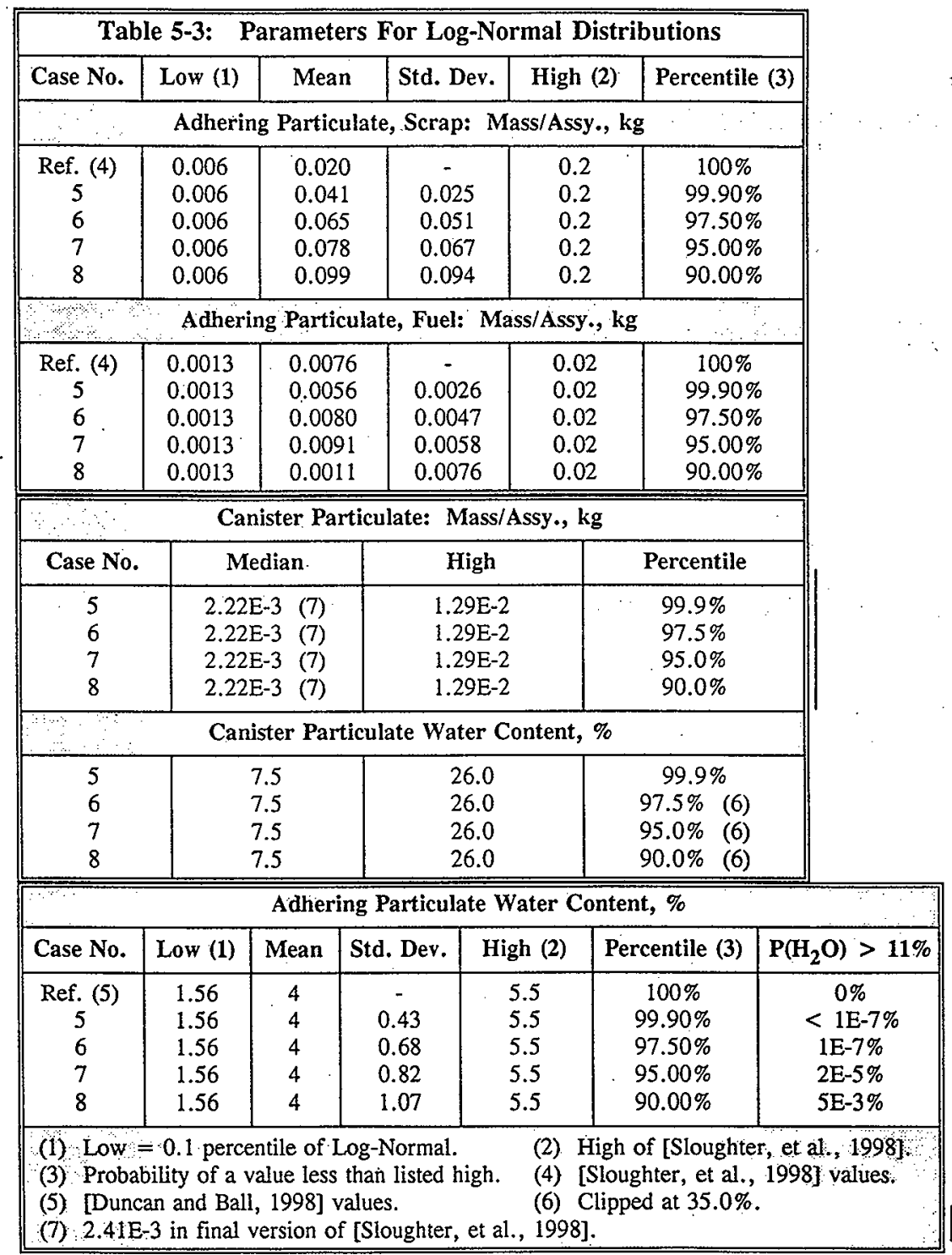


For canister particulate water, the reference nominal value was preserved as the median of the input pdf and values for the standard deviation were selected to recover the desired percentile for the reference high value, as was done for adhering particulate. In addition, the-: output value was truncated at $35 \%$ corresponding to a physical bound for pure $\mathrm{Al}(\mathrm{OH})_{3}$.

Log-normal pdf's are plotted in Appendix B. As discussed, particulate distributions are a conservative interpretation of reference inputs, and water content distributions are both consistent and physically reasonable.

Weibull distributions were created by manipulating the location, scale, and shape parameters to reflect reference estimates. The distributions used are summarized in Table 5-4 and Appendix C. For both particulate and water, the location parameter was set equal to the low value of the reference estimate. Weibull distributions have the property that no values below the location can be generated. The most likely value, as defined by reference estimate, was set equal to the mode (most probable value of the Weibull distribution), and the bound value was set equal to the particular percentile point used in that case. Mathematical details are in Appendix C.2.

\section{$5.4 \quad$ Results}

Each simulation produced a mean, standard deviation and incredible value $\left(1 \times 10^{-6}\right.$ exceedance probability) for the output particulate and water mass distributions. The simulations used 1,000 Monte Carlo trials. For each case, the simulation produced 1,000 random deviates for total water contact.

Output distributions were identified by curve fitting of the output random deviates. Random deviates for particulate mass and water content were tested against a variety of continuous distributions (normal, log-normal, Weibull, extreme value, etc.) using the AridersonDarling goodness-of-fit test [Decisioneering, 1996]. The Anderson-Darling test was preferred in this instance because it is most useful when the extreme tails of a distribution are of concern. 
HNF-2234, Rev. 2

\begin{tabular}{|c|c|c|c|c|c|}
\hline \multicolumn{6}{|c|}{ Table 5-4: Parameters For Weibull Distributions } \\
\hline Case No. & Low (Location) (1) & Scale & Shape & High (2) & Percentile (3) \\
\hline \multicolumn{6}{|c|}{ Adhering Particulate, Scrap: Mass/Assy., kg } \\
\hline Ref. (4) & 0.006 & - & - & 0.2 & $100 \%$ \\
\hline 9 & 0.006 & 0.0439 & 1.30 & 0.2 & $99.90 \%$ \\
\hline 10 & 0.006 & 0.0648 & 1.19 & 0.2 & $97.50 \%$ \\
\hline 11 & 0.006 & 0.0760 & 1.16 & 0.2 & $95.00 \%$ \\
\hline 12 & 0.006 & 0.0929 & 1.13 & 0.2 & $90.00 \%$ \\
\hline \multicolumn{6}{|c|}{ Adhering Particulate, Fuel: Mass/Assy,, kg } \\
\hline Ref. (4) & 0.0013 & - & - & 0.02 & $100 \%$ \\
\hline 9 & 0.0013 & 0.0081 & 2.30 & 0.02 & $99.90 \%$ \\
\hline $10^{\circ}$ & 0.0013 & 0.0094 & 1.89 & 0.02 & $97.50 \%$ \\
\hline 11 & 0.0013 & 0.0101 & 1.77 & 0.02 & $95.00 \%$ \\
\hline 12 & 0.0013 & 0.0113 & 1.64 & 0.02 & $90.00 \%$ \\
\hline \multicolumn{6}{|c|}{ Adhering Particulate Water Content, \% } \\
\hline Ref. (5) & 1.50 & - & - & 5.5 & $100 \%$ \\
\hline 9 & 1.50 & 2.63 & 4.60 & 5.5 & $99.90 \%$ \\
\hline 10 & 1.50 & 2.73 & 3.43 & 5.5 & $97.50 \%$ \\
\hline 11 & 1.50 & 2.83 & 3.16 & 5.5 & $95.00 \%$ \\
\hline 12 & 1.50 & 2.94 & 2.71 & 5.5 & $90.00 \%$ \\
\hline \multicolumn{6}{|c|}{ Canister Particulate: Mass/Assy., kg } \\
\hline 9 & 0.00 & $3.96 \mathrm{E}-3$ & 1.63 & 0.013 & $99.9 \%$ \\
\hline 10 & 0.00 & $5.19 \mathrm{E}-3$ & 1.42 & 0.013 & $97.5 \%$ \\
\hline 11 & 0.00 & $5.82 \mathrm{E}-3$ & 1.36 & 0.013 & $95.0 \%$ \\
\hline 12 & 0.00 & $6.84 \mathrm{E}-3$ & 1.30 & 0.013 & $90.0 \%$ \\
\hline \multicolumn{6}{|c|}{ Canister Particulate Water Content, \% } \\
\hline 9 & 2.0 & 8.40 & 1.843 & 26.0 & $99.9 \%$ \\
\hline 10 & 2.0 & 10.46 & 1.571 & $26.0(6)$ & $97.5 \%$ \\
\hline 11 & 2.0 & 11.52 & 1.495 & $26.0(6)$ & $95.0 \%$ \\
\hline 12 & 2.0 & 13.26 & 1.407 & $26.0(6)$ & $90.0 \%$ \\
\hline $\begin{array}{l}\text { (1) Locat } \\
\text { (3) Proba } \\
\text { (5) [Dun }\end{array}$ & $\begin{array}{l}\text { ity of a value less th } \\
\text { and Ball, 1998] va }\end{array}$ & $\begin{array}{l}\text { the lis } \\
\text { es. }\end{array}$ & h. (4) $\begin{array}{l}\text { (2) } \\
\text { (6) }\end{array}$ & $\begin{array}{l}\text { h of [Slough } \\
\text { ughter, et a } \\
\text { ped at } 35 \%\end{array}$ & $\begin{array}{l}\text { et al., } 1998] \text {. } \\
998] \text { values. }\end{array}$ \\
\hline
\end{tabular}


The Anderson-Darling test is similar to the Kolmogorov-Smirnov test in that both consider the differences between the two cumulative distributions (i.e., the data and the test distribution). The Anderson-Darling test places greater weight on the differences between the data and test $=$ : distribution at the tails than the differences at the mid-range, making it a good choice for computing an incredible water content value [Kotz, et al., 1982].

Resulting water content output deviates were tested against one of the following distributions: normal, log-normal, Weibull, gamma, and beta. Inspection of the output histograms showed that other distributions would not provide good fits. Crystal Ball ${ }^{\text {m }}$ ranked the distributions according to the Anderson-Darling statistic, with the best distribution having the lowest Anderson-Darling statistic $\left(\mathrm{A}^{2}\right)$. Not every set of output deviates was tested because there are 180 of them all told. For each case, several sets of output deviates were tested until it became clear that the outputs for that case could or could not be described by an assumed distribution.

The Anderson-Darling statistic is part of the Cramer-von Mises family given by [Kotz, et al., 1982],

$$
\dot{Q}=n \int_{-\infty}^{\infty}\left(F_{n}(x)-F(x)\right)^{2} \Psi(x) d F(x)
$$

where $Q$ is a statistic of the Cramer-von Mises family, $n$ is number of samples, $F_{n}(x)$ is the empirical distribution function (EDF), $\mathrm{F}(\mathrm{x})$ is the specified (cumulative) distribution, and $\psi$ is a weighing function. An empirical distribution function is defined by,

$$
F_{n}(x)=\frac{\text { number of observations } \leq x}{n} \text { for }-\infty<x<\infty
$$

In other words,

$$
\begin{array}{ll}
F_{n}(x)=0 & \text { if } \quad x<x_{1} \\
F_{n}(x)=\frac{i}{n} & x_{i}<x<x_{i+1} \quad \text { if } i=1 \ldots n-1
\end{array}
$$




$$
F_{n}(x)=1 \quad x_{n} \leq x
$$

for a random sample of size $n$ and $X_{1}, \ldots, X_{n}$. A plot of an EDF will resemble a number of $=$. step functions. .When the weighing function is chosen as

$$
\Psi=\frac{1}{F(x)[1-F(x)]}
$$

it is clearly large at the tails when $F(x) \rightarrow 0$ or $F(x) \rightarrow 1$, and the resulting statistic $Q$ is the Anderson-Darling statistic, $\mathrm{A}^{2}$.

The following procedure is used to test a sample population against a specified distribution with the Anderson-Darling statistic [D'Agostino and Stephens, 1986]:

- The null hypothesis is that the sample population $\mathrm{X}_{1}, \mathrm{X}_{2}, \ldots, \mathrm{X}_{\mathrm{n}}$ comes from $F(X, \theta)$, which is a completely specified continuous distribution.

- Place the sample population in ascending order $\mathrm{X}_{1}<\mathrm{X}_{2}<\ldots<\mathrm{X}_{\mathrm{n}}$.

- $\quad$ Calculate $\mathrm{Z}_{\mathrm{i}}=\mathrm{F}\left(\mathrm{X}_{\mathrm{i}}, \theta\right), \mathrm{i}=1,2, \ldots, \mathrm{n}$.

- Calculate the Anderson-Darling statistic using,

$$
A^{2}=-n-\frac{1}{n} \sum_{i=1}^{n}(2 i-1)\left[\log Z_{i}+\log \left(1-Z_{n+1-i}\right)\right]
$$

- If the statistic exceeds the value at level $\alpha$, the null hypothesis is rejected at significant level $\alpha$.

In some instances, more than one distribution was acceptable; i.e., the null hypothesis (the output deviates are from that particular distribution) could not be rejected. In these instances, a log-normal distribution was preferred because it is simple, has a longer tail, and results in a more conservative incredible value.

For triangular inputs, water. mass output was adequately described by a log-normal distribution. Depending on the case, Anderson-Darling statistics were between 0.2 and 0.6 , 
denoting levels of significance $(\alpha$ ) (Appendix H) between $94 \%$ and $65 \%$, respectively, for not rejecting the null hypothesis [D'Agostino and Stephens, 1986].

For Weibull distribution inputs, water mass output is well described by a log-normal distribution. Anderson-Darling statistics were generally less than 0.5 . In the Weibull input cases, the incredible content was calculated by taking the inverse of the log-normal distribution with an exceedance probability of $1 \times 10^{-6}$.

For log-normal input, output deviates were adequately described by a log-normal distribution, with the exception of a few cases were none of the continuous distributions available to Crystal Ball ${ }^{\text {m }}$ are a good fit to the data. These exceptions are the case with one fuel basket and high values at $95.0 \%$ or $90.0 \%$. In these instances, the Anderson-Darling statistic was much greater than one and the log-normal distribution was a poor fit. This is probably due to the fact that these distributions are highly skewed, with very long tails. This is evidenced by the incredible value calculated using a log-normal distribution with an exceedance of $1 \times 10^{-6}$. For the exceptional cases, the maximum output deviate, based on 1,000 trials, exceeded the incredible value assuming a log-normal distribution and $1 \times 10^{-6}$ exceedance probability. Clearly, a log-normal distribution, or any other standard distribution, cannot be used to calculate an incredible value. Two of these cases are shown in Figures 5-1 and 5-2.

For log-normal input and one scrap basket, the simulation was re-run using the Latin Hypercube Sampling (LHS) technique available with Crystal Ball ${ }^{\text {th }}$. This was an attempt to obtain output distributions that could be described by any of the standard, continuous distributions, and better estimates for the incredible value. With an LHS scheme, an input distribution is divided into intervals of equal probability. Crystal Ball ${ }^{\text {Tu }}$ then generates one random value for each interval. This is more precise than a direct Monte Carlo technique because the entire distribution is sample more evenly. The LHS scheme does not produce significantly better results. For log-normal input with high value equal to $90^{\text {th }}$ or $95^{\text {th }}$ percentile, output distributions do not fit any of the standard, continuous distributions, regardless of the sampling scheme. Means, standard deviations, incredible values, etc., did not change significantly by using a LHS technique. 
HNF-2234, Rev. 2

Figure 5-1:

Output Water Content Curve Fit for Case 8 (log-normal, 95 percentile) and 4 Groups, Log-Normal Inputs, One Scrap Basket.

For a log-normal distribution, Figure 5-1 shows the fit to the generated output. The fit is poor, based on an Anderson-Darling statistic of 1.5792 (refer to Appendix $\mathrm{H}$ ). Also, the maximum value of the 1,000 output deviates (4.562) exceeds the incredible value (4.369) based on a log-normal distribution with $10^{-6}$ exceedance probability (see Appendix F).

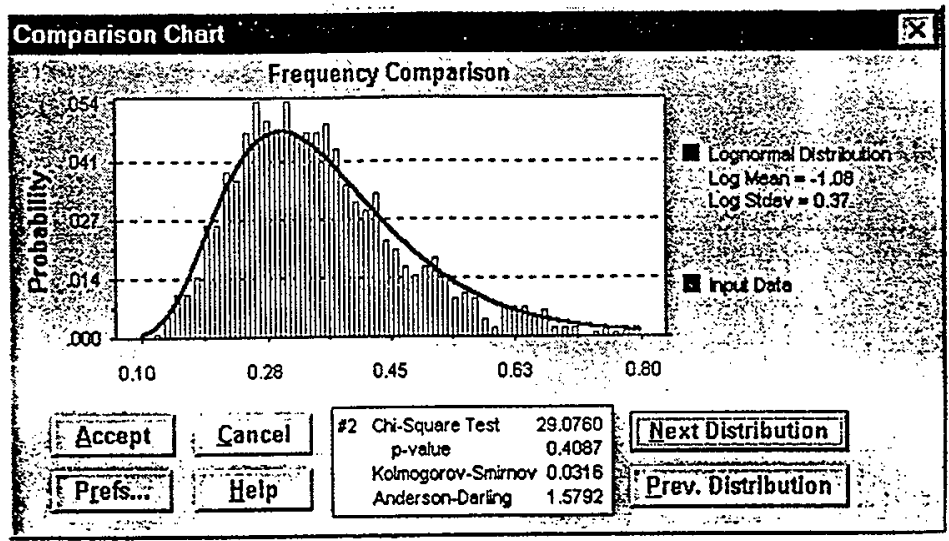


HNF-2234, Rev. 2

Figure 5-2:

Output Water Content Curve Fit for Case 8 (log-normal, 95 percentile) and 18 Groups,

Log-Normal Input, One Scrap Basket.

For a log-normal distribution, Figure 5-2 shows the fit to the generated output. The fit is poor, based on an Anderson-Darling statistic of 5.6398 (refer to Appendix H). Also, the maximum value of the 1,000 output deviates (1.338) exceeds the incredible value (1.117) based on a log-normal distribution with $10^{-6}$ exceedance probability (see Appendix F).

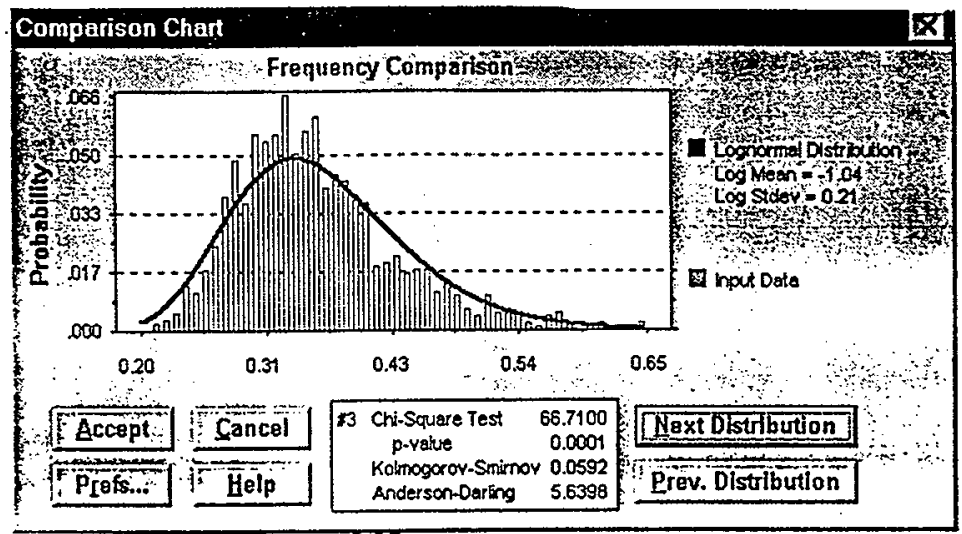


HNF-2234, Rev. 2

A simulation using 1,000 trials was performed for each case identified in Table 5-1, with $\mathrm{n}=4,7,10,14$, and 18 . Results are listed in Tables 5-5 through 5-13, and complete summary statistics are shown in Appendix F. Cumulative distributions are shown in Appendix G. $\equiv$

Results may be summarized as follows:

- For a given case, the calculated mean remains the same as the degree of damage state independence increases, but the standard deviation and incredible value decrease. These results are expected by theory (see Appendix D).

- The calculated mean increases as the percentile assigned to the reference high value increases; i.e., the mean is lowest for Case 1 (Case 5 or Case 9) and highest for Case 4 (Case 8 or Case 12). This is expected because the input distribution means increase.

- Log-normal distributions generally result in lower means but higher standard deviations than triangular cases, as expected based on inputs. As a result, the incredible values for the two sets of calculations are comparable.

- $\quad$ Results are relatively insensitive to input values for canister particulate mass/assembly (see Appendix I).

- Weibull distributions generally result in mean and incredible values that fall somewhere between mean and incredible values produced by triangular and log-normal distributions for the corresponding case.

- Reference high values for water content $(1.21,1.37$, and $1.55 \mathrm{~kg}$ for zero, one, and two scrap baskets, respectively) are only exceeded for extreme combinations of the sensitivity parameters: $90^{\text {th }}$ percentiles assigned to reference high values and a low degree of damage state independence. When log-normal input distributions are used, most of the $90^{\text {th }}$ percentile case results exceeded the reference high water content, and in two cases at the $95^{\text {th }}$ percentile and $n=4$ independent choices, the result exceeded the reference bound.

For the case of reference high inputs representing the $95^{\text {th }}$ percentile, and at least $n=10$ for independent choices of damage level, incredible values are calculated to be roughly $2 / 3$ the reference high water contents: 
Table 5-5: Triangular Results Summary: No Scrap Basket (Particulate Water Content, kg)

\begin{tabular}{|c|c|c|c|c|c|c|c|c|c|c|c|c|}
\hline \multirow{2}{*}{ Groups } & \multicolumn{3}{|c|}{ Case 1: Bounds@100\% } & \multicolumn{3}{|c|}{ Case 2: Bounds@ $97.5 \%$} & \multicolumn{3}{|c|}{ Case 3: Bounds @ 95\% } & \multicolumn{3}{|c|}{ Case 4: Bounds @ 90\% } \\
\hline & Mean & Std. Dev. & Incredible & Mean & Std. Dev. & Incredible & Mean & Std. Dev. & Incredible & Mean & Std. Dev. & Incredible \\
\hline 7 & 0.259 & 0.049 & 0.618 & 0.318 & 0.063 & 0.798 & 0.348 & 0.073 & 0.921 & 0.408 & 0.092 . & 1.149 \\
\hline 10 & 0.259 & 0.041 & 0.537 & 0.317 & 0.053 & 0.691 & 0.347 & 0.063 & 0.804 & 0.406 & 0.076 & 0.965 \\
\hline 18 & 0.258 & 0.030 & 0.443 & 0.316 & 0.040 & 0.570 & 0.347 & 0.047 & 0.654 & 0.405 & 0.057 & 0.780 \\
\hline
\end{tabular}

Table 5-6: Triangular Results Summary: One Scrap Basket (Particulate Water Content, kg)

\begin{tabular}{|c|c|c|c|c|c|c|c|c|c|c|c|c|}
\hline \multirow{2}{*}{ Groups } & \multicolumn{3}{|c|}{ Case.1: Bounds @ 100\% } & \multicolumn{3}{|c|}{ Case 2: Bounds@97.5\% } & \multicolumn{3}{|c|}{ Case 3: Bounds@95\% } & \multicolumn{3}{|c|}{ Case 4: Bounds @90\% } \\
\hline & Mean & Std. Dev. & Incredible & Mean & Std. Dev. & Incredible & Mean & Std. Dev. & Incredible & Mean & Std. Dev. & Incredible \\
\hline 4 & 0.312 & 0.062 & 0.787 & 0.387 & 0.085 & 1.059 & 0.420 & 0.090 & 1.131 & 0.492 & 0.116 & 1.450 \\
\hline 7 & 0.313 & 0.049 & 0.648 & 0.384 & 0.064 & 0.835 & 0.420 & 0.069 & 0.905 & 0.491 & 0.086 & 1.109 \\
\hline 10 & 0.314 & 0.041 & 0.578 & 0.384 & 0.053 & 0.729 & 0.420 & 0.061 & 0.826 & 0.491 & 0.072 & 0.974 \\
\hline 14 & 0.313 & 0.035 & 0.527 & 0.384 & 0.044 & 0.662 & 0.420 & 0.052 & 0.748 & 0.492 & 0.061 & 0.880 \\
\hline 18 & 0.314 & 0.031 & 0.497 & 0.383 & 0.040 & 0.623 & 0.419 & 0.045 & 0.691 & 0.491 & 0.053 & 0.817 \\
\hline
\end{tabular}




\begin{tabular}{|c|c|c|c|c|c|c|c|c|c|c|c|c|}
\hline Groups & Mean & Std. Dev. & Incredible & Mean & Std. Dev. & Incredible & Mean & Std. Dev. & Incredible & Mean & Std. Dev. & Incredible \\
\hline 4 & 0.369 & 0.081 & 1.010 & 0.445 & 0.102 & 1.281 & 0.492 & 0.113 & 1.412 & 0.575 & 0.140 & 1.756 \\
\hline 7 & 0.369 & 0.061 & 0.795 & 0.446 & 0.077 & 0.995 & 0.495 & 0.084 & 1.092 & 0.575 & 0.102 & 1.314 \\
\hline 14 & 0.371 & 0.042 & 0.629 & 0.449 & 0.055 & 0.796 & 0.496 & 0.057 & 0.851 & 0.575 & 0.074 & 1.049 \\
\hline 18 & 0.371 & 0.038 & 0.598 & 0.450 & 0.047 & 0.738 & 0.495 & 0.052 & 0.808 & 0.576 & 0.067 & 0.993 \\
\hline
\end{tabular}

Table 5-8: Log-Normal Results Summary: No Scrap Basket (Particulate Water Content, kg)

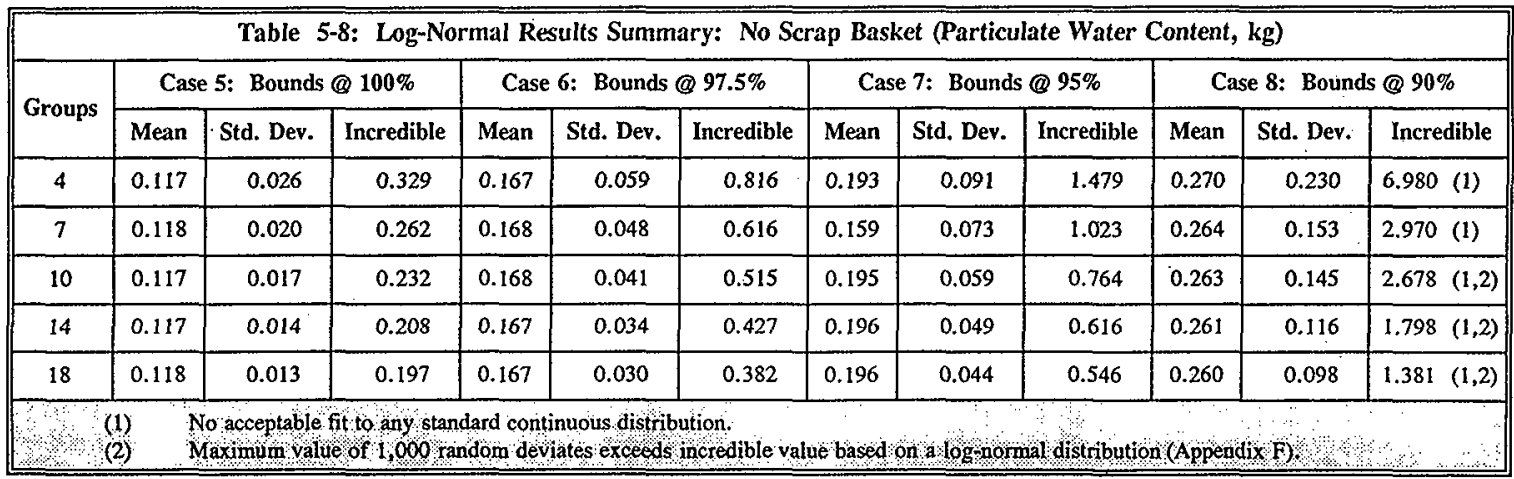




\begin{tabular}{|c|c|c|c|c|c|c|c|c|c|c|c|c|}
\hline \multirow{2}{*}{ Groups } & \multicolumn{3}{|c|}{ Case 5: Bounds @100\% } & \multicolumn{3}{|c|}{ Case 6: Bounds 97.5\% } & \multicolumn{3}{|c|}{ Case 7: Bounds @ 95\% } & \multicolumn{3}{|c|}{ Case 8: Bounds @ 90\% } \\
\hline & Mean & Std. Dev. & Incredible & Mean & Std. Dèv. & Incredible & Mean & Std. Dev. & Incredible & Mean & Std. Dev. & Incredible \\
\hline 4 & 0.158 & 0.031 & 0.387 & 0.237 & 0.071 & 0.915 & 0.281 & 0.095 & 1.274 & 0.370 & 0.220 & $4.369(1,2)$ \\
\hline 7 & 0.158 & 0.023 & 0.310 & 0.235 & 0.051 & 0.634 & 0.281 & 0.072 & 0.899 & 0.370 & 0.153 & $2.281(1,2)$ \\
\hline 10 & 0.157 & 0.019 & 0.279 & 0.235 & 0.043 & 0.546 & 0.280 & 0.060 & 0.748 & 0.370 & 0.130 & $1.776(1,2)$ \\
\hline 14 & 0.158 & 0.017 & 0.259 & 0.236 & 0.035 & 0.473 & 0.278 & 0.051 & 0.649 & 0.370 & 0.107 & $1.368(1,2)$ \\
\hline 18 & 0.158 & 0.015 & 0.243 & 0.236 & 0.032 & 0.441 & 0.279 & 0.045 & 0.590 & 0.368 & 0.089 & $1.117(1,2)$ \\
\hline & & ceptad & 0 any & 100 & an & ion, & 3 & 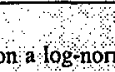 & 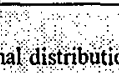 & $\therefore$ & 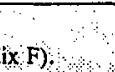 & \\
\hline
\end{tabular}

Table 5-10: Log-Normal Results Summary: Two Scrap Baskets (Particulate Water Content, kg)

\begin{tabular}{|c|c|c|c|c|c|c|c|c|c|c|c|c|}
\hline & & Table 5-1 & Log-Nor & nal Re & Jits Summ & ry: Two Sc & ap Bas & cets (Partic & slate Water & Content & $\mathrm{kg})$ & \\
\hline \multirow{2}{*}{ Groups } & \multicolumn{3}{|c|}{ Case 5: Bounds @ 100\% } & \multicolumn{3}{|c|}{ Case 6: Bounds @97.5\% } & \multicolumn{3}{|c|}{ Case 7: Bounds @ 95\% } & \multicolumn{3}{|c|}{ Case 8: Bounds @ 90\% } \\
\hline & Mean & Std. Dev. & Incredible & Mean & Std. Dev. & Incredible & Mean & Std. Dev. & Incredible & Mean & Std. Dev. & Incredible \\
\hline 4 & 0.194 & 0.042 & 0.522 & 0.307 & 0.095 & 1.242 & 0.362 & 0.123 & 1.664 & 0.479 & 0.224 & 3.612 \\
\hline 7 & 0.195 & 0.030 & 0.404 & 0.307 & 0.073 & 0.915 & 0.365 & 0.098 & 1.245 & 0.474 & 0.164 & 2.231 \\
\hline 10 & 0.195 & 0.025 & 0.360 & 0.306 & 0.062 & 0.775 & 0.364 & .0 .082 & 1.024 & 0.476 & 0.135 & 1.725 \\
\hline 14 & 0.196 & 0.022 & 0.334 & 0.308 & 0.053 & 0.683 & 0.365 & 0.068 & 0.865 & .0 .472 & 0.111 & 1.389 \\
\hline 18 & 0.196 & 0.019 & 0.311 & 0.307 & 0.046 & 0.619 & 0.364 & 0.062 & 0.805 & 0.475 & 0.098 & 1.235 \\
\hline
\end{tabular}




\begin{tabular}{|c|c|c|c|c|c|c|c|c|c|c|c|c|}
\hline \multirow{2}{*}{ Groups } & \multicolumn{3}{|c|}{ Case 9: Bounds @ 100\% } & \multicolumn{3}{|c|}{ Case 10: Bounds @ 97.5\% } & \multicolumn{3}{|c|}{ Case 11: Bounds @ 95\% } & \multicolumn{3}{|c|}{ Case 12: Bounds @ 90\% } \\
\hline & Mean & Std. Dev. & Incredible & Mean & Std. Dev. & Incredible & Mean & Std. Dev. & Incredible & Mean & Std. Dev. & Incredible \\
\hline 4 & 0.179 & 0.040 & 0.504 & 0.251 & 0.074 & 0.962 & 0.287 & 0.095 & 1.275 & 0.358 & 0.127 & $1.742^{\circ}$ \\
\hline 7 & 0.178 & 0.032 & 0.413 & 0.248 & 0.054 & 0.675 & 0.290 & 0.075 & 0.951 & 0.359 & 0.097 & 1.233 \\
\hline 10 & 0.178 & 0.026 & 0.356 & 0.247 & 0.046 & 0.586 & 0.288 & 0.062 & 0.780 & 0.358 & 0.082 & 1.030 \\
\hline 14 & 0.178 & 0.022 & 0.321 & 0.247 & 0.040 & 0.521 & 0.289 & 0.052 & 0.671 & 0.355 & 0.068 & 0.862 . \\
\hline 18 & 0.178 & 0.019 & 0.297 & 0.248 & 0.035 & 0.479 & 0.289 & 0.046 & 0.606 & 0.355 & 0.061 & 0.784 \\
\hline
\end{tabular}

$\stackrel{u}{\sim}$

Table 5-12: Weibull Results Summary: One Scrap Basket (Particulate Water Content, kg)

\begin{tabular}{|c|c|c|c|c|c|c|c|c|c|c|c|c|}
\hline \multirow{2}{*}{ Groups } & \multicolumn{3}{|c|}{ Case 9: Bounds @ 100\% } & \multicolumn{3}{|c|}{ Case 10: Bounds @ 97.5\% } & \multicolumn{3}{|c|}{ Case 11: Bounds@ 95\% } & \multicolumn{3}{|c|}{ Case 12: Bounds@90\% } \\
\hline & Mean & Std. Dev. & Incredible & Mean & Std. Dev. & Incredible & Mean & Std. Dev. & Incredible & Mean & Std. Dev. & Incredible \\
\hline 4 & 0.215 & 0.045 & 0.565 & 0.307 & 0.076 & 0.952 & 0.351 & 0.089 & 1.118 & 0.443 & 0.128 & 1.642 \\
\hline 7 & 0.216 & 0.034 & 0.446 & 0.303 & 0.056 & 0.718 & 0.353 & 0.070 & 0.884 & 0.441 & 0.097 & 1.216 \\
\hline 10 & 0.216 & 0.027 & 0.387 & 0.302 & 0.047 & 0.624 & 0.354 & 0.060 & 0.774 & 0.440 & 0.079 & 1.010 \\
\hline 14 & 0.215 & 0.022 & 0.347 & 0.302 & 0.039 & 0.555 & 0.353 & 0.049 & 0.678 & 0.439 & 0.067 & 0.896 . \\
\hline 18 & 0.215 & 0.020 & 0.333 & 0.301 & 0.035 & 0.518 & 0.352 & 0.044 & 0.633 & 0.437 & 0.060 & 0.832 \\
\hline
\end{tabular}




\begin{tabular}{|c|c|c|c|c|c|c|c|c|c|c|c|c|}
\hline \multirow{2}{*}{ Groups } & \multicolumn{3}{|c|}{ Case 9: Bounds @ 100\% } & \multicolumn{3}{|c|}{ Case 10: Bounds @ 97.5\% } & \multicolumn{3}{|c|}{ Case 11: Bounds @ 95\% } & \multicolumn{3}{|c|}{ Case 12: Bounds @90\% } \\
\hline & Mean & Std. Dev. & Incredible & Mean & Std. Dev. & Incredible & Mean & Std. Dev. & Incredible & Mean & Std. Dev. & Incredible \\
\hline 4 & 0.251 & 0.059 & 0.735 & 0.357 & 0.096 & 1.213 & 0.414 & 0.123 & 1.587 & 0.515 & 0.148 & 1.901 \\
\hline 7 & 0.252 & 0.044 & 0.564 & 0.360 & 0.074 & 0.925 & 0.414 & 0.093 & 1.160 & 0.516 & 0.111 & 1.391 \\
\hline 10 & 0.251 & 0.036 & 0.490 & 0.357 & 0.062 & 0.797 & 0.415 & 0.078 & 0.992 & 0.514 & 0.094 & 1.200 \\
\hline 14 & 0.250 & 0.030 & 0.437 & 0.357 & 0.054 & 0.719 & 0.415 & 0.064 & 0.853 & 0.516 & 0.082 & 1.086 \\
\hline 18 & 0.251 & 0.027 & 0.413 & 0.356 & 0.047 & 0.656 & 0.415 & 0.057 & 0.791 & 0.516 & 0.074 & 1.010 \\
\hline
\end{tabular}


HNF-2234, Rev. 2

$\therefore$

- For zero scrap baskets, about $0.8 \mathrm{~kg}$ are calculated to be incredible, versus the reference value of $1.2 \mathrm{~kg}$,

- For one scrap basket, 0.75 to $0.83 \mathrm{~kg}$ are calculated to be incredible, versus the reference value of $1.37 \mathrm{~kg}$, and

- For two scrap baskets, about $1.0 \mathrm{~kg}$ is calculated to be incredible, versus the reference value of $1.55 \mathrm{~kg}$. 
HNF-2234, Rev. 2

\subsection{REFERENCES}

D'Agostino, R., and Stephens, M., "Goodness-of-Fit Techniques," Marcel Dekker, Inc., 1986.

Decisioneering, Inc., 1996, "Crystal Ball ${ }^{\text {Tx }}$, Version 4.0, User Manual".

Duncan, D.R., and Ball, D.E., 1998, "K-Basins Particulate Water Content, Behavior, and Impact," HNF-1523, Rev. 1, Duke Engineering \& Services Hanford, Richland, WA. Draft, 10/13/48.

Kotz, S., Johnson, N.L., and Read, C.B., "Encyclopedia of Statistical Sciences," John Wiley \& Sons, Inc., 1982.

Miller, I., and Freund, J.E., 1977, "Probability and Statistics for Engineers," 2nd Edition, Prentice Hall, Englewood Cliffs, New Jersey.

Pitner, A.L., 1995, "K-East Basin Underwater Visual Survey," WHC-SD-SNF-TI-012, Rev. 0, February, 1995.

J. Sloughter, et al., "Estimates of Particulate Mass in Multi-Canister Overpacks," HNF-1527, Rev. 1, Numatec Hanford Corporation, Richland, WA, September 1998. 
HNF-2234, Rev. 2

APPENDIX A

TRIANGULAR INPUT DISTRIBUTIONS

\section{A.1. Crystal Balf Input}


HNF-2234, Rev. 2

Scrap Mass/Assy, kg: Bound $=100 \%$ ile

Triangular distribution with parameters:

Minimum

Likeliest

$6.00 \mathrm{E}-03$

Maximum

2.00E-02

2.00E-01

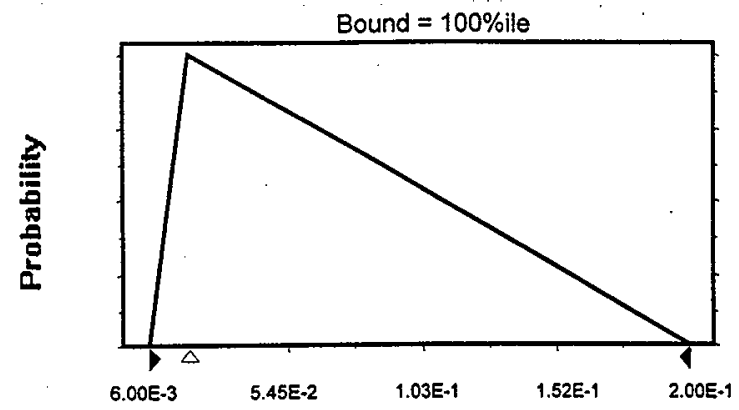

Scrap Mass/Assy, kg: Bound $=97.5 \%$ ile

Triangular distribution with parameters:

Minimum .

Likeliest

Maximum
6.00E-03

2.00E-02

2.35E-01

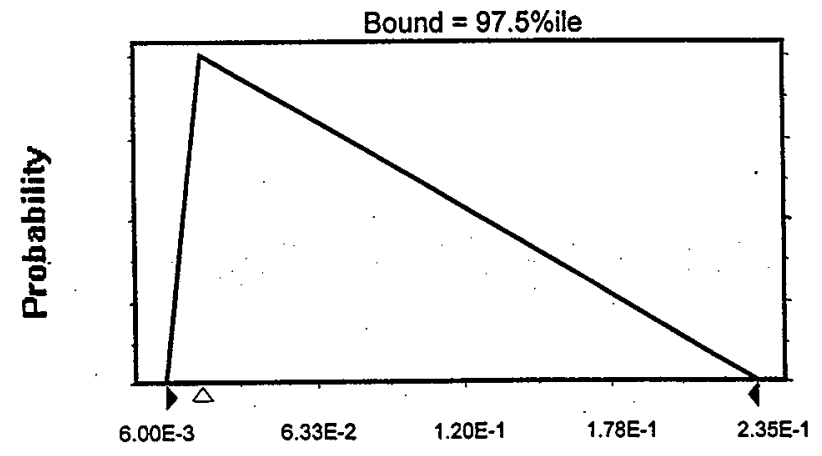


HNF-2234, Rev. 2

Scrap Mass/Assy, $\mathrm{kg:}$ Bound $=95.0 \%$ ile

Triangular distribution with parameters:

Minimum

. 6.00E-03

Likeliest

2.00E-02

Maximum

2.54E-01

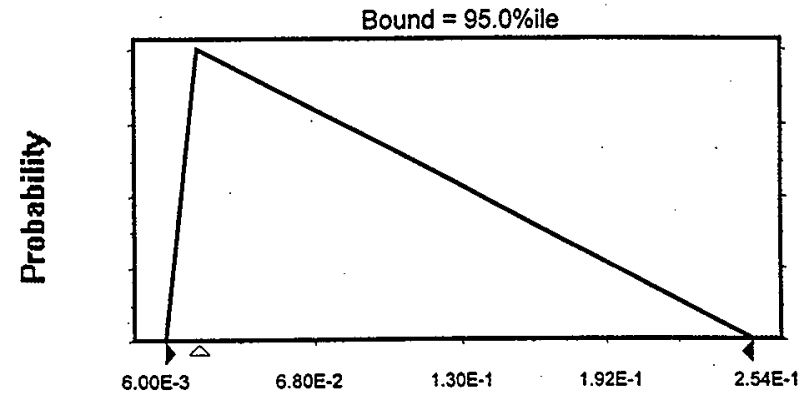

Scrap Mass/Assy, $\mathrm{kg}:$ Bound $=\mathbf{9 0 . 0 \% i l e}$

Triangular distribution with parameters:

Minimum

Likeliest

6.00E-03

Maximum

2.00E-02

2.86E-01

Bound $=90.0 \%$ ile

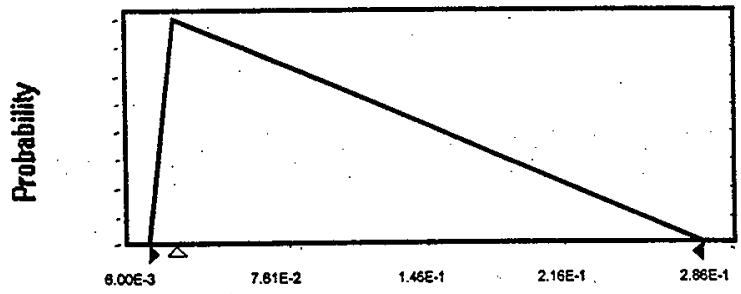


HNF-2234, Rev. 2

Fuel Mass/Assy, kg: Bound $=100 \%$ lle

Triangular distribution with parameters:

Minimum

1.30E-03

Likeliest

7.60E-03

Maximum

2.00E-02

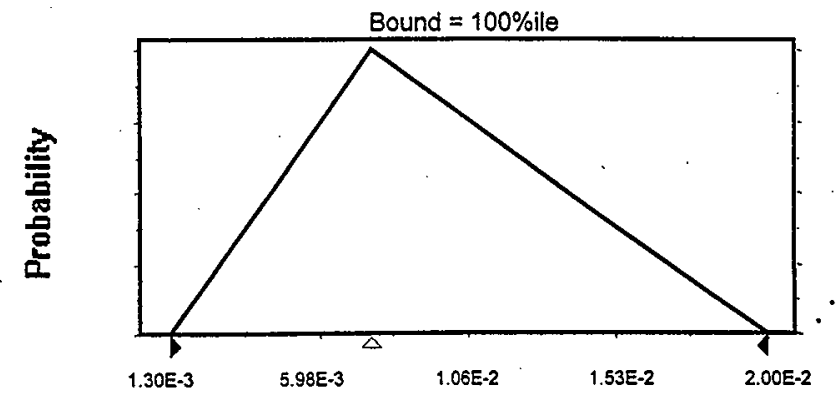

Fuel Mass/Assy, kg: Bound $=97.5 \%$ lio

Triangular distribution with parameters:

Minimum

Likeliest

$1.30 \mathrm{E}-03$

Maximum

7.60E-03

$2.29 E-02$

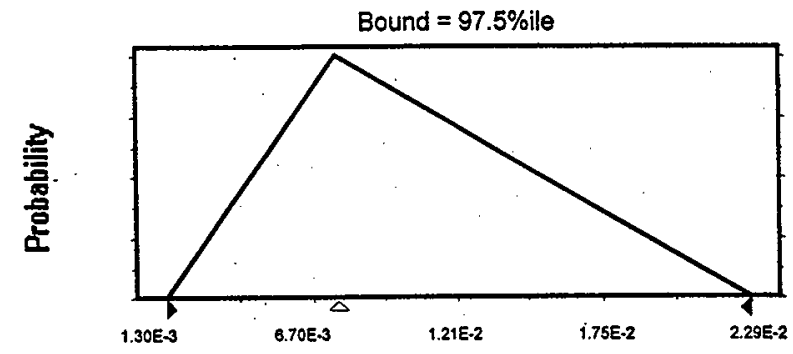


HNF-2234, Rev. 2

Fuel Mass/Assy, kg: Bound $=\mathbf{9 5 . 0 \% i l e ~}$

Triangular distribution with parameters:

Minimum

Likeliest

Maximum
1.30E-03

7.60E-03

2.44E-02

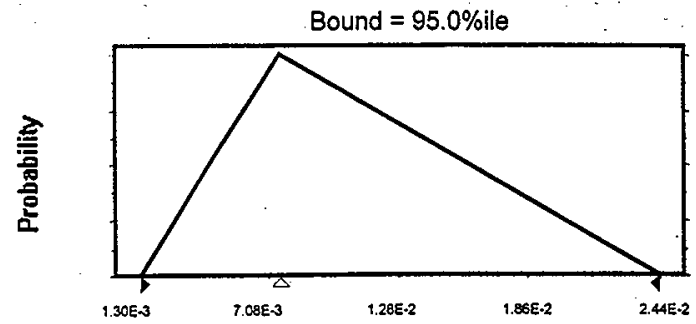

Fuel Mass/Assy, kg: Bound $=\mathbf{9 0 . 0} \%$ ile

Triangular distribution with parameters:

Minimum

Likeliest

Maximum
1.30E-03

7.60E-03

2.71E-02

Bound $=90.0 \%$ ile

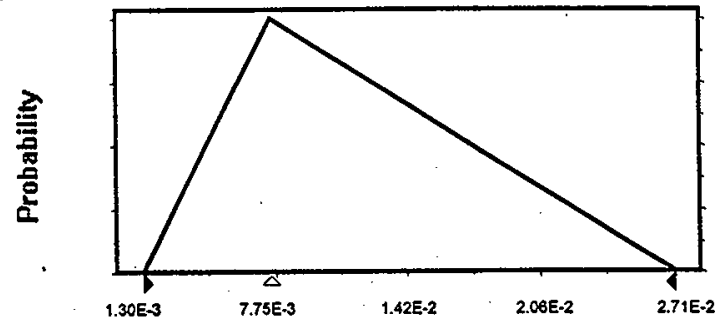


HNF-2234, Rev. 2

Water Content, \%: Bound $=100 \%$ lle

Triangular distribution with parameters:

Minimum

Likeliest

4.00

Maximum

5.50

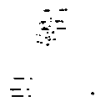

Bound $=100 \%$. .

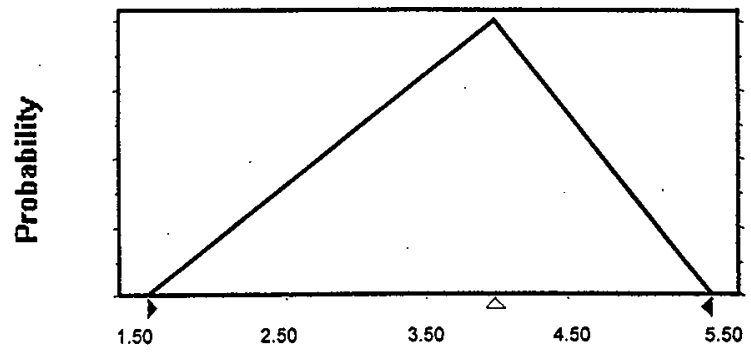

Water Content, \%: Bound $=97.5 \%$ ile

Triangular distribution with parameters:

Minimum

Likeliest

Maximum
1.50

4.00

5.97

Bound $=97.5 \%$ ile

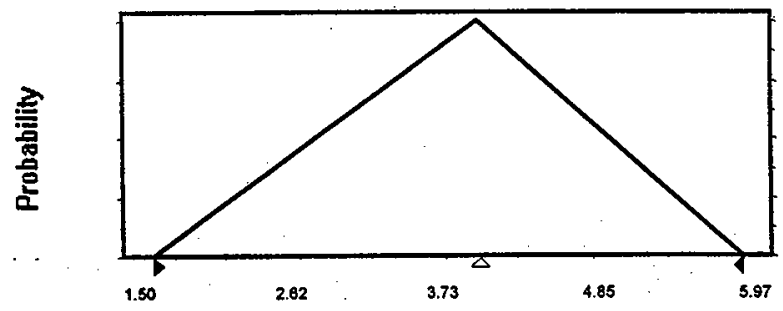


Water Content, \%: Bound $=95 \%$ ile

Triangular distribution with parameters:

Minimum

Likeliest

Maximum
6.23

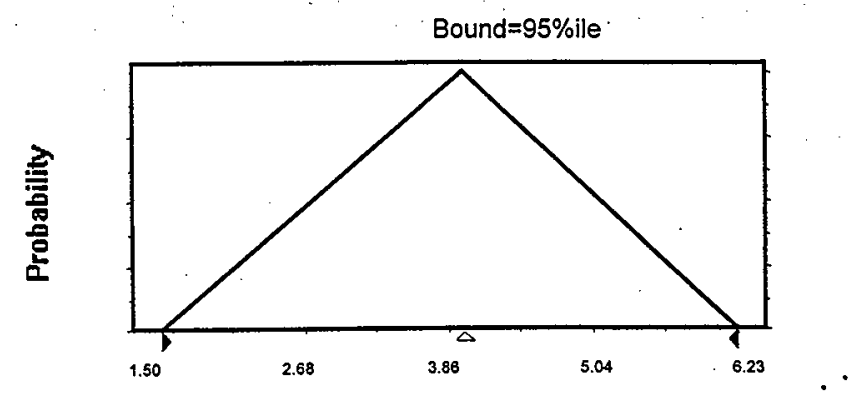

Water Content, \%: Bound=90\%ile

Triangular distribution with parameters:

Minimum

Likeliest

1.50

Maximum

Bound $=90 \%$ ile

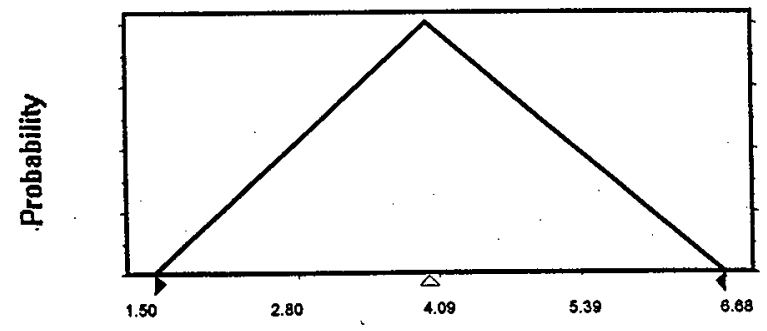




\section{A.2 Derivation of Triangular Distribution Parameters}

Consider the two triangular pdfs shown in Figure A-1. The first pdf has minimum "a", likeliest value " $\mathrm{b}$ ", and bounding value " $\mathrm{c}$ ". The second pdf has the same minimum and likeliest values as the first, but the maximum is $c^{\prime}$, which is greater than $c$. The second pdf illustrates how the minimum and likeliest values have been preserved, but the maximum has been shifted so that the bounding value now has some exceedance probability, P. Because the area of both triangles must be one, the value of $p$ is shown by the shaded area.

If $p$ is known or specified, the value of $c^{\prime}$ can be found using the relations for similar triangles. That is,

$$
\frac{h}{p_{12}}=\frac{c^{\prime}-c}{c^{\prime}-b}
$$

where $\mathrm{p}_{12}$ is the probability at the likeliest value of the second pdf. Recall that the probability of the likeliest value can be expressed as

$$
p_{12}=\frac{2}{c^{\prime}-a}
$$

for the second triangle. Because the shaded area is equal to $P$,

$$
\frac{\left(c^{\prime}-c\right) h}{2}=P
$$

or

$$
h=\frac{2 P}{c^{\prime}-c}
$$

Then,

$$
\frac{c^{\prime}-c}{c^{\prime}-b}=\frac{P\left(c^{\prime}-a\right)}{c^{\prime}-c}
$$


HNF-2234, Rev. 2

Figure A-1: Derivation of New Triangular Distribution Maximum.

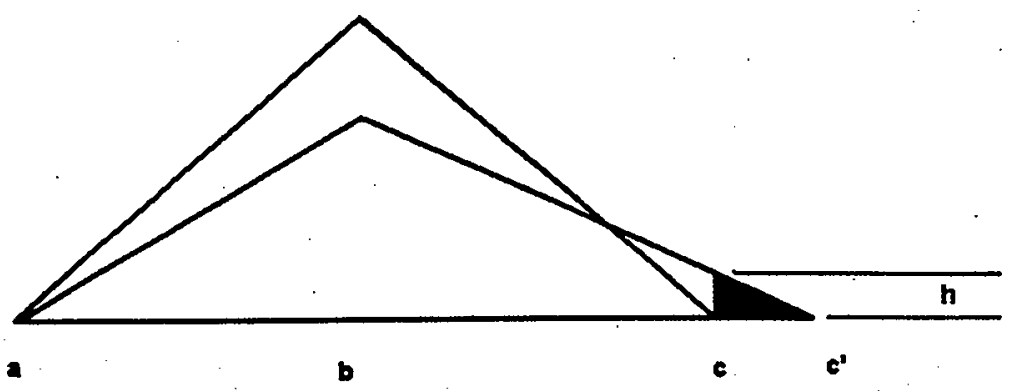


which can be rearranged for c' to yield:

$$
c^{\prime}=\frac{-(a P+b P-2 c)+\sqrt{(a P+b P-2 c)^{2}-4(1-P)\left(c^{2}-P a b\right)}}{2(1-P)}
$$

This solution was checked using Crystal Ball ${ }^{\text {ts }}$ to verify that indeed, the calculated c' produced an exceedance probability $P$, with triangular distribution parameters $a, b$, and $c$ '. 
Sludge Mass per Fuel Assembly, kg: High $=100 \%$

Triangular distribution with parameters:

Minimum

$0.00 E+00$

Likeliest

2.20E-03

Maximum

1.30E-02

Selected range is from $0.00 E+0$ to $2.00 E-2$

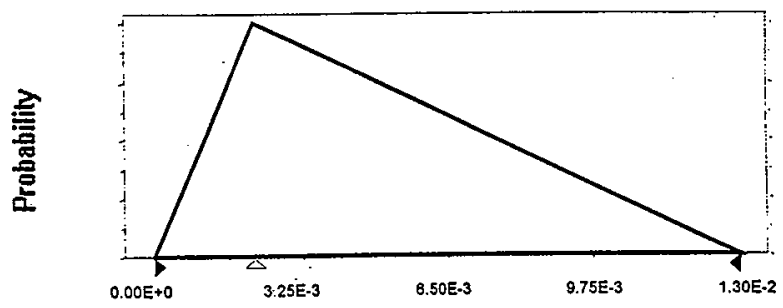

Sludge Mass per Fuel Assembly, kg: High $=97.5 \%$

Triangular distribution with parameters:

Minimum

Likeliest

Maximum
$0.00 E+00$

2.20E-03

$1.52 \mathrm{E}-02$

Selected range is from $0.00 E+0$ to $2.33 E-2$

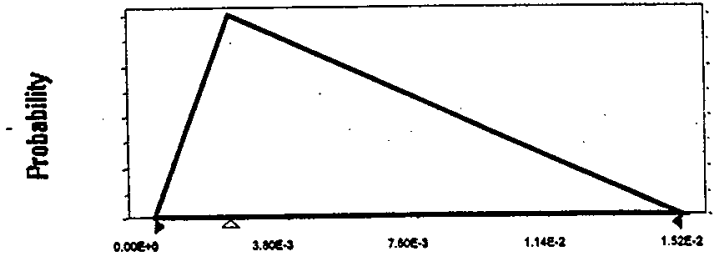


HNF-2234, Rev. 2

Sludge Mass per Fül Assembly, kg: High $=95 \%$

Triangular distribution with parameters:

Minimum

$0.00 E+00$

Likeliest

2.20E-03

Maximum

1.63E-02

Selected range is from $0.00 E+0$ to $2.50 \mathrm{E}-2$

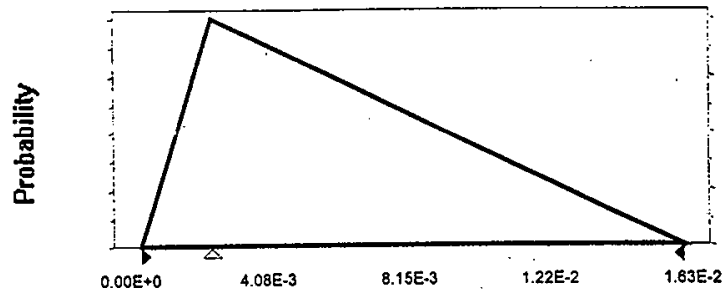

Sludge Mass per Fuel Assembly, kg: High = 90\%

Triangular distribution with parameters:

Minimum

$0.00 \mathrm{E}+00$

Likeliest

2.20E-03

Maximum

1.84E-02

Selected range is from $0.00 E+0$ to $2.82 E-2$

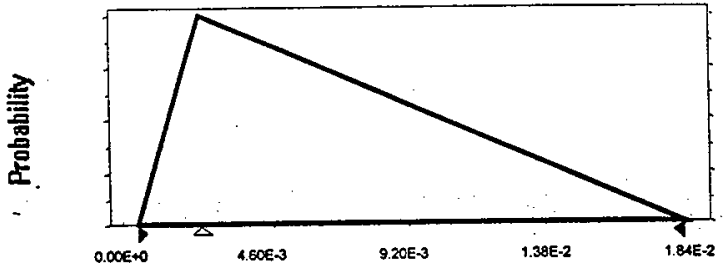


HNF-2234, Rev. 2

Sludge Water Contẹnt: High $=\mathbf{1 0 0 \%}$

Triangular distribution with parameters:

Minimum

Likeliest

Maximum

Selected range is from 2.00 to 35.00

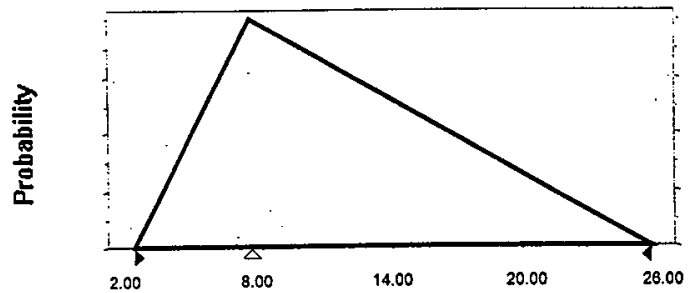

Sludge Water Content: High $=97.5 \%$

Triangular distribution with parameters:

Minimum

Likeliest

2.00

Maximum

7.50

29.97

Selected range is from 2.00 to 40.46

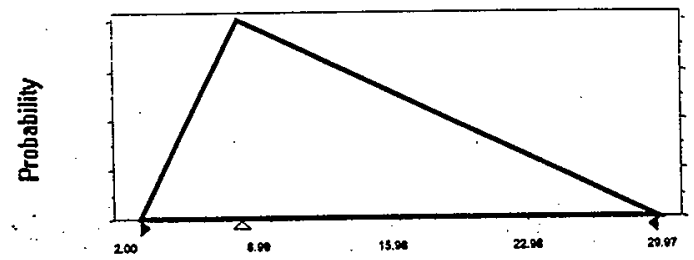


HNF-2234, Rev. 2

Sludge Water Conterit: High $=95 \%$

Triangular distribution with parameters:

Minimum

Likeliest

7.50

Maximum

32.08

Selected range is from 2.00 to 43.36

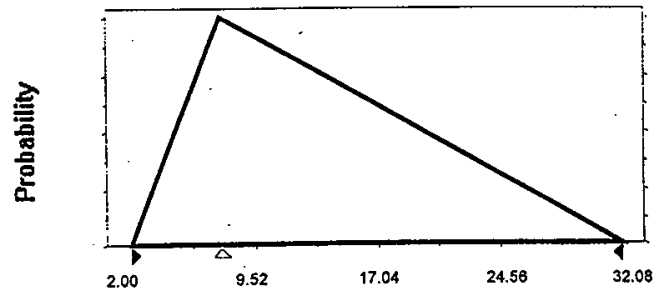

Sludge Water Content: High $=90 \%$

Triangular distribution with parameters:

Minimum

2.00

Likeliest

7.50

Maximum

35.00

Selected range is from 2.00 to 47.37

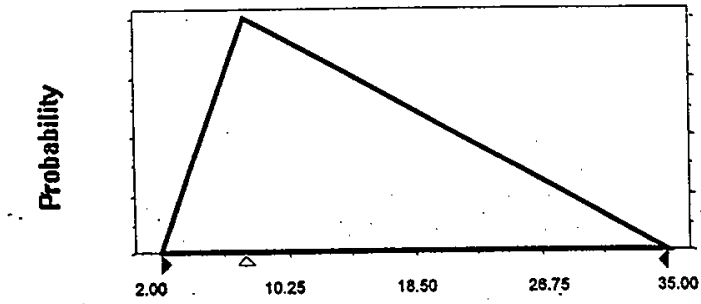

End of Assumptions 
HNF-2234, Rev. 2

APPENDIX B

LOG-NORMAL INPUT DISTRIBUTIONS 
HNF-2234, Rev. 2

Scrap Mass/Assy, kg: Bound $=100 \%$ lle

Lognormal distribution with parameters:

Log Mean

$-3.36 \mathrm{E}+00$

Log Std. Dev.

5.67E-01

Bound $=100 \%$ ile

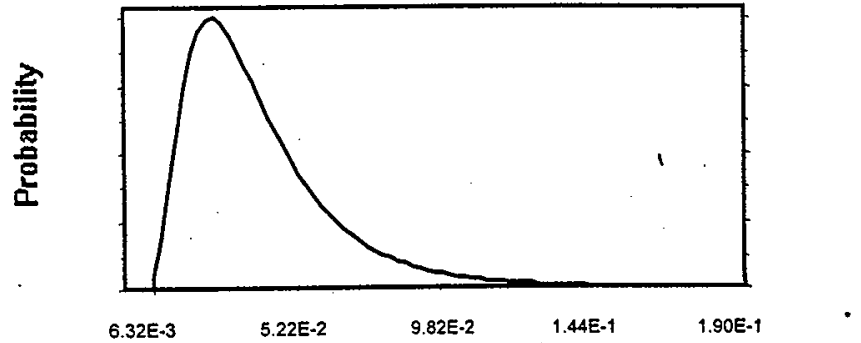

Scrap Mass/Assy, kg: Bound $=\mathbf{9 7 . 5 \% i l e ~}$

Lognormal distribution with parameters:

$\begin{array}{lr}\text { Log Mean } & -2.97 E+00 \\ \text { Log Std. Dev. } & 6.94 E-01\end{array}$

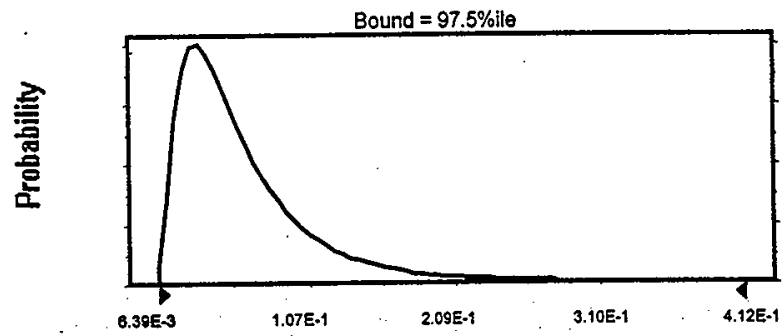


HNF-2234, Rev. 2

Scrap Mass/Assy, kg: Bound $=95.0 \%$ ile

Lognormal distribution with parameters:

Log Mean

$-2.83 E+00$

Log Std. Dev.

7.41E-01

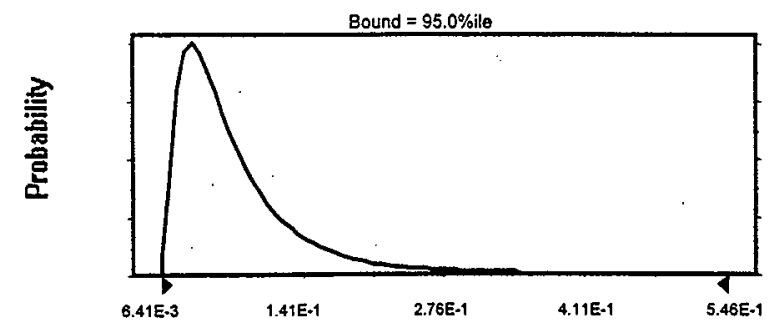

Scrap Mass/Assy, kg: Bound $=\mathbf{9 0 . 0 \% i l e ~}$

Lognormal distribution with parameters:

Log Mean

Log Std. Dev.

$-2.64 E+00$

8.02E-01

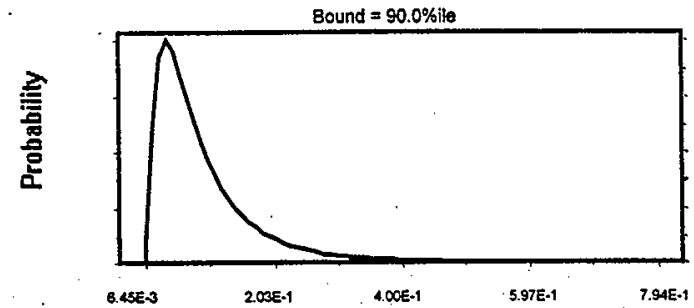


HNF-2234, Rev. 2

Fuel Mass/Assy, kg: Bound $=100 \%$ llo

Lognormal distribution with parameters:

Log Mean

Log Std. Dev.

$-5.28 E+00$

4.42E-01

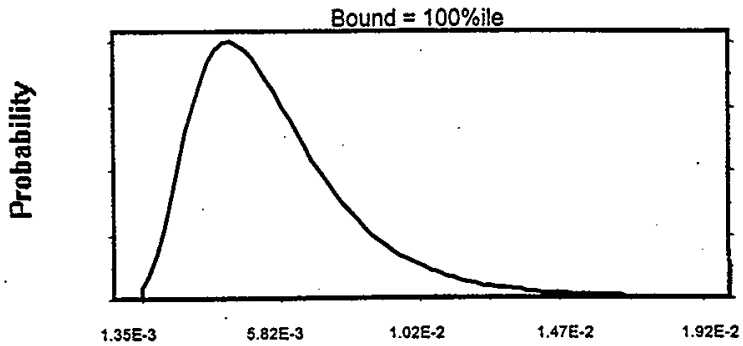

Fuel Mass/Assy, kg: Bound = 97.5\%ile

Lognormal distribution with parameters:

Log Mean

Log Std. Dev.
$-4.97 E+00$
$5.41 E-01$

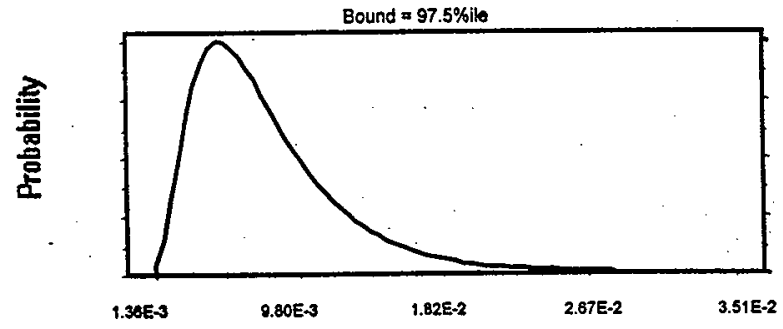


HNF-2234, Rev. 2

Fuel Mass/Assy, kg: Bound = 95.0\%ile

Lognormal distribution with parameters:

Log Mean

$-4.86 \mathrm{E}+00$

Log Std. Dev.

5.77E-01

$=$

Bound $=95.0 \%$ ile

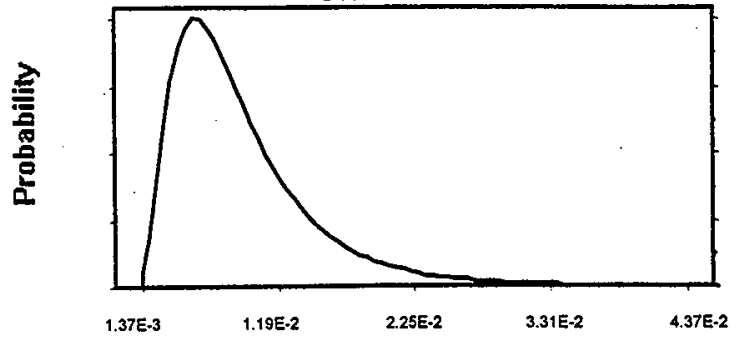

Fuel Mass/Assy: Bound $=90.0 \%$ ile

Lognormal distribution with parameters:
. Log Mean
$-4.71 E+00$
Log Std. Dev.
$6.25 \mathrm{E}-01$

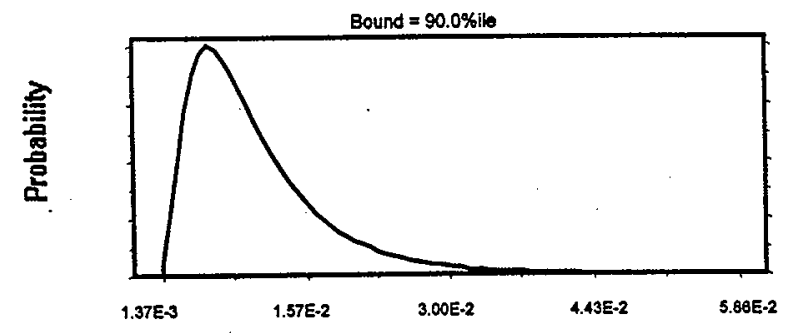


HNF-2234, Rev. 2

Water Content \%, Bound $=100 \%$

Lognormal distribution with parameters:

Log Mean

1.38

Log Std. Dev.

0.11

Content \%

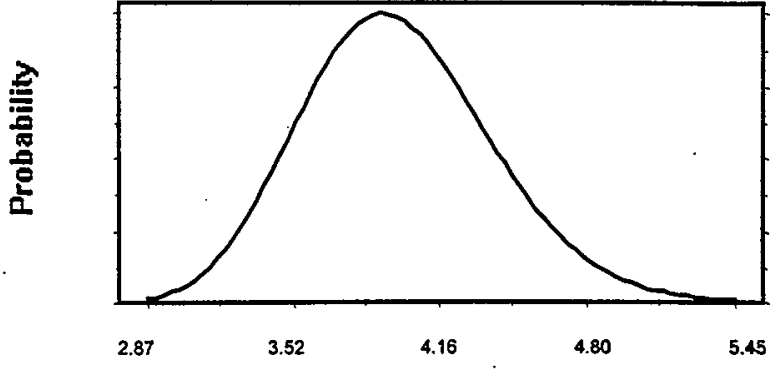

Water Content \%: Bound $=\mathbf{9 7 . 5 \%}$

Lognormal distribution with parameters:

Log Mean

1.38

Log Std. Dev.

0.17

Bound $=97.5 \%$

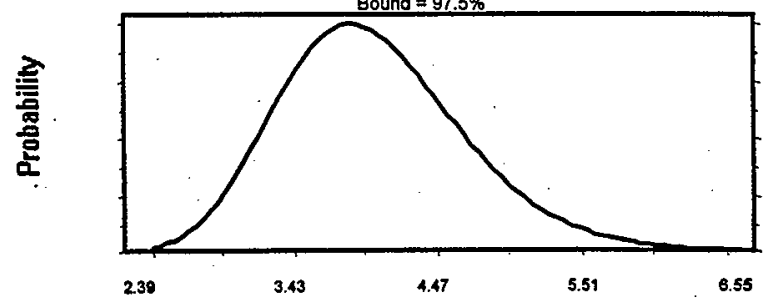


HNF-2234, Rev. 2

Water Content \%: Bound $=95.0 \%$

Lognormal distribution with parameters:

Log Mean

Log Std. Dev.

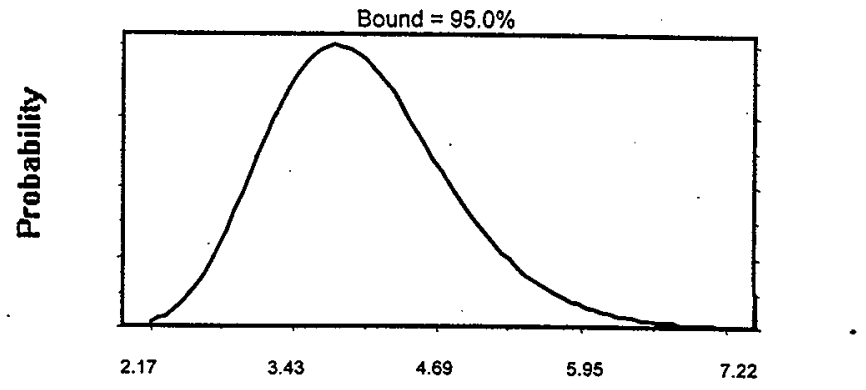

Water Content,\%: Bound $=\mathbf{9 0 . 0 \%}$

Lognormal distribution with parameters:

Log Mean

Log Std. Dev.

Bound $=90.0 \%$

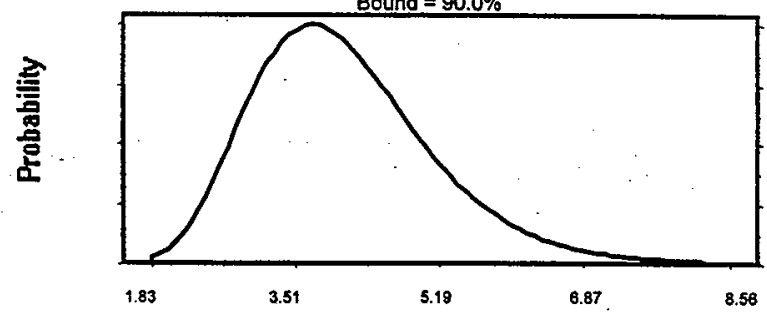


Sludge Mass/ Assy., kg,: High = 99.9\%ile

Lognormal distribution with parameters:

Geometric Mean

2.22E- 03

$99.9 \%$ - tile

1.29E-02

Selected range is from $0.00 E+0$ to +Infinity

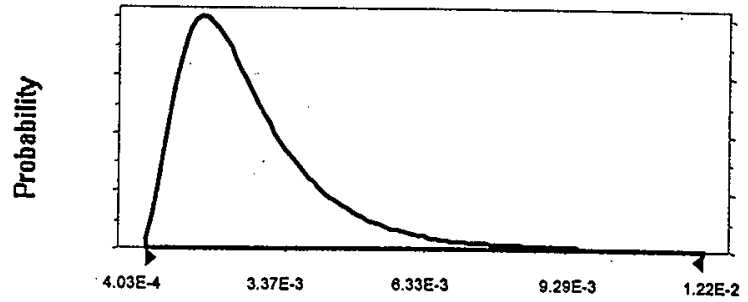

Sludge Mass/ Assy., kg,: High $=97.5 \%$ ile

Lognormal distribution with parameters:

Geometric Mean

$97.5 \%$ - tile

2.22E-03

$1.29 \mathrm{E}-02$

Selected range is from $0.00 E+0$ to + Infinity

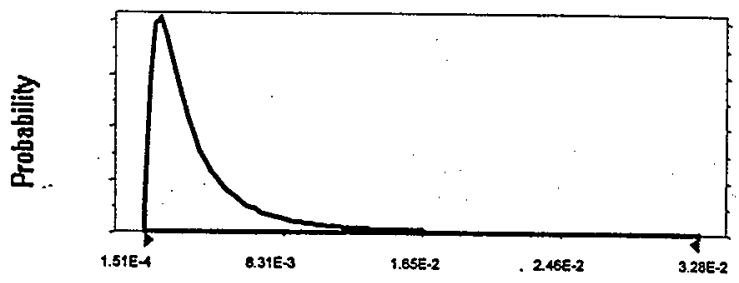


HNF-2234, Rev. 2

Sludge Mass/ Assy., kg,: High $=95.0 \%$ ile

Lognormal distribution with parameters:

Mean

Standard Dev.

3.94E-03

5.75E-03

Selected range is from $0.00 E+O$ to + Infinity

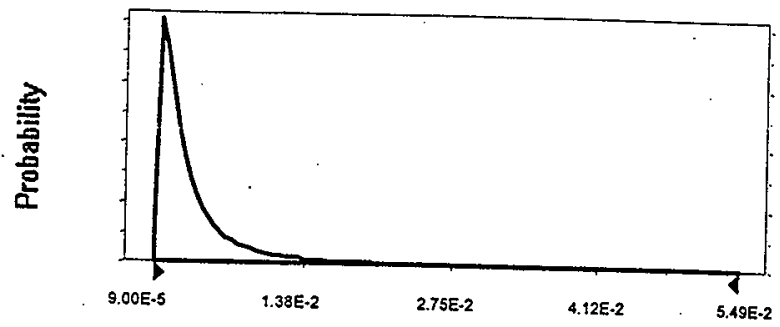

Sludge Mass/ Assy., kg,: High $=90.0 \%$ ile

Lognormal distribution with parameters:

Geometric Mean

$90 \%$ - tile

2.22E-03

1.29E-02

Selected range is from $0.00 E+0$ to + Infinity

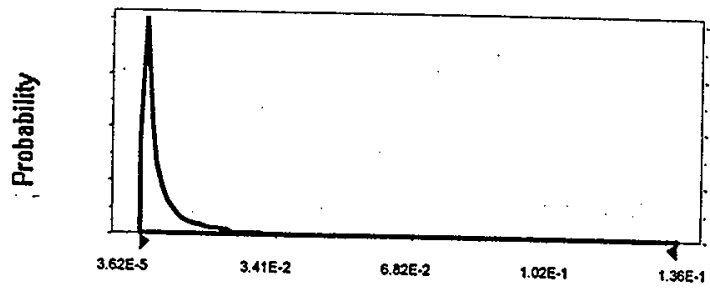


HNF-2234, Rev. 2

Sludge Water Content, \%: High $=99.9 \%$

Lognormal distribution with parameters:

Geometric Mean

$99.9 \%$ - tile

Selected range is from 0.00 to + Infinity

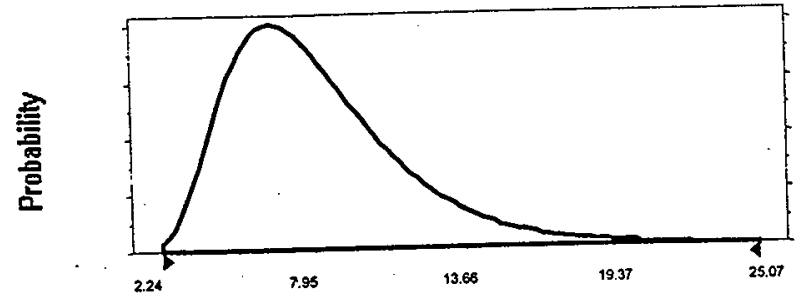

Sludge Water Content, $\%:$ High $=97.5 \%$

Lognormal distribution with parameters:

Geometric Mean

$97.5 \%$ - tile

Selected range is from 0.00 to 35.00

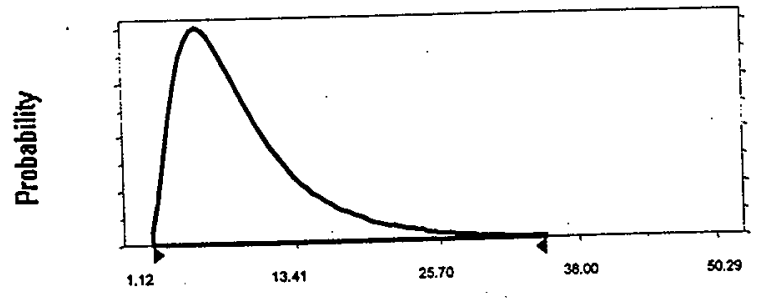


HNF-2234, Rev. 2

\section{APPENDIX $C$ \\ WEIBULL INPUT DISTRIBUTIONS}

C.1 Weibull Input 


\section{HNF-2234, Rev . 2}

Scrap Mass/Assy, kg: Bound $=99.9 \%$ ile

Weibull distribution with parameters:

$\begin{array}{lr}\text { Location } & 6.00 E-03 \\ \text { Scale } & 4.39 E-02 \\ \text { Shape } & 1.30 \mathrm{E}+00\end{array}$

Mean value in simulation was 4.65E-2

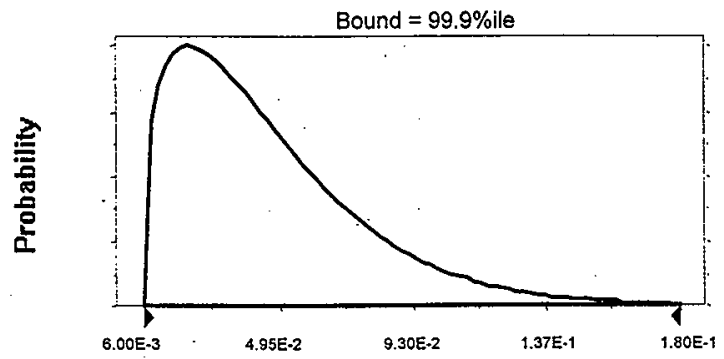

Scrap Mass/Assy, kg: Bound $=97.5 \%$ ile

Weibull distribution with parameters:

Location

Scale

Shape
6.00E-03

6.48E-02

$1.19 E+00$

Mean value in simulation was $6.70 \mathrm{E}-2$

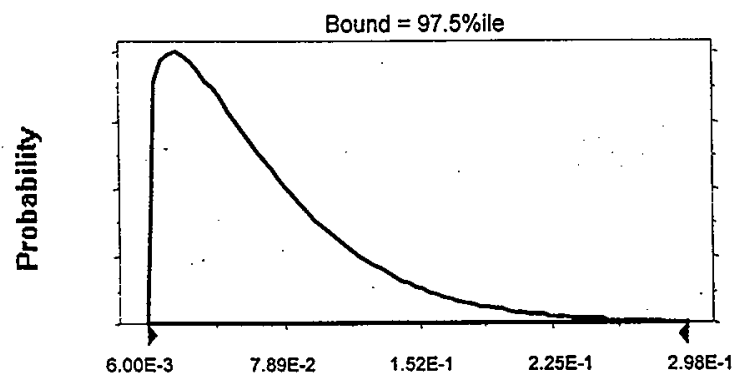


HNF-2234, Rev. 2

Scrap Mass/Assy, kg: Bound $=95.0 \%$ ile

Weibull distribution with parameters:

Location

Scale

Shape
$6.00 \mathrm{E}-03$

7.56E-02

$1.16 \mathrm{E}+00$

Mean value in simulation was $7.77 E-2$

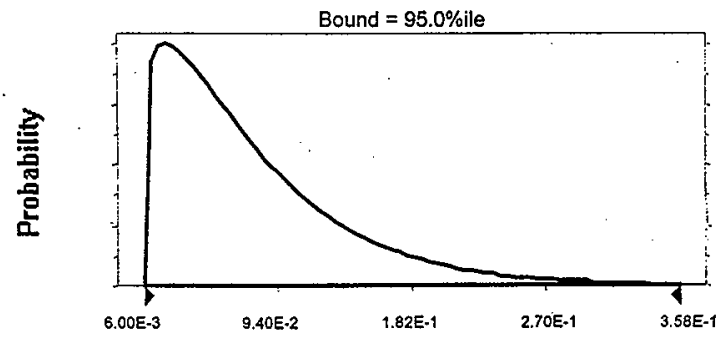

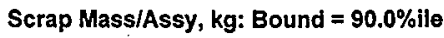

Weibull distribution with parameters:

$\begin{array}{lr}\text { Location } & 6.00 E-03 \\ \text { Scale } & 9.29 E-02 \\ \text { Shape } & 1.13 E+00\end{array}$

Mean value in simulation was $9.48 E-2$

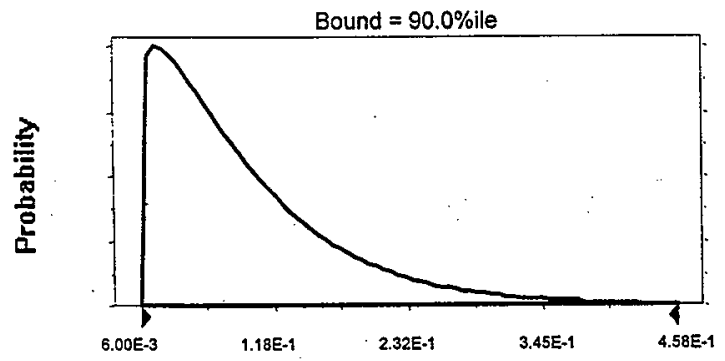


HNF-2234, Rev. 2

Fuel Mass/Assy: Bound $=\mathbf{9 9 . 9 \% i l e ~}$

Weibull distribution with parameters:

Location

Scale

Shape
1.30E-03

8.07E-03

$2.30 \mathrm{E}+00$

Mean value in simulation was $8.45 E-3$

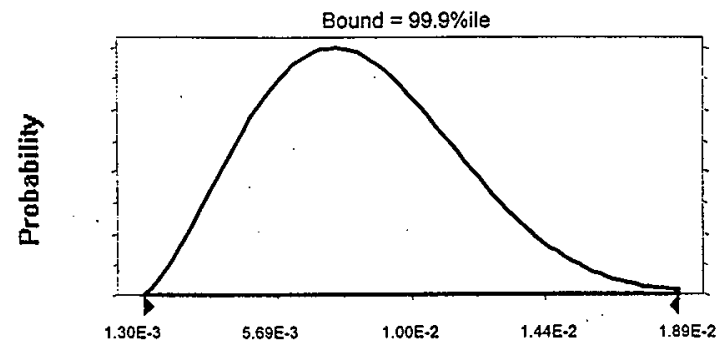

Fuel Mass/Assy: Bound $=\mathbf{9 7 . 5 \%} \%$

Weibull distribution with parameters:

Location

Scale

Shape
1.30E-03

$9.36 \mathrm{E}-03$

$1.89 \mathrm{E}+00$

Mean value in simulation was $9.61 \mathrm{E}-3$

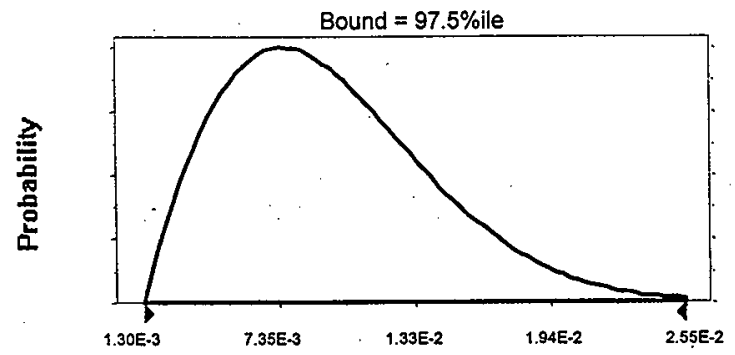

FAI/98-1, Rev. 4

C -4

Date: $10 / 05 / 98$ 
Fuel Mass/Assy: Bound $=95 \%$ ile

Weibull distribution with parameters:

$\begin{array}{lr}\text { Location } & 1.30 \mathrm{E}-03 \\ \text { Scale } & 1.01 \mathrm{E}-02 \\ \text { Shape : } & 1.77 \mathrm{E}+00\end{array}$

Mean value in simulation was $1.02 \mathrm{E}-2$

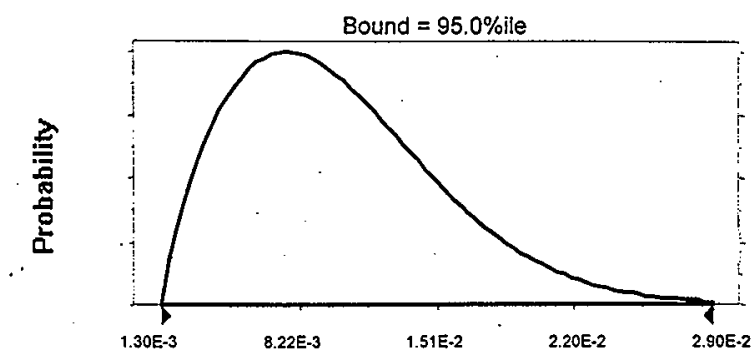

Fuel Mass/Assy: Bound $=90 \%$ ile

Weibull distribution with parameters:

$\begin{array}{lr}\text { Location } & 1.30 \mathrm{E}-03 \\ \text { Scale } & 1.13 \mathrm{E}-02 \\ \text { Shape } & 1.64 \mathrm{E}+00\end{array}$

Mean value in simulation was $1.13 E-2$

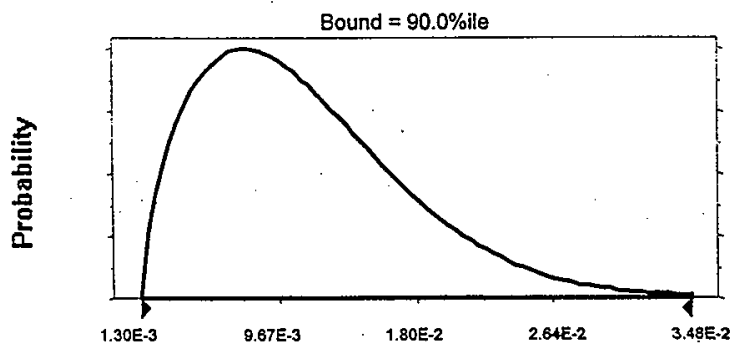


HNF-2234, Rev. 2

Water Content, \%: Bound $=99.9 \%$ ile

Weibull distribution with parameters:

Location

Scale

Shape
1.50

2.63

4.6

Mean value in simulation was 3.90

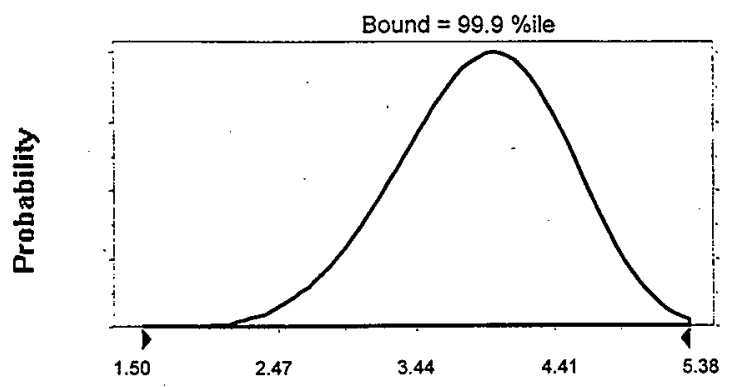

Water Content, $\%:$ Bound $=97.5 \%$ ile

Weibull distribution with parameters:

Location

Scale

Shape
1.50

2.73

3.43

Mean value in simulation was 3.96

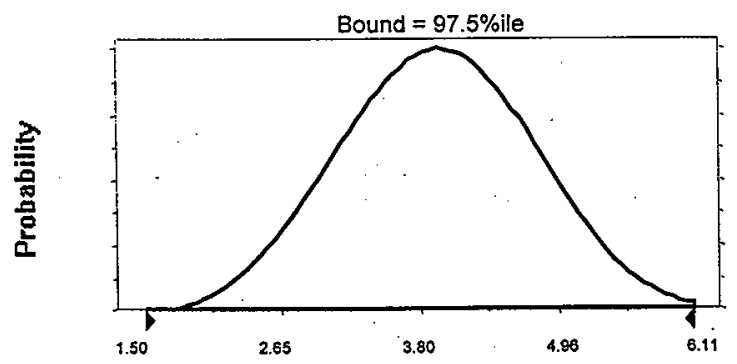

FAI/98-1, Rev. 4

C -6

Date: $10 / 05 / 98$ 
HNF-2234, Rev. 2

Water Content, $\%:$ Bound $=95.0 \%$ ile

Weibull distribution with parameters:

Location

Scale

Shape

Mean value in simulation was 4.03

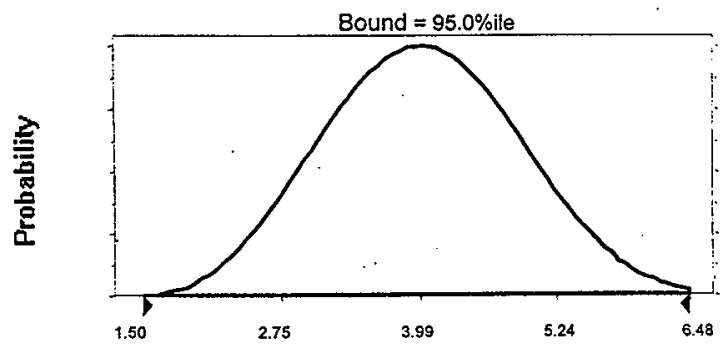

Water Content, $\%:$ Bound $=\mathbf{9 0 . 0} \%$ ile

Weibull distribution with parameters:

Location

Scale

Shape
1.50

2.94

2.71

Mean value in simulation was 4.11

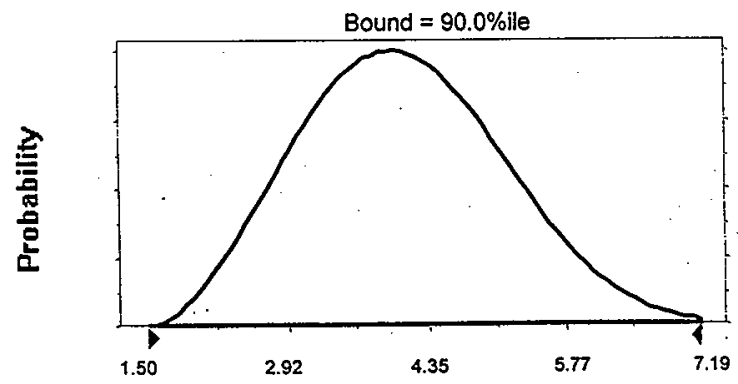


HNF-2234, Rev. 2

\section{C.2 Derivation of Weibull Distribution Parameters}

Recall that the Weibull distribution is given by:

$$
f(x)=\frac{\beta}{\alpha}\left(\frac{x-L}{\alpha}\right)^{\beta-1} \exp \left(\frac{x-L}{\alpha}\right)^{\beta}
$$

where $\mathrm{L}$ is the location, $\alpha$ is the scale, and $\beta$ is the shape. The cumulative distribution is

$$
F(x)=1-\exp ^{-\left(\frac{x-1}{\alpha}\right)^{\beta}}
$$

Weibull distribution parameters were specified in the following manner:

1. The output deviates were greater than the low value from the reference estimate,

2. The mode (most probable value), $x_{m}$, was set equal to the most likely value from the reference estimate, and

3. The bound value, $x_{b}$, corresponded to the particular percentile point defined for the case (i.e., $99.9 \%, 97.5 \%, 95 \%$, or $90 \%$ ).

The properties of the three-parameter Weibull distribution are such that the output deviates are always greater than the location parameter, $L$, which allows is to simply set $L$ equal to the low value from the reference estimate.

To find the mode, $x_{\mathfrak{m}}$, of the Weibull distribution, differentiate equation (C-1) and set it equal to zero to obtain:

$$
\frac{\mathrm{x}_{\mathrm{m}}-\mathrm{L}}{\alpha}=\left(\frac{\beta-1}{\beta}\right)^{\frac{1}{\beta}}
$$

The bound value, $x_{b}$, is easily determined using the cumulative distribution (equation (C-2)), 


$$
\begin{array}{r}
\text { HNF-2234, Rev. } 2 \\
\frac{x_{b}-L}{\alpha}=\left[-\ln \left(1-F\left(x_{b}\right)\right]\right]^{\frac{1}{\beta}}
\end{array}
$$

where $F\left(x_{b}\right)$ is the desired percentile point.

The scale parameter $(\alpha)$ can be eliminated to obtain an equation for the shape parameter $(\beta)$;

$$
\frac{x_{b}-L}{x_{m}-L}=\left[\frac{-\ln \left(1-F\left(x_{b}\right)\right)}{\frac{\beta-1}{\beta}}\right]^{\frac{1}{\beta}}
$$

because $x_{b}, x_{m}, L$, and $F\left(x_{b}\right)$ are specified. Once $\beta$ is known, $\alpha$ can be found from equation (C-3) or (C-4).

This solution was checked using Crystal Ball ${ }^{\text {Th }}$. A Weibull distribution with specified location, scale, and shape was used to generate output deviates. Output histograms verified that the $x_{m}$ corresponded to the mode and $x_{b}$ corresponded to the selected percentile point. 
HNF-2234, Rev. 2

C3. Cansister Particulate Input for Crystal Ball

Sludge Mass/Assy, $\mathrm{kg}::$ High $=\mathbf{9 9 . 9} \%$ ile

Weibull distribution with parameters:

Location

Scale

Shape
$0.00 E+00$

3.96E-03

$1.63 E+00$

Selected range is from $0.00 E+0$ to +Infinity

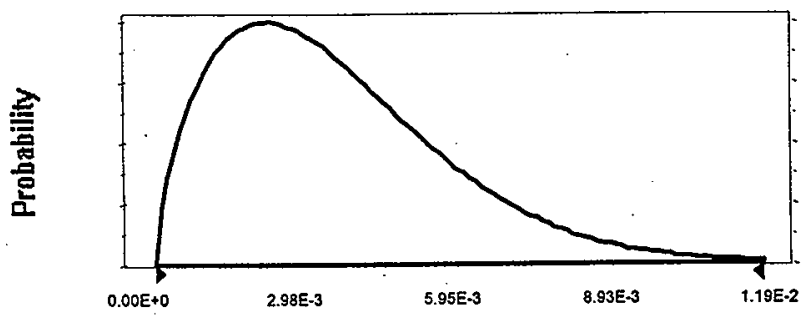

Sludge Mass/Assy., kg:: High $=\mathbf{9 7 . 5} \%$ ile

Weibull distribution with parameters:
Location
$0.00 \mathrm{E}+00$
Scale
$5.19 \mathrm{E}-03$
Shape
$1.42 \mathrm{E}+00$

Selected range is from $0.00 E+0$ to + Infinity

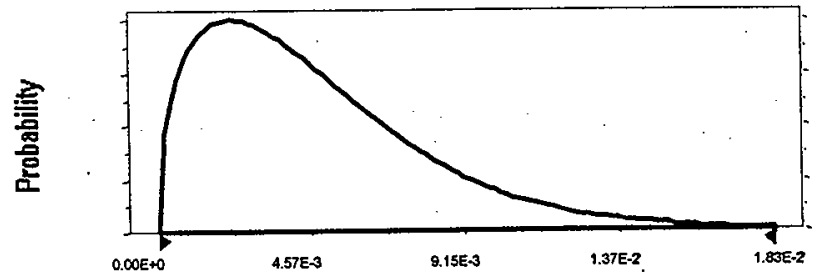


Sludge Mass/Assy., kg:: High $=95.0 \%$ ile

Weibull distribution with parameters:

Location

Scale

Shape
$0.00 E+00$

$5.82 E-03$

$1.36 E+00$

Selected range is from $0.00 E+0$ to +Infinity

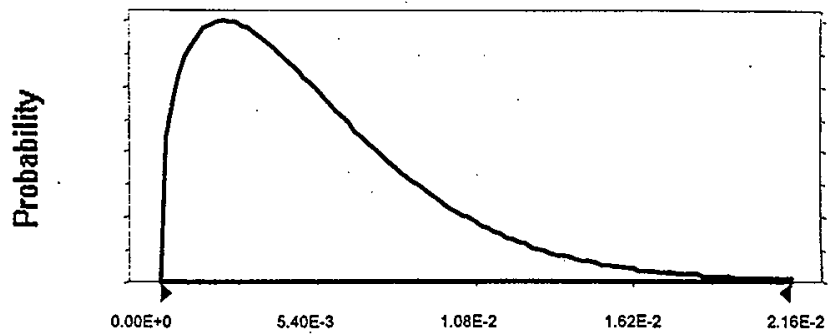

Sludge Mass/Assy., kg:: High $=90.0 \%$ ile

Weibull distribution with parameters:

$\begin{array}{lr}\text { Location } & 0.00 E+00 \\ \text { Scale } & 6.84 \mathrm{E}-03 \\ \text { Shape } & 1.30 E+00\end{array}$

Selected range is from $0.00 \mathrm{E}+0$ to +Infinity

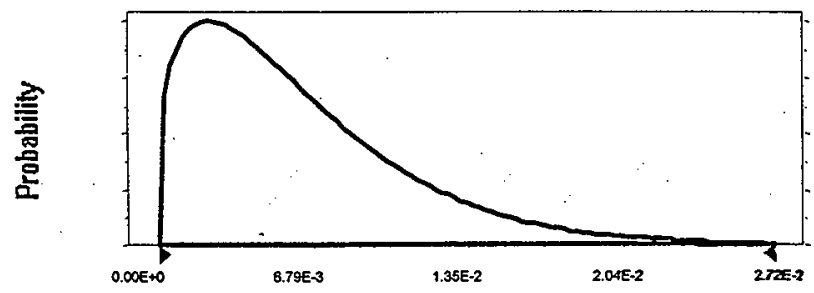


Sludge Water Content, \%:: High $=99.9 \%$

Weibul! distribution with parameters:

$\begin{array}{lr}\text { Location } & 2.00 \\ \text { Scale } & 8.40 \\ \text { Shape } & 1.843\end{array}$

Selected range is from 2.00 to +Infinity

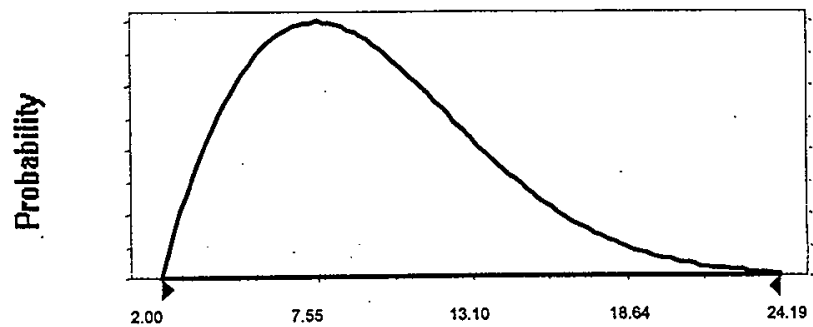

Sludge Water Content, \%:: High $=97.5 \%$

Weibull distribution with parameters:

$\begin{array}{lr}\text { Location } & 2.00 \\ \text { Scale } & 10.46 \\ \text { Shape } & 1.571\end{array}$

Selected range is from 2.00 to 35.00

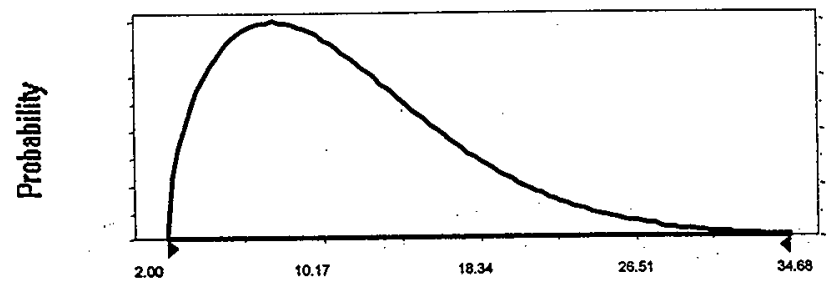


HNF-2234, Rev. 2

Sludge Water Content, $\%::$ High $=95.0 \%$

Weibull distribution with parameters: Location

Scale

Shape

Selected range is from 2.00 to 35.00

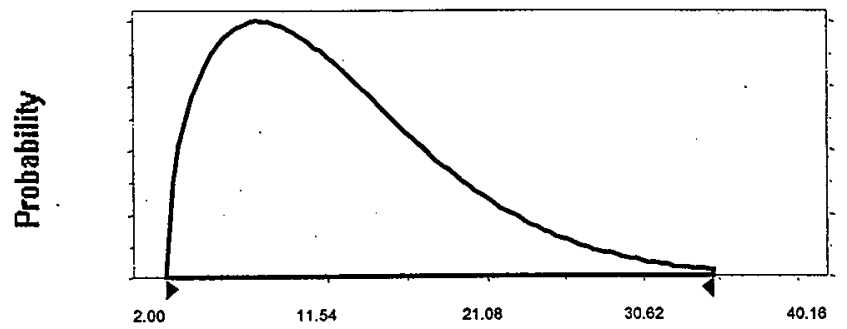

Sludge Water Content, \%:: High $=\mathbf{9 0 . 0} \%$

Weibull distribution with parameters: Location

Scale

Shape

Selected range is from 2.00 to 35.00

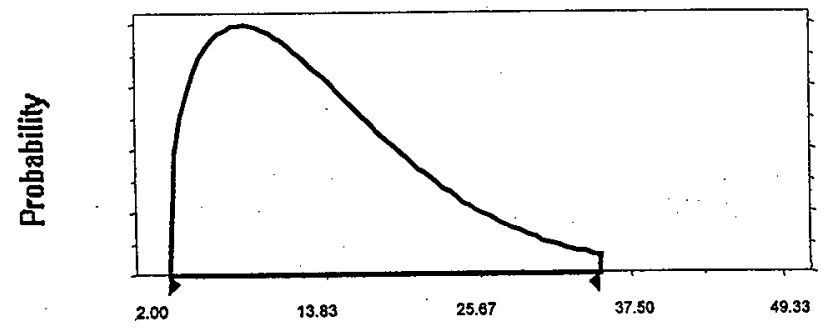


HNF-2234, Rev. 2

APPENDIX D

VALIDATION OF MONTE CARLO CALCULATIONS

\section{D.1 Particulate Mass Hand Calculation}

Any sum $S_{n}$ of random variables $x_{i}, i=1$ to $n$,

$$
S_{n}=x_{1}+x_{2}+x_{3} \ldots x_{n}
$$

with the same underlying distribution of mean $\mu$ and variance $\sigma^{2}$ has a mean of $n \mu$ and variance . $n \sigma^{2}$. Linear combinations, such as the MCO particulate mass, have similarly weighted parameter values:

$$
\begin{aligned}
& \mu_{\mathrm{MCO}}=39.1 \mu_{\text {scrap }}+216 \mu_{\text {fuel }} \\
& \sigma_{\mathrm{MCO}}^{2}=\mathrm{n}\left[\left(\frac{39.1}{\mathrm{n}}\right)^{2} \sigma_{\text {scrap } \cdot}^{2}+\left(\frac{216}{\mathrm{n}}\right)^{2} \sigma_{\text {fuel }}^{2}\right]
\end{aligned}
$$

These formulas are used to check the particulate mass for Case 7 (log-normal inputs), 95-th percentile for the reference bound, and $n=10$ independent choices:

$\begin{array}{ll}\mu_{\text {scrap }} & 0.0778 \\ \mu_{\text {fuel }} & 0.00914 \\ \mu_{\mathrm{MCO}} \text { (equation (D-2)) } & 5.016 \\ \mu_{\mathrm{MCO}} \text { (Appendix E) } & 5.006 \\ & \\ \sigma_{\text {scrap }}^{2} & 4.42 \mathrm{e}-3 \\ \sigma_{\text {fuel }}^{2} & 3.31 \mathrm{e}-5 \\ \sigma_{\mathrm{MCO}}^{2} \text { (equation (D-3)) } & 0.830 \\ \sigma_{\mathrm{MCO}}^{2} \text { (Appendix E) } & 0.839\end{array}$




\section{D.2 Independent Calculation}

Attached is an independent evaluation for water content results for Case 7 and $n=10-:$ independent choices using MATHCAD. In Section 1 of the calculation, values from Appendix $B$ for the mean and standard deviations of particulate and water pdf's are assigned, and in Section 2 these are used to derive the log-normal distribution parameters. Input pdf's are then plotted to demonstrate that the cpdf's agree with the 95-th percentile for the reference bounding values. In Section 3, a Monte Carlo method is used with 10,000 trials to generate histograms for MCO particulate and water. The plots in these sections compare the local Monte Carlo results with those using the derived log-normal parameters, and agreement is excellent.

A technical concern noted in this review is that the output distribution for water mass may not be well-characterized by a log-normal. It is possible for the log-normal parameters derived from output distribution sample statistics to imply a water content at the $10^{-6}$ probability level which is exceeded once or a few times during 10,000 trials. Thus, the procedure to fit lognormal distributions and extrapolate the $10^{-6}$ or "incredible" water content may not in all cases be conservative. 
File: pwaterc.med Date: 9/24/98 PagejHFF-2234, Rev. 2

\section{INDEPENDENT CHECK OF TENACIOUS PARTICULATE \& CANISTER PARTICULATE WATER}

Martin G. Plys, Fauske \& Associates, Inc. 16W070 W. 83rd St. Burr Ridige IL 60521

Phone: 630-887-5207, Fax 630-986-5481

Prepared for Duke Engineering \& Services, Hanford, Inç.

Purpose: For Quality Assurance, Independent check of 'incredible' water mass loaded into an MCO associated with water of hydration on tenaciously clinging particulate and sludge.

Concern: Must address the following 3 key points:

1) Level of independence. Fuel assemblies are selected independently at no finer grain than the canister level.

2) Percentile represented by "high" value. The "high" value represents some percentile of possible values, not literally the $100 \%$ upper bound.

3) Value of Extreme Parameter. Extent of the 'tail' on the pdf for a parameter.

CASE OBJECTIVE : Reproduce particulate and water distributions for 95th percentile, 10 choices

input and derived values for particulate $(\mathrm{kg})$ :

$$
\text { Low@ Mean\& Sigma Bound @ }
$$

$\begin{array}{llcc}\text { Scrap } & 0.0014 & 0.0778,0.0665 & 95 \% \text { (in) } \\ \text { Fuel } & 0.0064 & 0.0914,0.00575 & 0.02\end{array}$

Input and derived values for water. Mean $4.04 \%$, Sigma=0.82, yields $5.5 \% @ 95 \%$.

Note: here mean and sigma are sample values; log-normal parameters must be derived.

Expected output (Sample statistics) to agree with Crystal Ball:

$\begin{array}{lll} & \text { Mean, } \mathrm{kg} & \text { Sigma } \\ \text { Particulate } & 5.0 & 0.916 \\ \text { Water } & 0.20 & 0.040\end{array}$

Input and derived values for sludge - which only exists on fuel assemblies

$$
\text { Low@. Mean \& Sigma Bound@ }
$$

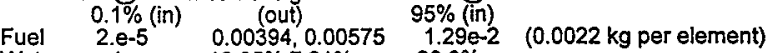

Water $\mathrm{n} / \mathrm{a} \quad 12.35 \%, 7.21 \% \quad 28.0 \%$

Expected output (Sample statistics) to agree with Crystal Ball:

$\begin{array}{lll} & \text { Mean, } \mathrm{kg} & \text { Sigma } \\ \text { Sludge } & 0.848 & 0.387 \\ \text { Water } & 0.078 & 0.048\end{array}$

Total expected water output:

Mean 0.280

Std Deviation $\quad 0.062$

Incredible $\left(10^{* *-}-6\right)$ value using lognormal: 0.747

Note: Crystal ball model truncates the sludge water percentage, resulting in lower output

standard deviation and lower "incredible" value. 
File: pwaterc.mcd Date: 9/24/98 Pageifif-2234, Rev. 2

1.0 Assign inputs

$\mathrm{m}_{\mathrm{bs}}:=0.2 \quad$ Scrap particulate bound

$P_{b}:=0.95 \quad$ Percentile of reference bound

$\mathrm{m}_{\mathrm{bf}}:=0.02 \quad$ Fuel particulate bound

$N:=10 \quad$ Independent choices

$\mu_{s s}:=0.0778$ Scrap particulate mean

$A_{f}:=216 \quad$ Fuél assemblies

$\mu_{\mathrm{fs}}:=0.00914$ Fuel particulate mean

$A_{S}:=39.1 \quad$ Scrap assemblies

$\mu_{\text {ws }}:=4.04$ Particulate water fraction mean

$\mu_{\mathrm{gs}}:=0.00394$ Sludge particulate mean

$M:=10 \cdot 10^{3} \quad$ Number of Monte Carlo trials, i.e. \# of MCOs filled

$\mu_{\text {gws }}:=9.98$ Sludge water mean

$\sigma_{s s}:=0.0665$ Scrap particulate sigma

$\sigma_{\text {gs }}:=0.00575$ Sludge particulate sigma

$\sigma_{\text {fs }}:=0.00575$ Fuel particulate sigma

$\sigma_{\text {gws }}:=8.76 \quad$ Sludge water sigma

$\sigma_{w s}:=0.82$ Water fraction sigma

Subscript 's' is used for mu and sigma above to designate sample (not log-normal) values

2.0 Derive input distributions and plot

$f \sigma_{i} \mu_{s}, \sigma_{s}:=\left[\ln \left[\left(\frac{\sigma_{s}}{\mu_{s}}\right)^{2}+1\right]\right]^{\frac{1}{2}} \quad \begin{aligned} & \text { Function for log-normal parameter sigma } \\ & \text { given sample mean and standard deviation }\end{aligned}$

$f u(\mu, \sigma):=\ln \left(\mu,-\frac{1}{2} \cdot \sigma^{2} \quad\right.$ Function for log-normal parameter mu

$f \mu\left(\mu_{s}, \sigma\right):=\ln \left(\mu_{s}\right)-\frac{1}{2} \cdot \sigma^{2} \quad$ given sample mean and log-normal parameter sigma $g \sigma\left(x_{b}, \mu, \sigma, P_{b}\right):=\operatorname{root}\left(\operatorname{plnom}\left(x_{b}, \mu, \sigma\right)-P_{b}, \sigma\right) \quad \begin{aligned} & \text { Function to get log-nomal parameter sigma } \\ & \text { given log-normal parameter mu and value } x\end{aligned}$ with given probability $P$

Log-normal parameters, subscript 'i' for log normal input distributions:

$\begin{array}{lll}\sigma_{\mathrm{si}}:=\mathrm{f} \sigma\left(\mu_{\mathrm{ss}}, \sigma_{\mathrm{ss}}\right) & \sigma_{\mathrm{si}}=0.741 & \text { Scrap particulate sigma } \\ \sigma_{\mathrm{fi}}:=\mathrm{f} \sigma\left(\mu_{\mathrm{fs}}, \sigma_{\mathrm{fs}}\right) & \sigma_{\mathrm{fi}}=0.577 & \text { Fuel particulate sigma } \\ \sigma_{\mathrm{wi}}:=f \sigma\left(\mu_{\mathrm{ws}}, \sigma_{\mathrm{ws}}\right) & \sigma_{\mathrm{wi}}=0.201 & \text { Particulate Water sigma } \\ \mu_{\mathrm{si}}:=\mathrm{f} \mu\left(\mu_{\mathrm{ss}}, \sigma_{\mathrm{si}}\right) & \mu_{\mathrm{si}}=-2.828 & \text { Scrap particulate mu } \\ \mu_{\mathrm{fi}}:=\mathrm{f} \mu\left(\mu_{\mathrm{fs}}, \sigma_{\mathrm{fi}}\right) & \mu_{\mathrm{fi}}=-4.862 & \text { Scrap particulate mu } \\ \mu_{\mathrm{wi}}:=\mathrm{f} \mu\left(\mu_{\mathrm{ws}}, \sigma_{\mathrm{wi}}\right) & \mu_{\mathrm{wi}}=1.376 & \text { Particulate water mu }\end{array}$




$$
\begin{aligned}
& \sigma_{\mathrm{gi}}:=f \sigma i \mu_{\mathrm{gs}}, \sigma_{\mathrm{gs}: \quad} \quad \sigma_{\mathrm{gi}}=1.068 \quad \text { Sludge particulate sigma } \\
& \sigma_{\mathrm{gwi}}:=\mathrm{f \sigma}: \mu_{\mathrm{gws}}, \sigma_{\text {gws }} \text {. } \sigma_{\text {gwi }}=0.756 \quad \text { Sludge Water sigma } \\
& \left.\mu_{\mathrm{gi}}:=f \mu_{\mathrm{H}} \mu_{\mathrm{gs}}, \sigma_{\mathrm{gi}}\right) \quad \mu_{\mathrm{gi}}=-6.107 \quad \text { Sludge particulate } \mathrm{mu} \\
& \mu_{\text {gwi }}:=f \mu . \mu_{\text {gws }}, \sigma_{\text {gwi }} \quad \cdot \mu_{\text {gwi }}=2.015 \quad \text { Sludge water mu }
\end{aligned}
$$

Check of desired percentile values:

$$
\begin{array}{ll}
\text { qinorm }\left(0.001, \mu_{\mathrm{si}}, \sigma_{\mathrm{si}}\right)=5.997 \cdot 10^{-3} & \text { scrap low bound check at } 0.1 \% \text { level } \\
\text { qlnorm }\left(0.001, \mu_{\mathrm{fi}}, \sigma_{\mathrm{fi}}\right)=1.299 \cdot 10^{-3} & \text { fuel low bound check at } 0.1 \% \text { level } \\
\text { qlnorm }\left(0.95, \mu_{\mathrm{si}}, \sigma_{\mathrm{si}}\right)=0.2 & \text { scrap upper bound check at } 95 \% \text { level } \\
\text { qlnorm }\left(0.95, \mu_{\mathrm{fi}}, \sigma_{\mathrm{fi}}\right)=0.02 & \text { fuel upper bound check at } 95 \% \text { level } \\
\text { qlnorm }\left(0.95, \mu_{\text {wi }}, \sigma_{\mathrm{wi}}\right)=5.51 & \text { water upper bound check at } 95 \% \text { level } \\
\text { qinorm }\left(0.95, \mu_{\mathrm{gi}}, \sigma_{\mathrm{gi}}\right)=0.013 & \text { sludge upper bound check at } 95 \% \text { level } \\
\text { qlnorm }\left(0.95, \mu_{\mathrm{gwi}}, \sigma_{\mathrm{gwi}}\right)=26.001 & \text { sludge water upper bound check at } 95 \% \\
\end{array}
$$

Loop over set of particulate and water masses to plot pdifs and cpdf's:

$$
\begin{aligned}
& x p_{\max }:=0.4 \quad x w_{\max }:=12 \quad i:=0 . .1000 \quad x p_{i}:=\frac{i \cdot x p_{\max }}{1000} \quad x w_{i}:=\frac{i \cdot x w_{\max }}{1000} \\
& \mathrm{pps}_{\mathrm{i}}:=\operatorname{dinom}\left(\mathrm{xp}_{\mathrm{i}}, \mu_{\mathrm{si}}, \sigma_{\mathrm{si}}\right) \quad \mathrm{PPS}_{\mathrm{i}}:=\operatorname{pinorm}\left(\mathrm{xp}_{\mathrm{i}}, \mu \mu_{\mathrm{si}}, \sigma_{\mathrm{si}}\right) \quad \text { Scrap particulate } \mathrm{p} \text { and } \mathrm{cp} \\
& \mathrm{ppf}_{\mathrm{i}}:=\operatorname{dlnorm}\left(\mathrm{xp}_{\mathrm{i}}, \mu_{\mathrm{fi}}, \sigma_{\mathrm{fi}}\right) \quad \mathrm{PPF}_{\mathrm{i}}:=\operatorname{p\operatorname {lnorm}}\left(\mathrm{xp}_{\mathrm{i}}, \mu_{\mathrm{fi}}, \sigma_{\mathrm{fi}}\right) \quad \text { Fuel particulate } \mathrm{p} \text { and } \mathrm{cp} \\
& \mathrm{pw}_{\mathrm{i}}:=\operatorname{d\operatorname {lnom}}\left(\mathrm{xw}_{\mathrm{i}}, \mu_{\mathrm{wi}}, \sigma_{\mathrm{wi}}\right) \quad \mathrm{PW_{i }}:=\operatorname{p\operatorname {nnorm}}\left(\mathrm{xw}_{\mathrm{i}}, \mu_{\mathrm{wi}}, \sigma_{\mathrm{wi}}\right) \quad \text { Water } p \text { and } \mathrm{cp} \\
& \mathrm{ppg}_{\mathrm{i}}:=\operatorname{dlnorm}\left(\mathrm{xp}_{\mathrm{i}}, \mu_{\mathrm{gi}}, \sigma_{\mathrm{gi}}\right) \quad \mathrm{PPG}_{\mathrm{i}}:=\operatorname{p\operatorname {lnorm}}\left(\mathrm{xp}_{\mathrm{i}}, \mu_{\mathrm{gi}}, \sigma_{\mathrm{gi}}\right) \quad \text { Sludge particulate } \mathrm{p} \text { and } \mathrm{cp} \\
& \mathrm{xgw}_{\mathrm{i}}:=\mathrm{i} \cdot 40 \cdot 0.001 \\
& \text { Different range for sludige } \\
& \text { h2o } \\
& \mathrm{pgw}_{\mathrm{i}}:=\mathrm{d} \operatorname{lnorm}\left(\mathrm{xgw}_{\mathrm{i}}, \mu_{\mathrm{gwi}}, \sigma_{\mathrm{gwi}}\right) \mathrm{PGW_{i }}:=\operatorname{plnorm}\left(\mathrm{xgw}_{\mathrm{i}}, \mu_{\mathrm{gwi}}, \sigma_{\mathrm{gwi}}\right) \text { Sludge Water } \mathrm{p} \text { and } \mathrm{cp}
\end{aligned}
$$


File: pwaterc.mcd Date: 9/24/98 Page: 4 HNF-2234, Rev. 2

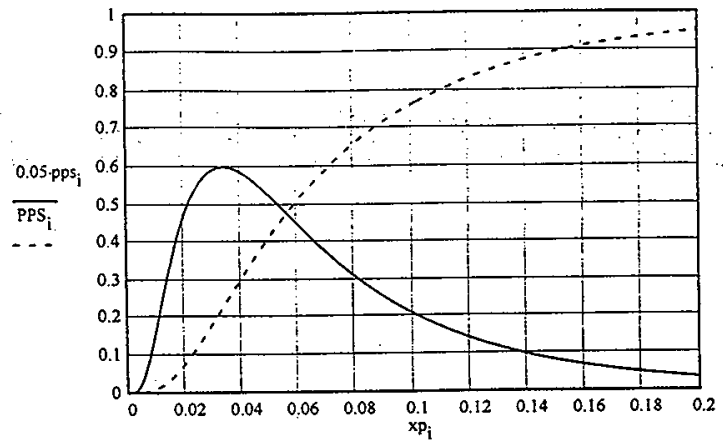

Scrap Particulate:

CPDF $=$ dash

pdf = solid

$95 \%$ value $\mathrm{OK}$

at $0.2 \mathrm{~kg}$

Median conservative

about $0.06 \mathrm{~kg}$

Mode about 0.033

vs $0.02 \mathrm{~kg}$ reference

best-estimate

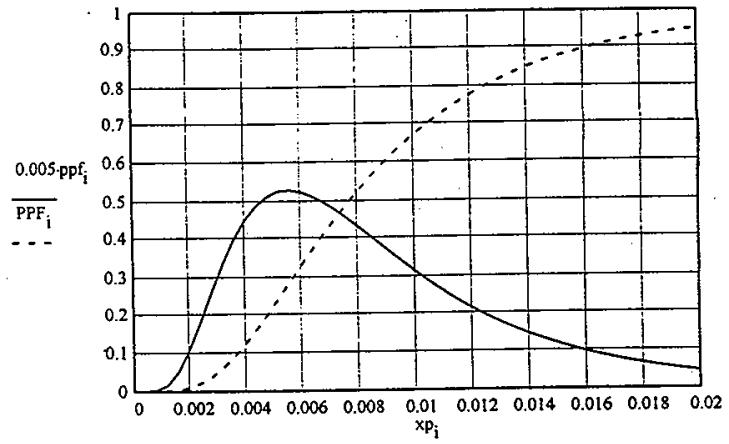

Fuel Particulate:

$C P D F=$ dash

pdf solid

$95 \%$ value $O K$

at $0.02 \mathrm{~kg}$

Median OK

about $0.008 \mathrm{~kg}$

Mode about $0.005 \mathrm{~kg}$

vs $0.01 \mathrm{~kg}$ reference

best-estimate

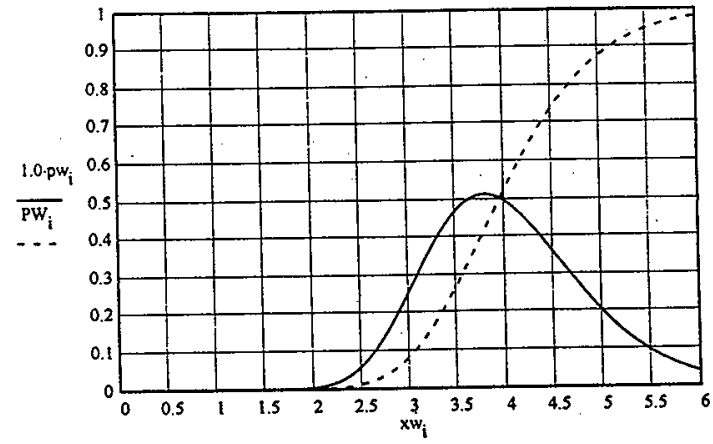

Water \%:

CPDF $=$ dash

pdf $=$ solid

$95 \%$ value OK at $5.5 \%$

$50 \%$ value OK

about $4 \%$

Mode about $3.75 \%$

vs $4 \%$ reference 
Flle: pwaterc.mca vate: $y / \angle 4 / y 0$ ragêtif-2234, Rev. 2

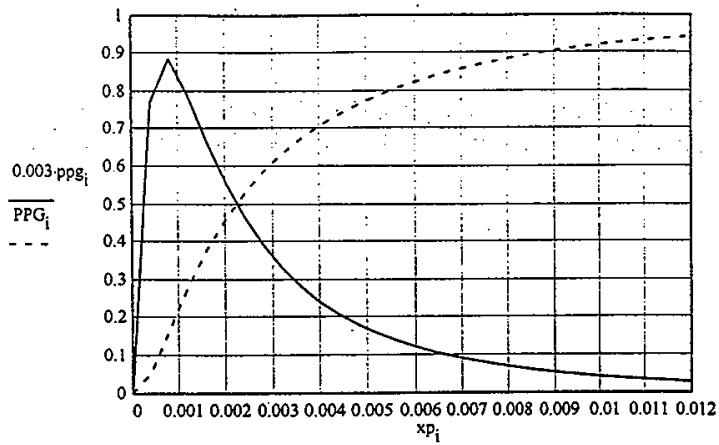

Sludge Particulate:

CPDF $=$ dash

poff= solid

$95 \%$ value OK

at $0.013 \mathrm{~kg}$

Median OK

$0.0022 \mathrm{~kg}$

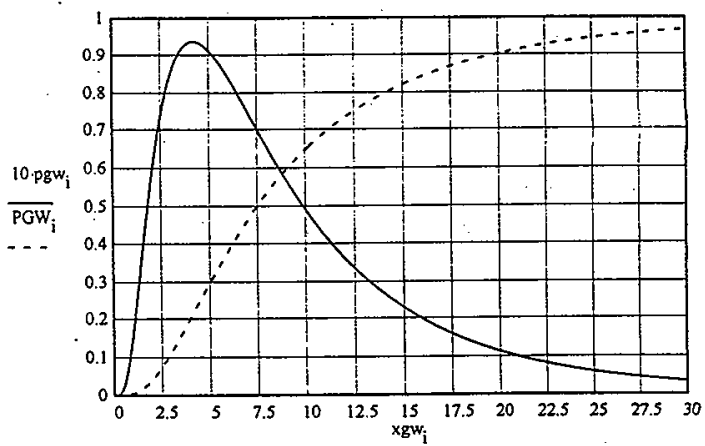

Sludge Water \%:

CPDF $=$ dash

podf $=$ solid

$95 \%$ value OK

at $26 \%$

$50 \%$ value perfect at $7.5 \%$

* Conclusion: Input distributions are reasonable. 
File: pwatercmcd Date: 9/24/98 Page; $\hat{F}_{F}-2234$, Rev. 2

3.0 Get MCO loading for $N=10$ choices using input parameters / assembly defined above

Function to fill M MCO's. Output matrix has 1 column/MCO, and rows for scrap particulate, fuel particulate, scrap water, and fuel water. Uses function rinorm which yields a vector of $N$ values distributed' log-normally with the input mu's and sigma's.

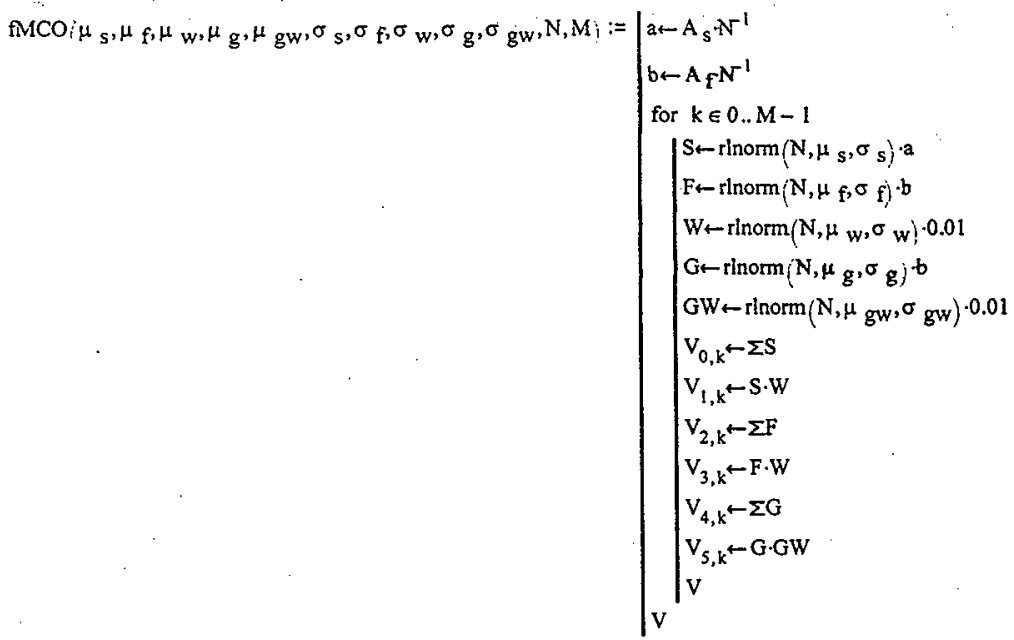

Test for 10 MCO's: $\quad V:=f M C O\left(\mu_{\mathrm{si}}, \mu_{\mathrm{fi}}, \mu_{\text {wi }}, \mu_{\mathrm{gi}}, \mu_{\mathrm{gwi}}, \sigma_{\mathrm{si}}, \sigma_{\mathrm{fi}}, \sigma_{\text {wi }}, \sigma_{\mathrm{gi}}, \sigma_{\mathrm{gwi}}, \mathrm{N}, 10\right)$

$\mathrm{V}=$\begin{tabular}{llllllllllll}
\hline 2.576 & 3.219 & 2.32 & 3.317 & 2.728 & 5.468 & 2.728 & 2.461 & 3.173 & 3.888 \\
\hline 0.123 & 0.129 & 0.1 & 0.127 & 0.121 & 0.229 & 0.099 & 0.108 & 0.112 & 0.158 \\
\hline 1.878 & 1.554 & 2.617 & 1.657 & 2.478 & 1.943 & 2.29 & 1.97 & 2.392 & 1.798 \\
\hline 0.09 & 0.061 & 0.116 & 0.066 & 0.103 & 0.08 & 0.084 & 0.089 & 0.091 & 0.072 \\
\hline 0.71 & 0.672 & 0.458 & 1.059 & 2.288 & 1.008 & 0.795 & 0.601 & 1.913 & 0.435 \\
\hline 0.063 & 0.056 & 0.059 & 0.092 & 0.219 & 0.078 & 0.074 & 0.1 & 0.213 & 0.032 \\
\hline
\end{tabular}

Rows contain:

0 Scrap particulate

1 Scrap water

2 Fuel particulate

3 Fuel water

4 Sludge mass

5 Sludge water

Expected results:

scrap particulate $39^{*} 0.0778=3$, scrap water $3^{*} 0.04=0.12$

fuel particulate $216^{*} 0.00914=2$, fuel water $0.04^{*} 2=0.08$

sludge 0.48 , sludge water 0.036 . So sludge water and mass mean values exceed the median. 


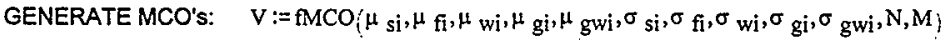

Sum particulate and its water per MCO: $\quad j:=0 . . M-1$

$$
D P_{j}:=V_{0, j}+V_{2, j}
$$

$D W_{j}:=V_{1, j}+V_{3, j}$

$$
D_{W T}:=V_{1, j}+V_{3, j}+V_{5, j}
$$

$$
D G_{j}:=V_{4, j}
$$$$
D G W_{j}:=V_{5, j}
$$

Sample statistics:

$$
\begin{aligned}
& \mu_{s p}:=\operatorname{mean}(D P) \quad \mu_{s p}=5.019 \quad \mu_{s w}:=\operatorname{mean}(D W) \quad \mu_{s w}=0.203 \quad \text { Particulate and its water } \\
& \sigma_{\mathrm{sp}}:=\operatorname{stdev}(\mathrm{DP}) \quad \sigma_{\mathrm{sp}}=0.903 \quad \sigma_{\mathrm{sw}}:=\operatorname{stdev}(\mathrm{DW}) \quad \sigma_{\mathrm{sw}}=0.039 \\
& \mu_{s g}:=\operatorname{mean}(D G) \quad \mu_{s g}=0.845 \quad \mu_{s g w}:=\operatorname{mean}(D G W) \quad \mu_{s g w}=0.083 \quad \text { Sludge and its water } \\
& \sigma_{\mathrm{sg}}:=\operatorname{stdev}(D G) \quad \sigma_{\mathrm{sg}}=0.392 \quad \sigma_{\mathrm{sgw}}:=\operatorname{stdev}(D G W) \quad \sigma_{\mathrm{sgw}}=0.053 \\
& \mu_{\text {swt }}:=\operatorname{mean}(\mathrm{DWT}) \mu_{\text {swt }}=0.286 \text {. Total water } \\
& \sigma_{\text {swt }}:=\operatorname{stdev}(D W T) \quad \sigma_{\text {swt }}=0.065
\end{aligned}
$$

Lognormal parameters:

$$
\begin{aligned}
& \sigma_{\mathrm{lp}}:=f \sigma\left(\mu_{\mathrm{sp}}, \sigma_{\mathrm{sp}}\right) \quad \mu_{\mathrm{lp}}:=\mathrm{f} \mu\left(\mu_{\mathrm{sp}}, \sigma_{\mathrm{lp}}\right) \quad \sigma_{\mathrm{lpw}}:=\mathrm{f} \sigma\left(\mu_{\mathrm{sw}}, \sigma_{\mathrm{sw}}\right) \quad \mu_{\mathrm{lpw}}:=\mathrm{f \mu}\left(\mu_{\mathrm{sw}}, \sigma_{\mathrm{lpw}}\right) \\
& \sigma_{\mathrm{lg}}:=\mathrm{f} \sigma\left(\mu_{\mathrm{sg}}, \sigma_{\mathrm{sg}}\right) \quad \mu_{\mathrm{lg}}:=\mathrm{f} \mu\left(\mu_{\mathrm{sg}}, \sigma_{\mathrm{lg}}\right) \quad \sigma_{\mathrm{lgw}}:=\mathrm{f \sigma}\left(\mu_{\mathrm{sgw}}, \sigma_{\mathrm{sgw}}\right) \mu_{\mathrm{lgw}}:=\mathrm{f} \mu\left(\mu_{\mathrm{sgw}}, \sigma_{\mathrm{lgw}}\right) \\
& \left.\sigma_{1 t w}:=f \sigma\left(\mu_{\text {swt }}, \sigma_{\text {swt }}\right) \quad \mu_{\text {ltw }}:=f \mu \mu_{\text {swt }}, \sigma_{1 t w}\right)
\end{aligned}
$$

Gamma parameters for total water:

$$
\beta_{\mathrm{tw}}:=\sigma_{\mathrm{swt}^{2}}{ }^{2} \mu_{\mathrm{swt}}{ }^{-1} \quad \alpha_{\mathrm{tw}}:=\mu_{\mathrm{swt}} \cdot \beta_{\mathrm{tw}}{ }^{-1} \quad \beta_{\mathrm{tw}}=0.015 \quad \alpha_{\mathrm{tw}}=19.347
$$

Incredible values using lognormal fit parameters:

$$
\begin{aligned}
& \text { qlnorm }\left(0.999999, \mu_{\mathrm{lp}}, \sigma_{\mathrm{lp}}\right)=11.54 \quad \text { Incredible particulate and its water } \\
& \text { qInorm }\left(0.999999, \mu_{\mathrm{lpw}}, \sigma_{\mathrm{lpw}}\right)=0.498 \\
& \text { qlnorm }\left(0.999999, \mu_{\mathrm{lg}}, \sigma_{\mathrm{lg}}\right)=6.249 \quad \text { Incredible sludge and its water } \\
& \text { qlnorm }\left(0.999999, \mu_{\mathrm{lgw}}, \sigma_{\mathrm{lgw}}\right)=1.104 \\
& \text { qinorm }\left(0.999999, \mu_{\mathrm{ltw}}, \sigma_{\mathrm{ltw}}\right)=0.811 \quad \text { Incredible total water } \\
& 1-\operatorname{plnorm}\left(0.825, \mu_{\mathrm{ltw}}, \sigma_{\mathrm{ltw}}\right)=6.883 \cdot 10^{-7} \quad \text { Value checks for total water }
\end{aligned}
$$

Gamma model yields lower incredible water content

Gamma for total water: $\quad$ qgamma $\left(0.999999, \alpha_{t w}\right) \cdot \beta_{\text {tw }}=0.708$

Range of sample values: $\quad \min (D G W)=0.012 \cdot \max (D G W)=0.844$

*** Very important the maximum of from trials may exceed the 'incredible' value from the curve fit. This does not occur every time this worksheet is invoked because of the random selection of values.
** CONCLUSION: CRYSTAL BALL RESULTS ARE INDEPENDENTLY CHECKED AND ARE CORRECTLY CALCULATED, bUt BEWARE OF CURVE FITTING THE OUTPUT DISTRIBUTIONS TO DERIVE INCREDIBLE VALUES.


File: pwaterc.mcd Uate: $9 / 24 / 98$ Page: 8 NF-2234, Rev. 2

For plots, generate histograms of total particulate and water:

$$
\begin{array}{lll}
\mathrm{n}:=200 & \mathrm{P}_{\max }:=20 & \mathrm{~W}_{\max }:=1.0 \delta \mathrm{p}:=\frac{\mathrm{P}_{\max }}{\mathrm{n}} \delta \mathrm{w}:=\frac{\mathrm{W}_{\max }}{\mathrm{n}} \text { Bounds and intervals of histograms } \\
\mathrm{k}:=0 . . \mathrm{n} . \mathrm{Pb}_{\mathrm{k}}:=\mathrm{k} \cdot \delta \mathrm{p} & \mathrm{Wb}_{\mathrm{k}}:=\mathrm{k} \cdot \delta \mathrm{w} & \text { Histogram boundary assignment } \\
\mathrm{MP}:=\operatorname{hist}(\mathrm{Pb}, \mathrm{DP}) & \mathrm{MW}:=\operatorname{hist}(\mathrm{Wb}, \mathrm{DW}) & \text { Frequency assignment } \\
\mathrm{MG}:=\operatorname{hist}(\mathrm{Pb}, \mathrm{DG}) & \mathrm{MGW}:=\operatorname{hist}(\mathrm{Wb}, \mathrm{DGW}) & \\
& M \mathrm{MTW}:=\operatorname{hist}(\mathrm{Wb}, \mathrm{DWT}) &
\end{array}
$$$$
\mathrm{k}:=0 . . \mathrm{n}-1 \quad \mathrm{Pc}_{\mathrm{k}}:=0.5 \cdot\left(\mathrm{Pb}_{\mathrm{k}}+\mathrm{Pb}_{\mathrm{k}+1}\right) \quad \mathrm{W} \mathrm{c}_{\mathrm{k}}:=0.5 \cdot\left(\mathrm{Wb}_{\mathrm{k}}+\mathrm{W} \mathrm{b}_{\mathrm{k}+1}\right) \quad \text { Histogram centers }
$$

For particulate and its water, get normalized histograms and lognormal distributions:

$$
\begin{aligned}
& \text { norp }:=(M \cdot \delta p)^{-1} \text { NP }:=M P \cdot \text { norp norw }:=(M \cdot \delta w)^{-1} \mathrm{NW}:=\mathrm{MW} \text { norw Normalized histograms } \\
& n p_{k}:=\operatorname{dinorm}\left(\mathrm{Pc}_{\mathrm{k}}, \mu_{\mathrm{lp}}, \sigma_{\mathrm{lp}}\right) \quad \mathrm{nw_{k }}:=\operatorname{dnnorm}\left(\mathrm{Wc}_{c_{\mathrm{k}}}, \mu \mathrm{lpw}_{\mathrm{p}}, \sigma_{\mathrm{lpw}}\right) \quad \text { Derived distributions }
\end{aligned}
$$

For siudge and its water, get normalized histograms and gamma distributions:

$$
\begin{aligned}
& \text { norg }:=(M \cdot \delta p)^{-1} \quad N G:=M G \cdot n o r g \text { norgw }:=(M \cdot \delta w)^{-1} \quad \text { NGW }:=M G W \text { norgw } \quad \text { Normalized histograms } \\
& \mathrm{ng}_{\mathrm{k}}:=\operatorname{dlnorm}\left(\mathrm{Pc}_{\mathrm{k}}, \mu \mathrm{lg}, \sigma_{\mathrm{lg}}\right) \quad \mathrm{ngw}_{\mathrm{k}}:=\operatorname{dlnorm}\left(\mathrm{Wc}_{\mathrm{k}}, \mu \mathrm{lgw}, \sigma_{\mathrm{lgw}}\right) \quad \text { Derived dismibutions }
\end{aligned}
$$

For total water get its normalized histograms and lognormal and gamma distributions:

$$
\begin{aligned}
& \text { nortwg }:=\left(\frac{M \cdot \delta w}{\beta_{t w}}\right)^{-1} \quad \text { NTWG }:=M T W \cdot \text { nortwg } \quad \text { ntwg } g_{k}:=d g a m m a\left(\frac{W c_{k}}{\beta_{t w}}, \alpha_{t w}\right) \\
& \text { nortwl }:=(M \cdot \delta w)^{-1} \quad N T W L:=M T W \cdot \text { nortwl } \quad n t w l_{k}:=\operatorname{dlnom}\left(W c_{k}, \mu l_{1 t w}, \sigma \mid t w\right)
\end{aligned}
$$


Adhering particulate (left) and its water (right): Normalized histograms (solid) compared to derived distributions (dashed):
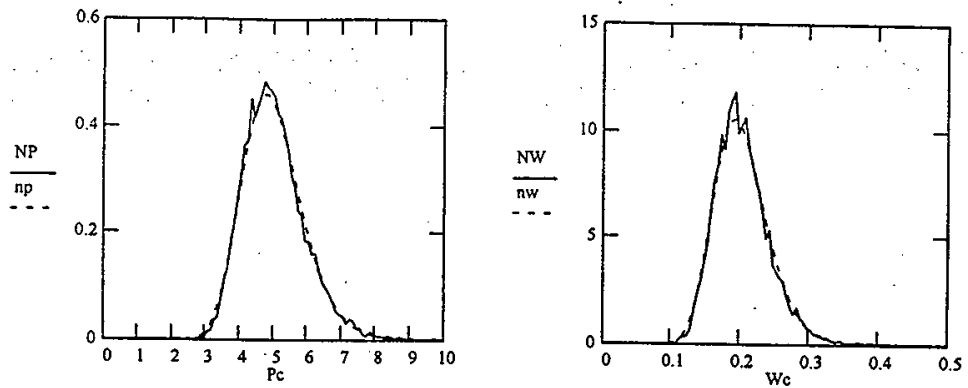

$=$

Canister particulate (left) and its water (right): Normalized histograms (solid) compared to derived distributions (dashed):
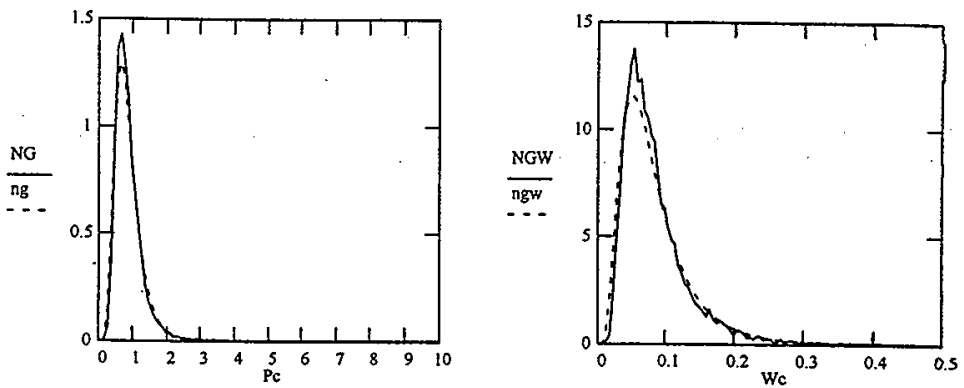
Gamma distribution for total water, histogram vs fit. The gamma distribution is not good because its tail does not extend as far as the histogram.
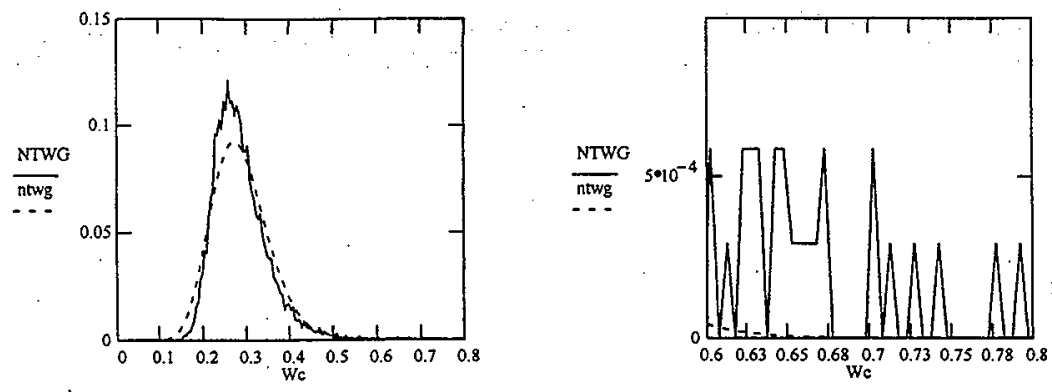

Lognormal distribution for fotal water, histogram vs fit. When this worksheet is invoked, sometimes the extreme value of the samples exceeds the tail of the lognormal; sometimes not.
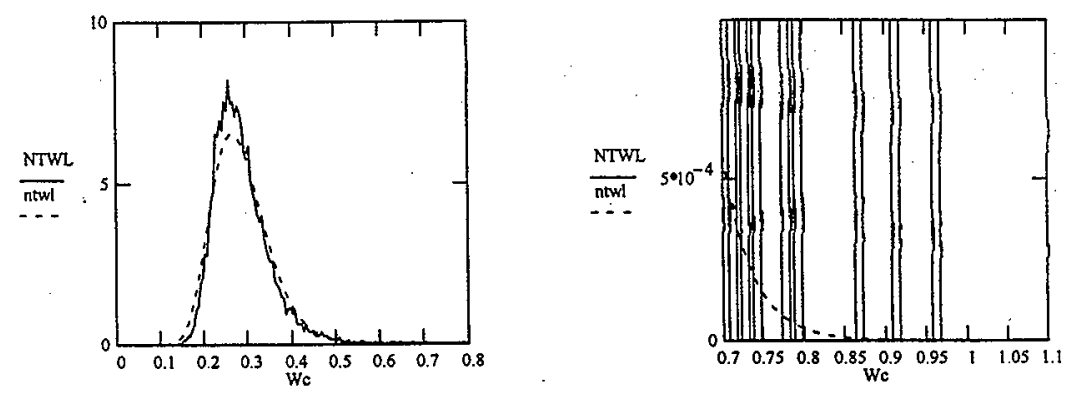

Conclusion: The large skew in the output distribution makes it hard to fit with a lognormal, so that predictions for extreme values are difficult. 
HNF-2234, Rev. 2

APPENDIX E

DETAILED RESULTS FOR MONTE CARLO VALIDATION 
lognormal_rev3_one_base_stats.xls

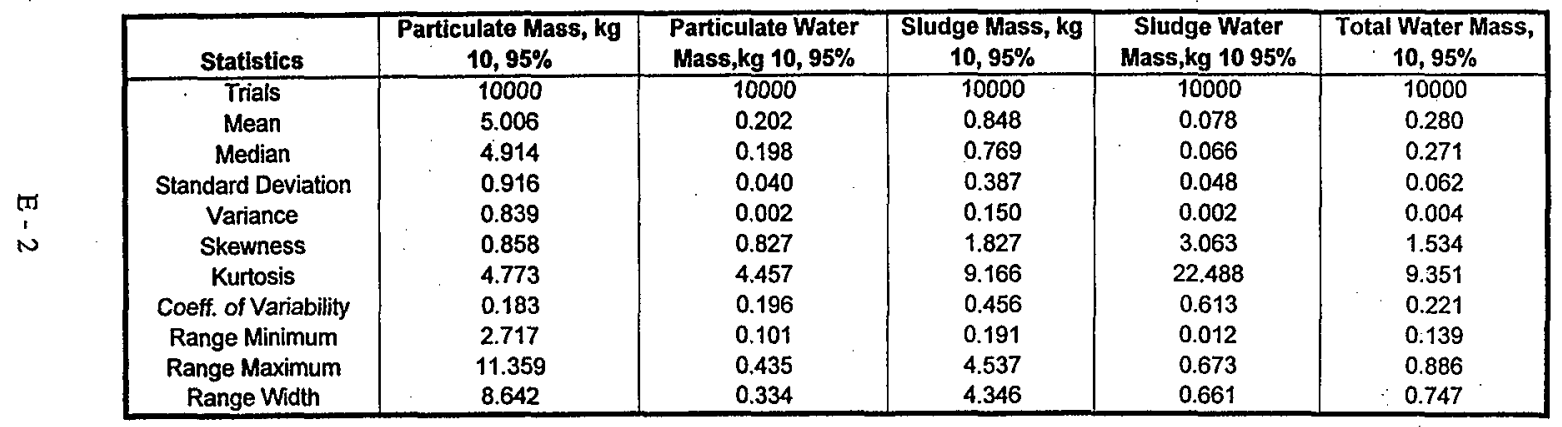


HNF-2234, Rev. 2

APPENDIX F

COMPLETE RESULTS FOR TOTAL WATER CONTENT 
HNF-2234, Rev. 2

water_zero_stats.xis.

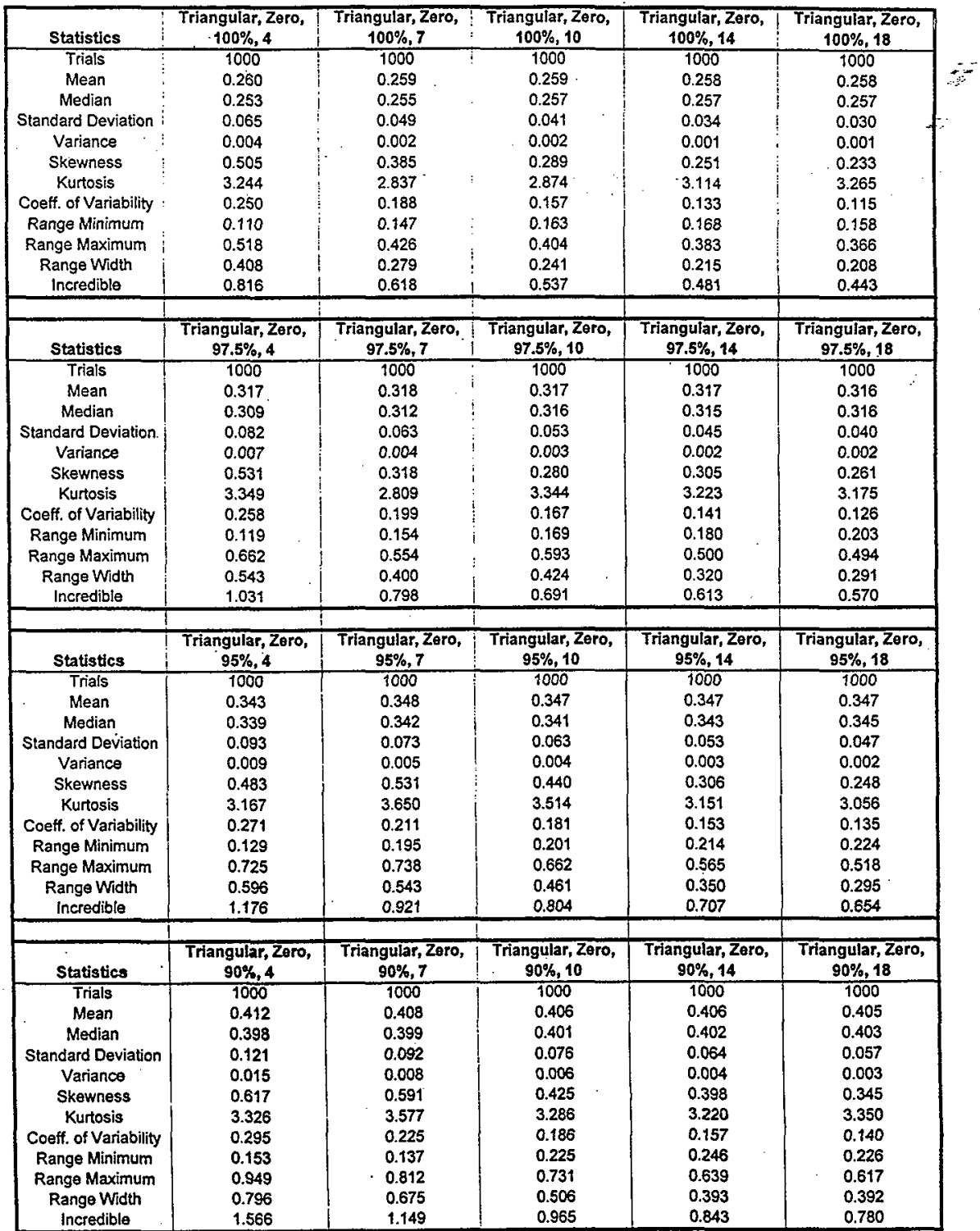


HNF-2234, Rev. 2

water_rev3_one_stats.xls

\begin{tabular}{|c|c|c|c|c|c|}
\hline Statistics & $\begin{array}{c}\text { Triangular, One, } \\
100 \%, 4\end{array}$ & $\begin{array}{c}\text { Triangular, One, } \\
100 \%, 7\end{array}$ & $\begin{array}{c}\text { Triangular, One, } \\
100 \%, 10\end{array}$ & $\begin{array}{c}\text { Triangular, One, } \\
100 \%, 14\end{array}$ & $\begin{array}{c}\text { Triangular, One, } \\
100 \%, 18\end{array}$ \\
\hline Trials & 1000 & 1000 & 1000 & 1000 & 1000 \\
\hline Mean & 0.312 & 0.313 & 0.314 & 0.313 & 0.314 \\
\hline Median & 0.308 & 0.311 & 0.313 & 0.311 & 0.312 \\
\hline Standard Deviation & 0.062 & 0.049 & 0.041 & 0.035 & 0.031 \\
\hline Variance. & 0.004 & 0.002 & 0.002 & 0.001 & 0.001 \\
\hline Skewness & 0.325 & 0.313 & 0.154 & 0.196 & 0206 \\
\hline Kurtosis & 3.002 & 2.935 & 2.816 & 2.731 & 2.817 \\
\hline Coeff. of Variability & 0.200 & 0.156 & 0.130 & 0.111 & 0.098 \\
\hline Range Minimum & 0.133 & 0.181 & 0.198 & 0.225 & 0.231 \\
\hline Range Maximum & 0.550 & 0.492 & 0.450 & 0.418 & 0.408 \\
\hline Range Width & 0.418 & 0.311 & 0.251 & 0.192 & 0.177 \\
\hline Incredible Value & 0.787 & 0.648 & 0.578 & 0.527 & 0.497 \\
\hline & & & & & \\
\hline Statistics & $\begin{array}{c}\text { Triangular, One, } \\
97.5 \%, 4\end{array}$ & $\begin{array}{c}\text { Triangular, One, } \\
97.5 \%, 7\end{array}$ & $\begin{array}{c}\text { Triangular, One, } \\
97.5 \%, 10\end{array}$ & $\begin{array}{c}\text { Triangular, One, } \\
97.5 \%, 14\end{array}$ & $\begin{array}{c}\text { Triangular, One, } \\
97.5 \%, 18\end{array}$ \\
\hline Trials & 1000 & 1000 & 1000 & 1000 & 1000 \\
\hline Mean & 0.387 & 0.384 & 0.384 & 0.384 & 0.383 \\
\hline Median & 0.383 & 0.380 & 0.380 & 0.382 & 0.382 \\
\hline Standard Deviation & 0.085 & 0.064 & 0.053 & 0.044 & 0.040 \\
\hline Variance & 0.007 & 0.004 & 0.003 & 0.002 & 0.002 \\
\hline Skewness & 0.290 & 0.245 & 0.301 & 0.156 & 0.140 \\
\hline Kurtosis & 2.723 & 2.770 & 3.079 & 3.203 & 3.079 \\
\hline Coeff. of Variability & 0.218 & 0.167 & 0.137 & 0.116 & 0.104 \\
\hline Range Minimum & 0.141 & 0.216 & 0.257 & 0.255 & 0.265 \\
\hline Range Maximum & 0.638 & 0.618 & 0.617 & 0.550 & 0.526 \\
\hline Range Width & 0.497 & 0.402 & 0.360 & 0.295 & 0.261 \\
\hline Incredible Value & 1.059 & 0.835 & 0.729 & 0.662 & 0.623 \\
\hline & Triangular, One, & Triangular, Ono, & Triangular, One, & Triangular, on $\theta$, & Triangular, One, \\
\hline Statistics & $95 \%, 4$ & $95 \%, 7$ & $95 \%, 10$ & $95 \%, 14$ & $95 \%, 18$ \\
\hline Trials & 1000 & 1000 & 1000 & 1000 & 1000 \\
\hline Mean & 0.420 & 0.420 & 0.420 & 0.420 & 0.419 \\
\hline Median & 0.413 & 0.416 & $0.4 \uparrow 6$ & 0.418 & 0.416 \\
\hline Standard Deviation & 0.090 & 0.069 & 0.061 & 0.052 & 0.045 \\
\hline Variance & 0.008 & 0.005 & 0.004 & 0.003 & 0.002 \\
\hline Skewness & 0.400 & 0.415 & 0.384 & 0.329 & 0.226 \\
\hline Kurtosis & 3.319 & 3.453 & 3.222 & 3.010 & 2.913 \\
\hline Coeff. of Variability & 0.215 & 0.165 & 0.144 & 0.123 & 0.106 \\
\hline Range Minimum & 0.203 & 0.225 & 0.270 & 0.287 & 0.286 \\
\hline Range Maximum & 0.797 & 0.728 & 0.664 & 0.615 & 0.557 \\
\hline Range Width & 0.595 & 0.503 & 0.394 & 0.328 & 0.271 \\
\hline Incredible Value & 1.131 & 0.905 & 0.826 & 0.748 & 0.691 \\
\hline Statistics & $\begin{array}{c}\text { Triangular, One, } \\
90 \%, 4\end{array}$ & $\begin{array}{c}\text { Triangular, One, } \\
90 \%, 7\end{array}$ & $\begin{array}{c}\text { Triangular, One, } \\
90 \%, 10\end{array}$ & $\begin{array}{c}\text { Triangular, One, } \\
90 \%, 14\end{array}$ & $\begin{array}{c}\text { Triangular, One, } \\
90 \%, 18\end{array}$ \\
\hline Trials & 1000 & 1000 & 1000 & 1000 & 1000 \\
\hline Mean & 0.492 & 0.491 & 0.491 & 0.492 & 0.491 \\
\hline Median & 0.486 & 0.487 & 0.485 & 0.489 & 0.488 \\
\hline Standard Deviation & 0.116 & 0.086 & 0.072 & 0.061 & 0.053 \\
\hline Varianco & 0.013 & 0.007 & 0.005 & 0.004 & 0.003 \\
\hline Skewness & 0.427 & 0.356 & 0.306 & 0.220 & 0.223 \\
\hline Kurtosis & 3.267 & 3.197 & 3.010 & 2.840 & 2.947 \\
\hline Coeff. of Variability & 0.236 & 0.175 & 0.147 & 0.124 & 0.108 \\
\hline Range Minimum & 0.179 & 0.253 & 0.294 & 0.321 & 0.351 \\
\hline Range Maximum & 0.989 & -0.855 & 0.737 & 0.700 & 0.682 \\
\hline Range Width & 0.810 & 0.602 & 0.443 & 0.379 & 0.330 \\
\hline Incredible Value & 1.450 & 1.109 & 0.974 & 0.880 & 0.817 \\
\hline
\end{tabular}

FAI/98-1, Rev. 4

F -3

Date: $10 / 05 / 98$ 
HNF-2234, Rev. 2

water_two_stats.xis

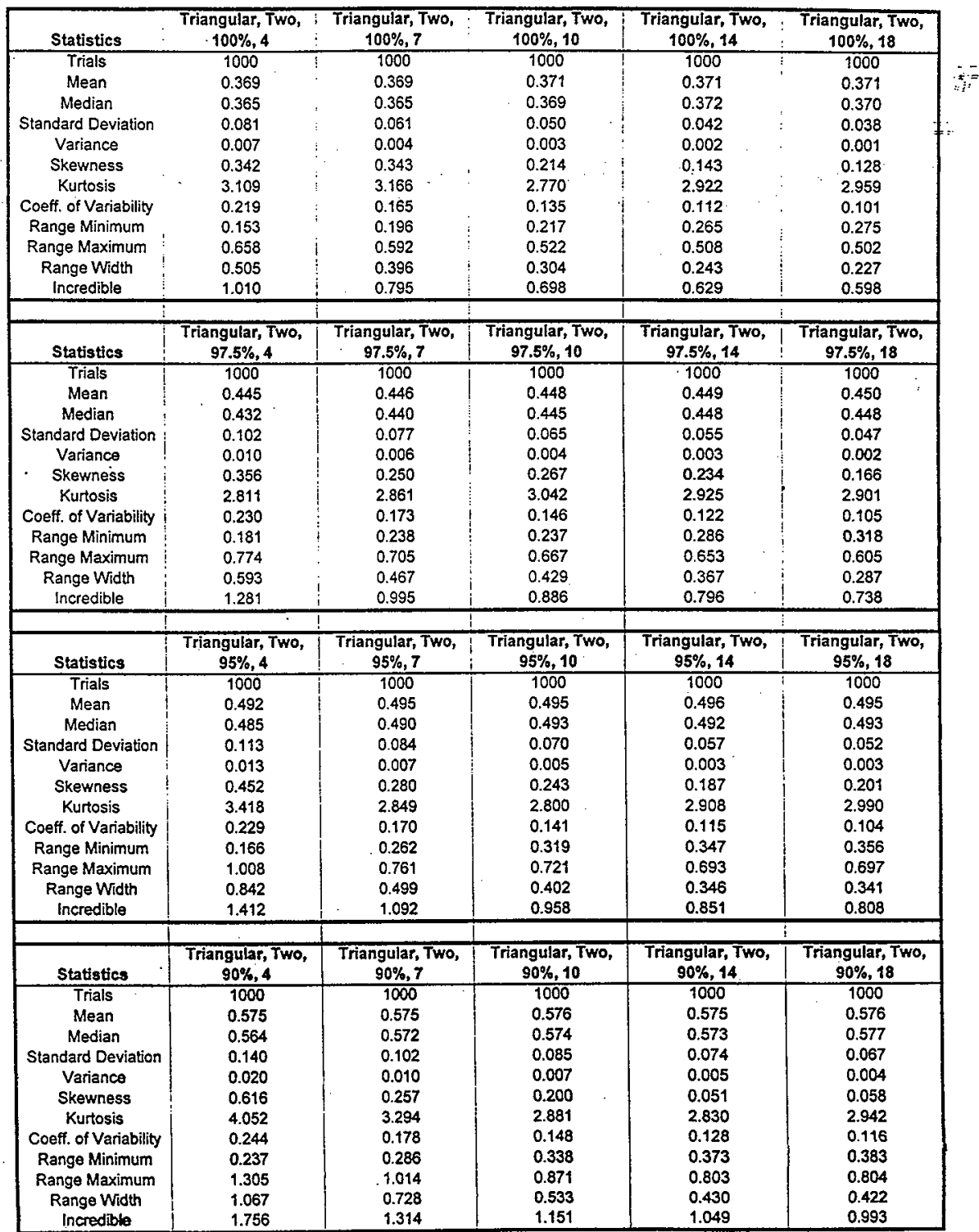


HNF-2234, Rev. 2

lognormal_rev3_zero_stats.xis

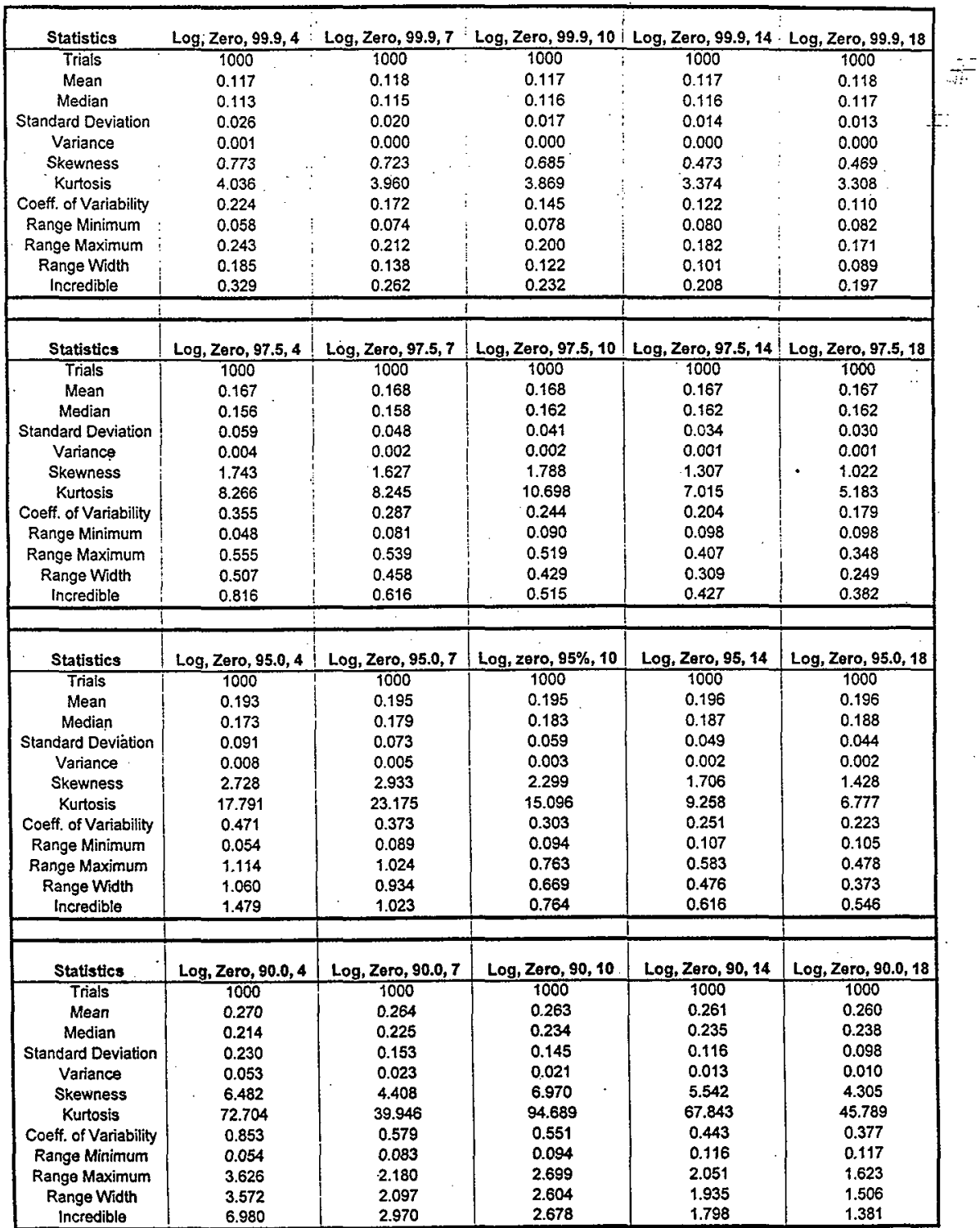


HNF-2234, Rev. 2

lognormal_rev3_one_stats.xis

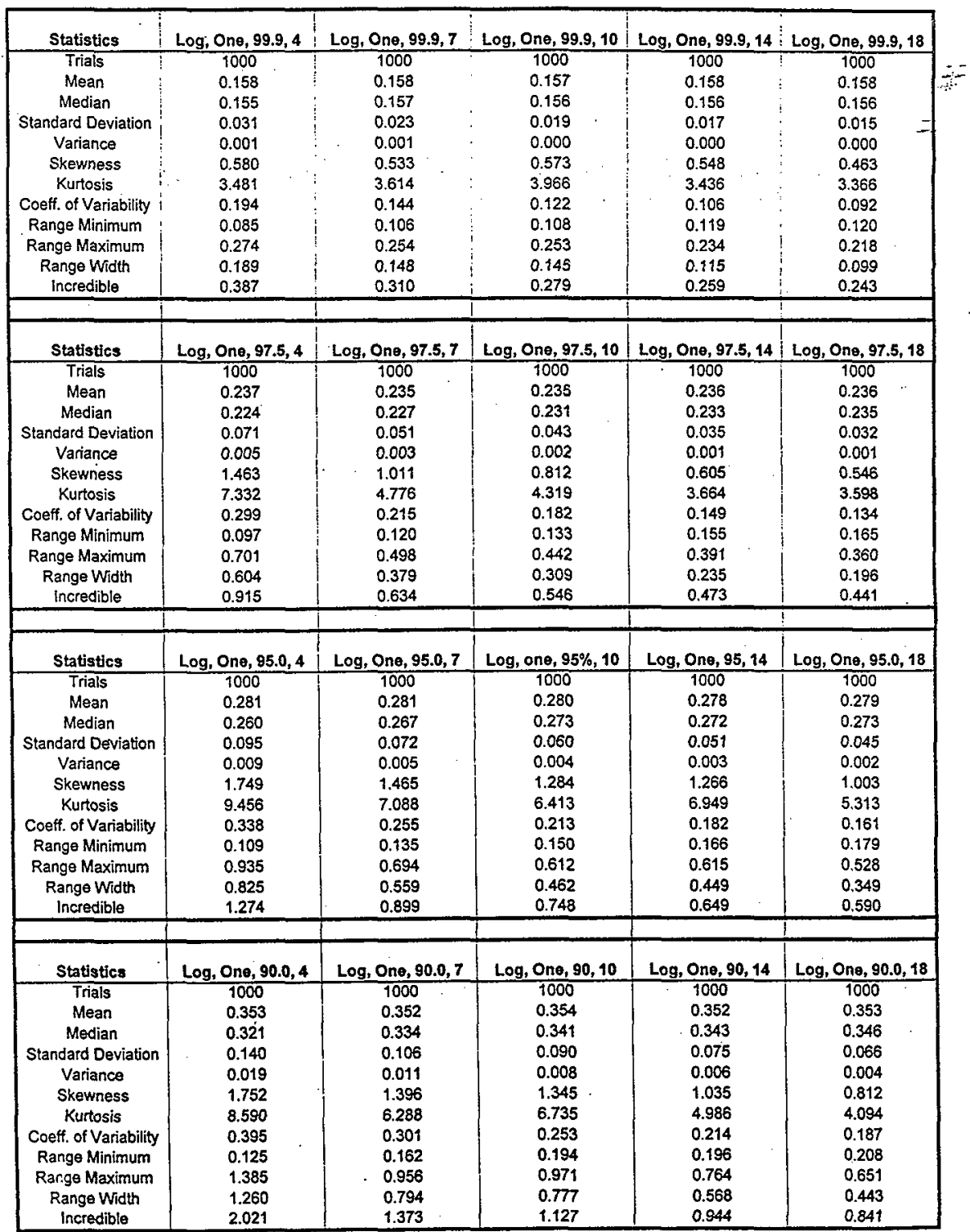

FAI/98-1, Rev. 4

F -6

Date: $10 / 05 / 98$ 
HNF-2234, Rev. 2

lognorma!_rev3_two_stats.xis

\begin{tabular}{|c|c|c|c|c|c|}
\hline Statistics & $\log _{1}$ Two, $99.9,4$ & Log, Two, 99.9, 7 & $\log _{1}$ Two, $99.9,10$ & $\log _{1}$ Two, 99.9, 14 & $\log _{,}$Two, 99.9, 18 \\
\hline Trials & 1000 & 1000 & 1000 & 1000 & 1000 \\
\hline Mean & 0.194 & 0.195 & 0.195 & 0.196 & 0.196 \\
\hline Median & 0.189 & 0.192 & 0.193 & 0.195 & 0.194 \\
\hline Standard Deviation & 0.042 & 0.030 & 0.025 & 0.022 & 0.019 \\
\hline Variance & 0.002 & 0.001 & 0.001 & 0.000 & $0.000=$ \\
\hline Skewness & 0.741 & 0.448 & 0.371 & 0.380 & 0.316 \\
\hline Kurtosis & 3.860 & 3.180 & 3.408 & 3.301 & 3.255 \\
\hline Coeff. of Variability & 0.214 & 0.156 & 0.131 & 0.114 & 0.098 \\
\hline Range Minimum & 0.107 & 0.120 & 0.125 & 0.129 & 0.144 \\
\hline Range Maximum & 0.376 & 0.324 & 0.306 & 0.300 & 0.279 \\
\hline Range Width & 0.269 & 0.204 & 0.181 & 0.171 & 0.135 \\
\hline Incredible & 0.522 & 0.404 & 0.360 & 0.334 & 0.311 \\
\hline Statistics & Log, Two, 97.5, 4 & Log, Two, 97.5,7 & Log, Two, 97.5, 10 & Log, Two, 97.5, 14 & Log, Two, 97.5, 18 \\
\hline Trials & 9000 & 1000 & 1000 & 1000 & 1000 \\
\hline Mean & 0.307 & 0.307 & 0.306 & 0.308 & 0.307 \\
\hline Median & 0.290 & 0.298 & 0.300 & 0.301 & 0.301 \\
\hline Standard Deviation & 0.095 & 0.073 & 0.062 & 0.053 & 0.046 \\
\hline Variance & 0.009 & 0.005 & 0.004 & 0.003 & 0.002 \\
\hline Skewness & 1.304 & 0.882 & 0.699 & 0.525 & 0.584 \\
\hline Kurtosis & 5.762 & 4.367 & 3.710 & 3.170 & 3.659 \\
\hline Coeff. of Variability & 0.310 & 0.238 & 0.201 & 0.171 & 0.150 \\
\hline Range Minimum & 0.122 & 0.142 & 0.169 & 0.173 & 0.177 \\
\hline Range Maximum & 0.815 & 0.650 & 0.555 & 0.517 & 0.528 \\
\hline Range Width & 0.693 & 0.508 & 0.386 & 0.345 & 0.350 \\
\hline Incredible & 1.242 & 0.915 & 0.775 & 0.683 & 0.619 \\
\hline Statistics & Log, Two, 95.0, 4 & Log, Two, 95.0,7 & Log, Two $95 \%, 10$ & Log, Two, 95, 14 & Log, Two, 95.0, 18 \\
\hline Trials & 1000 & 1000 & 1000 & 1000 & 1000 \\
\hline Mean & 0.362 & 0.365 & 0.364 & 0.365 & 0.364 \\
\hline Median & 0.341 & 0.354 & 0.358 & 0.357 & 0.356 \\
\hline Standard Deviation & 0.123 & 0.098 & 0.082 & 0.068 & 0.062 \\
\hline Variance & 0.015 & 0.010 & 0.007 & 0.005 & 0.004 \\
\hline Skewness & 1.242 & 1.098 & 1.057 & 0.801 & 1.060 \\
\hline Kurtosis & 5.586 & 5.199 & 5.194 & 4.007 & 6.165 \\
\hline Coeff. of Variability & 0.341 & 0.269 & 0.225 & 0.186 & 0.171 \\
\hline Range Minimum & 0.118 & 0.141 & 0.159 & 0.201 & 0.218 \\
\hline Range Maximum & 1.037 & 0.834 & 0.790 & 0.643 & 0.803 \\
\hline $\begin{array}{l}\text { Range Width } \\
\text { Incredible }\end{array}$ & $\begin{array}{l}0.919 \\
1.664\end{array}$ & $\begin{array}{l}0.693 \\
1.245\end{array}$ & $\begin{array}{l}0.631 \\
1.024\end{array}$ & $\begin{array}{l}0.442 \\
0.865\end{array}$ & $\begin{array}{l}0.586 \\
0.805\end{array}$ \\
\hline & & & & & \\
\hline Statistics & $\log , T_{w 0}, 90.0,4$ & $\log _{1}$ Two, $90.0,7$ & Log, Two, 90, 10 & Log, Two, 90, 14 & Log, Two, 90.0, 18 \\
\hline Trials & 1000 & 1000 & 1000 & 1000 & 1000 \\
\hline Mean & 0.479 & 0.474 & 0.476 & 0.472 & 0.475 \\
\hline Median & 0.436 & 0.442 & 0.458 & 0.457 & 0.461 \\
\hline Standard Deviation & 0.224 & 0.164 & 0.135 & 0.111 & 0.098 \\
\hline Variance & 0.050 & 0.027 & 0.018 & 0.012 & 0.010 \\
\hline Skewness & 2.881 & 2.161 & 1.503 & 1.160 & 0.942 \\
\hline Kurtosis & 20.551 & 12.105 & 7.310 & 5.497 & 4.564 \\
\hline Coeff. of Variability & 0.467 & 0.346 & 0.284 & 0.235 & 0.207 \\
\hline Range Minimum & 0.143 & 0.210 & 0.210 & 0.227 & 0.266 \\
\hline Range Maximum & 2.820 & 1.732 & 1.349 & 1.115 & 0.944 \\
\hline Range Width & 2.677 & 1.522 & 1.139 & 0.889 & 0.678 \\
\hline Incredible & 3.612 & 2.231 & 1.725 & 1.389 & 1.235 \\
\hline
\end{tabular}


HNF-2234, Rev. 2

weibull_one_stats.xis

\begin{tabular}{|c|c|c|c|c|c|}
\hline Statistics & $\begin{array}{l}\text { Weibull, One, } \\
99.9 \%, 4\end{array}$ & $\begin{array}{l}\text { Woibull, One, } \\
99.9 \%, 7\end{array}$ & $\begin{array}{c}\text { Weibull, One, } \\
99.9 \%, 10\end{array}$ & $\begin{array}{c}\text { Woibull, One, } \\
99.9 \%, 14\end{array}$ & $\begin{array}{l}\text { Weibull, One, } \\
99.9 \%, 18\end{array}$ \\
\hline Trials & 1000 & 1000 & 1000 & 1000 & 1000 \\
\hline Mean & 0.215 & 0.216 & 0.216 & 0.215 & 0.215 \\
\hline Median & 0.212 & 0.214 & 0.214 & 0.213 & 0.215 \\
\hline Stantard Deviation & 0.045 & 0.034 & 0.027 & 0.022 & 0.020 \\
\hline Variance & 0.002 & 0.001 & 0.001 & 0.000 & 0.000 \\
\hline Skewness & 0.507 & 0.463 & 0.330 & 0.265 & 0.148 \\
\hline Kurtosis & 3.183 & 3.098 & 2.987 & 3.228 & 3.086 \\
\hline Coeff. of Variability & 0.209 & 0.155 & 0.124 & 0.101 & 0.093 \\
\hline Range Minimum & 0.106 & 0.138 & 0.147 & 0.145 & 0.151 \\
\hline Range Maximum & 0.388 & 0.347 & 0.312 & 0.296 & 0.284 \\
\hline Range Width & 0.282 & 0.209 & 0.164 & 0.151 & 0.134 \\
\hline Incredible & 0.565 & 0.446 & 0.387 & 0.347 & 0.333 \\
\hline & Wolbull, One, & Weibull, One, & Weibull, One, & Weibull, One, & Woibull, One, \\
\hline Statistics & $97.5 \%, 4$ & $97.5 \%, 7$ & $97.5 \%, 10$ & $97.5 \%, 14$ & $97.5 \%, 18$ \\
\hline Trials & 1000 & 1000 & 1000 & 1000 & 1000 \\
\hline Mean & 0.307 & 0.303 & 0.302 & 0.302 & 0.301 \\
\hline Median & 0.299 & 0.298 & 0.298 & 0.300 & 0.298 \\
\hline Standard Deviation & 0.076 & 0.056 & 0.047 & 0.039 & 0.035 \\
\hline Variance & 0.006 & 0.003 & 0.002 & 0.002 & 0.001 \\
\hline Skewness & 0.688 & 0.577 & 0.442 & 0.358 & 0.407 \\
\hline Kurtosis & 3.872 & 3.498 & 3.401 & 3.404 & 3.300 \\
\hline Coeff. of Variability & 0.247 & 0.186 & 0.156 & 0.130 & 0.116 \\
\hline Range Minimum & 0.133 & 0.163 & 0.157 & 0.172 & 0.201 \\
\hline Range Maximum & 0.655 & 0.531 & 0.479 & 0.452 & 0.417 \\
\hline Range Width & 0.522 & 0.368 & 0.322 & 0.281 & 0.216 \\
\hline Incredible & 0.952 & 0.718 & 0.624 & 0.555 & 0.518 \\
\hline & & & & & \\
\hline Statistics & $\begin{array}{c}\text { Weibuli, One, } 95 \%, \\
4\end{array}$ & $\begin{array}{c}\text { Weibull, One, 95\%, } \\
7\end{array}$ & $\begin{array}{c}\text { Weibull, one, } 95 \%, \mid \\
10\end{array}$ & $\begin{array}{c}\text { Weibull, One, 95\%,1 } \\
4\end{array}$ & $\begin{array}{c}\text { Woibuli, One, } 95 \%, \\
18\end{array}$ \\
\hline Trials & 1000 & 1000 & 1000 & 1000 & 1000 \\
\hline Mean & 0.351 & 0.353 & 0.354 & 0.353 & 0.352 \\
\hline Median. & 0.343 & 0.347 & 0.351 & 0.352 & 0.350 \\
\hline Standard Deviation & 0.089 & 0.070 & 0.060 & 0.049 & 0.044 \\
\hline Variance & 0.008 & 0.005 & 0.004 & 0.002 & 0.002 \\
\hline Skewness & 0.575 & 0.443 & 0.362 & 0.264 & 0.329 \\
\hline Kurtosis & 3.492 & 3.316 & 3.164 & 3.275 & 3.484 \\
\hline Coeff. of Variability & 0.253 & 0.198 & 0.168 & 0.140 & 0.125 \\
\hline Range Minimum & 0.140 & 0.168 & 0.205 & 0.215 & 0.213 \\
\hline Range Maximum & 0.744 & 0.671 & 0.587 & 0.566 & 0.520 \\
\hline Range Width & 0.604 & 0.502 & 0.382 & 0.351 & 0.307 \\
\hline Incredible & 1.118 & 0.884 & 0.774 & 0.678 & 0.633 \\
\hline Statistics & $\begin{array}{c}\text { Weibull, One, 90\%, } \\
4\end{array}$ & $\begin{array}{c}\text { Weibull, One, 90\%, } \\
7\end{array}$ & $\begin{array}{c}\text { Weibull, One, 90\%, } \\
10\end{array}$ & $\begin{array}{c}\text { Weibuli, One, 90\%, } \\
14\end{array}$ & $\begin{array}{c}\text { Weibuli, One, } 90 \%, \\
18\end{array}$ \\
\hline Trials & 1000 & 1000 & 1000 & 1000 & 1000 \\
\hline Mean & 0.443 & 0.441 & 0.440 & 0.439 & 0.437 \\
\hline Median & 0.428 & 0.432 & 0.433 & 0.433 & 0.433 \\
\hline Standard Deviation & 0.128 & 0.097 & 0.079 & 0.067 & 0.060 \\
\hline Variance & 0.016 & 0.009 & 0.006 & 0.005 & 0.004 \\
\hline Skewness & 0.795 & 0.601 & 0.521 & 0.552 & 0.569 \\
\hline Kurtosis & 4.499 & 3.623 & 3.543 & 3.912 & 3.791 \\
\hline Coeff. of Variability & 0.289 & 0.220 & 0.179 & 0.153 & 0.137 \\
\hline Range Minimum & 0.128 & 0.203 & 0.233 & 0.276 & 0.282 \\
\hline Range Maximum & 1.158 & 0.870 & 0.783 & 0.744 & 0.690 \\
\hline Range Width & 1.029 & 0.667 & 0.550 & 0.468 & 0.408 \\
\hline Incredible & 1.642 & 1.216 & 1.010 & 0.896 & 0.832 \\
\hline
\end{tabular}


HNF-2234, Rev. 2

weibull_two_stats.xis

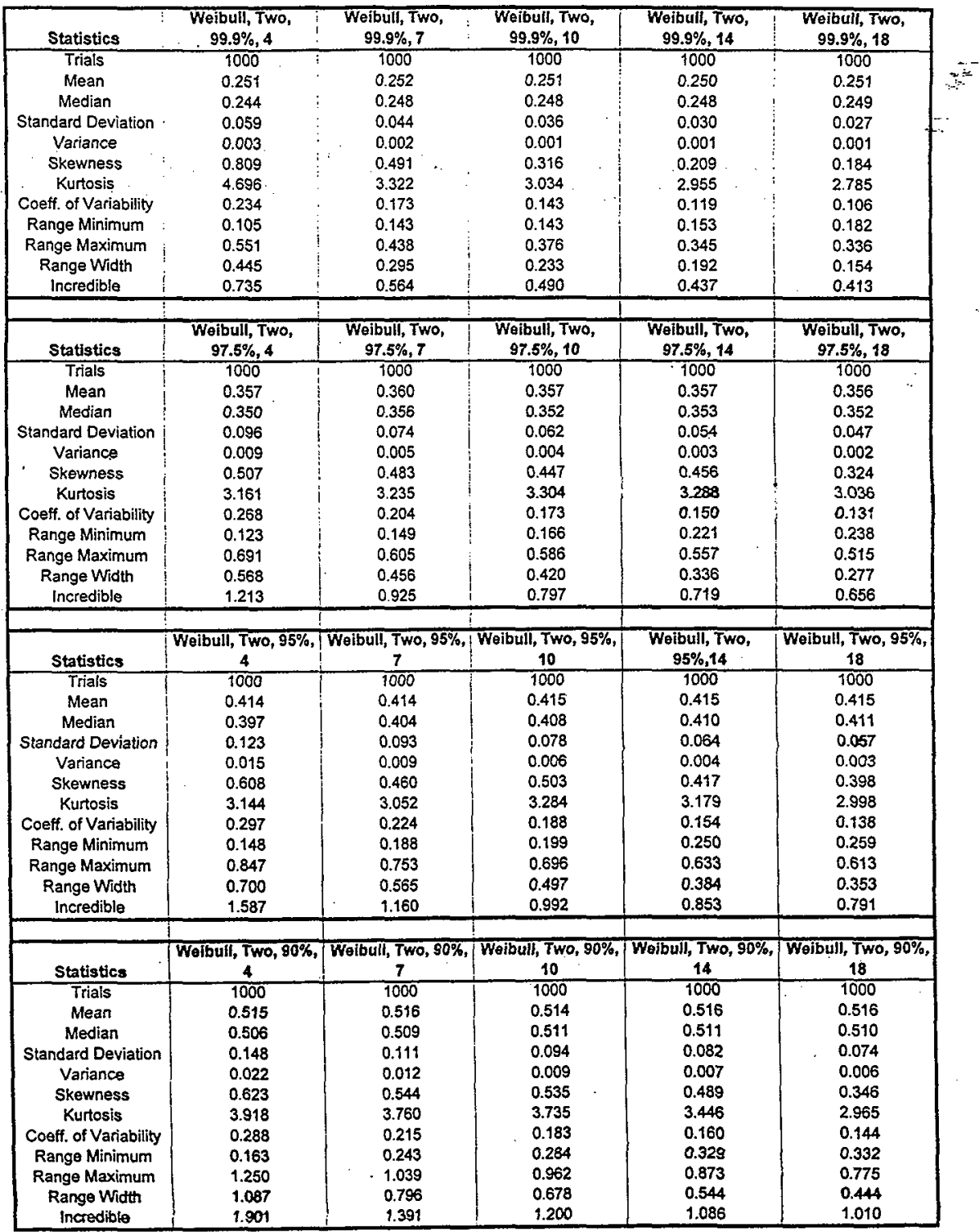


HNF-2234, Rev. 2

weibull_two_stat.xis

\begin{tabular}{|c|c|c|c|c|c|}
\hline Statistics & $\begin{array}{c}\text { Weibull, Zero, } \\
99.9 \%, 4\end{array}$ & $\begin{array}{c}\text { Weibull, Zero, } \\
99.9 \%, 7\end{array}$ & $\begin{array}{c}\text { Woibull, Zero, } \\
99.9 \%, 10\end{array}$ & $\begin{array}{c}\text { Weibull, Zero, } \\
99.9 \%, 14\end{array}$ & $\begin{array}{c}\text { Weibull, Zoro, } \\
99.9 \%, 18 \\
\end{array}$ \\
\hline Trials & 1000 & 1000 & 1000 & 1000 & 1000 \\
\hline Mean & 0.179 & 0.178 & 0.178 & 0.178 & 0.178 \\
\hline Median & 0.174 & 0.175 & 0.177 & 0.177 & 0.177 \\
\hline Standard Deviation & 0.040 & 0.032 & 0.026 & 0.022 & 0.019 \\
\hline Variance & 0.002 & 0.001 & 0.001 & 0.000 & 0.000 \\
\hline Skewness & 0.694 & 0.554 & 0.340 & 0.413 & 0.374 \\
\hline Kurtosis & 3.491 . & 3.363 & 3.074 & 3.651 & 3.836 \\
\hline Coeff. of Variability & $0.226^{\circ}$ & 0.181 & 0.148 & 0.125 & 0.109 \\
\hline Range Minimum & 0.081 & 0.107 & 0.111 & 0.117 & 0.116 \\
\hline Range Maximum & 0.331 & 0.321 & 0.283 & 0.304 & 0.283 \\
\hline Range Width & 0.251 & 0.214 & 0.171 & 0.187 & 0.167 \\
\hline Incredible & 0.504 & 0.413 & 0.356 & 0.321 & 0.297 \\
\hline Statistics & $\begin{array}{c}\text { Weibull, Zero, } \\
97.5 \%, 4\end{array}$ & $\begin{array}{c}\text { Weibull, Zero, } \\
97.5 \%, 7\end{array}$ & $\begin{array}{c}\text { Weibull, Zero, } \\
97.5 \%, 10 \\
\end{array}$ & $\begin{array}{c}\text { Welbull, Zero, } \\
97.5 \%, 14\end{array}$ & $\begin{array}{c}\text { Weibull, Zero, } \\
97.5 \%, 18\end{array}$ \\
\hline Trials & 1000 & 1000 & 1000 & 1000 & 1000 \\
\hline Mean & 0.251 & 0.248 & 0.247 & 0.247 & 0.248 \\
\hline Median & 0.240 & 0.242 & 0.244 & 0.243 & 0.245 \\
\hline Standard Deviation & 0.074 & 0.054 & 0.046 & 0.040 & 0.035 \\
\hline Variance & 0.006 & 0.003 & 0.002 & 0.002 & 0.001 \\
\hline Skewness & 0.790 & 0.600 & 0.649 & 0.544 & 0.415 \\
\hline Kurtosis & 3.743 & 3.668 & 4.350 & 3.637 & 3.153 \\
\hline Coeff. of Variability & 0.297 & 0.217 & 0.187 & 0.160 & 0.141 \\
\hline Range Minimum & 0.089 & 0.115 & 0.111 & 0.140 & 0.162 \\
\hline Range Maximum & 0.586 & 0.493 & 0.512 & 0.421 & 0.377 \\
\hline Range Width & 0.498 & 0.377 & 0.401 & 0.280 & 0.215 \\
\hline Incredible & 0.962 & 0.675 & 0.586 & 0.521 & 0.479 \\
\hline & Woibull, Zero, 95\%, & Wojbull, Zero, 95\%, & Weibull, Zero, 95\%, & Welbull, Zero, & Woibull, Zero, $95 \%$, \\
\hline Statistics & $\begin{array}{c}\text { Wotiduin, } \\
4\end{array}$ & $\begin{array}{c}7 \\
\end{array}$ & $\begin{array}{c}10 \\
10\end{array}$ & $95 \%, 14$ & 18 \\
\hline Trials & 1000 & 1000 & 1000 & 1000 & 1000 \\
\hline Mean. & 0.287 & 0.290 & 0.288 & 0.289 & 0.289 \\
\hline Median' & 0.273 & 0.278 & 0.283 & 0.285 & 0.284 \\
\hline Standard Deviation & 0.095 & 0.075 & 0.062 & 0.052 & 0.046 \\
\hline Variance & 0.009 & 0.006 & 0.004 & 0.003 & 0.002 \\
\hline Skewness & 0.983 & 0.831 & 0.678 & 0.581 & 0.471 \\
\hline Kurtosis & 4.520 & 4.062 & 3.554 & 3.694 & 3.234 \\
\hline Coeff. of Variability & 0.333 & 0.261 & 0.216 & 0.181 & 0.159 \\
\hline Range Minimum & 0.084 & 0.123 & 0.151 & 0.163 & 0.172 \\
\hline Range Maximum & 0.753 & 0.624 & 0.556 & 0.514 & 0.457 \\
\hline Range Width & 0.669 & 0.501 & 0.404 & 0.351 & 0.285 \\
\hline Incredible & 1.275 & 0.951 & 0.780 & 0.671 & 0.606 \\
\hline & Welbull, Zero, 90\%, & Weibuli, Zero, 90\%, & Woibull, Zero, 90\%, & Weibuli, Zero, 90\%, & Woibuil, Zero, $90 \%$, \\
\hline Statistics & 4 & 7 & 10 & 14 & 18 \\
\hline Trials & 1000 & 1000 & 1000 & 1000 & 1000 \\
\hline Mean & 0.358 & 0.359 & 0.358 & 0.355 & 0.355 \\
\hline Median & 0.342 & 0.346 & 0.347 & 0.348 & 0.349 \\
\hline Standard Deviation & 0.127 & 0.097 & 0.082 & 0.068 & 0.061 \\
\hline Variance & 0.016 & 0.009 & 0.007 & 0.005 & 0.004 \\
\hline Skewness & 0.862 & 0.550 & 0.641 & 0.533 & 0.477 \\
\hline Kurtosis & 4.184 & 3.173 & 3.572 & 3.412 & 3.318 \\
\hline Coeff. of Variability & 0.355 & 0.271 & 0.230 & 0.191 & 0.171 \\
\hline Range Minimum & 0.107 & 0.149 & 0.181 & 0.201 & 0.211 \\
\hline Range Maximum & 1.073 & 0.781 & 0.762 & 0.647 & 0.583 \\
\hline Range Width & 0.966 & 0.632 & 0.582 & 0.446 & 0.372 \\
\hline
\end{tabular}

FAI/98-1, Rev. 4 
HNF-2234, Rev. 2

\section{APPENDIX G \\ TOTAL WATER CONTENT DISTRIBUTION FUNCTIONS}

For a given distribution type and a given number of fuel baskets, there are four sets of curves on a plot. Each set corresponds to a percentile point for the high values. Starting from the left and proceeding to the right, the four sets of curves show the results with the high value set to the $100^{\text {th }}$ percentile $(99.9 \%$, actually), 97.5 percentile, 95.0 percentile, and 90.0 percentile, respectively. Each set consists of five cumulative distribution functions representing the five levels of independence. The curves show that the mean value of the simulation increases and the high value percentile decreases. It also shows that as the level of independence decreases, the S-shaped curves become flatter; i.e., the standard deviation increases. 
HNF-2234, Rev. 2

water_rev3_zero_ovrly.xls

Crystal Ball Report

Simulation started on 9/22/98 at 15:06:50

Simulation stopped on $9 / 22 / 98$ at $15: 12: 24$

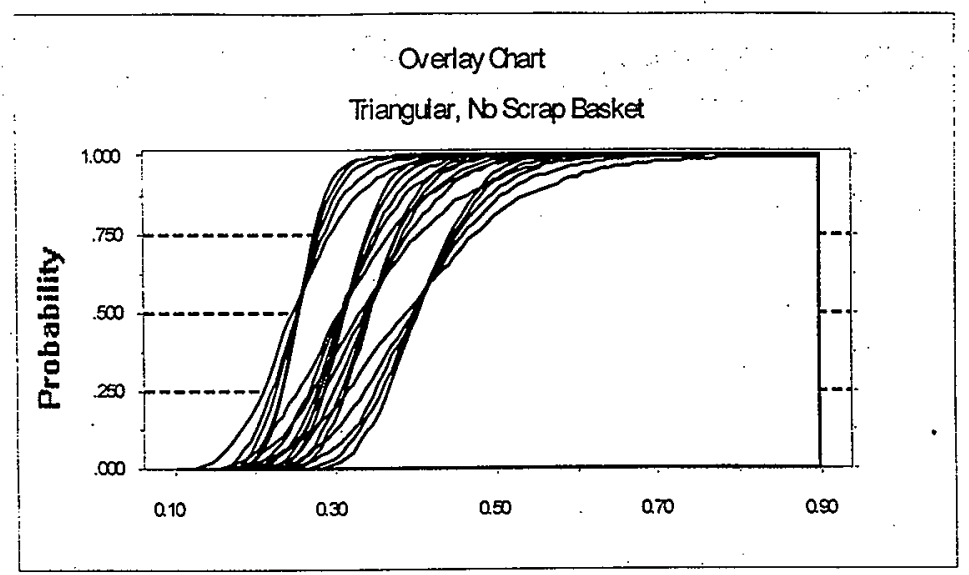


HNF-2234, Rev. 2

water_rev3_one_ovrly.xls

Crystal Ball Report

Simulation started on $9 / 22 / 98$ at $14: 35: 45$

Simulation stopped on $9 / 22 / 98$ at $14: 42: 23$

Overlay Chat

Triangular, One Scrap Basket

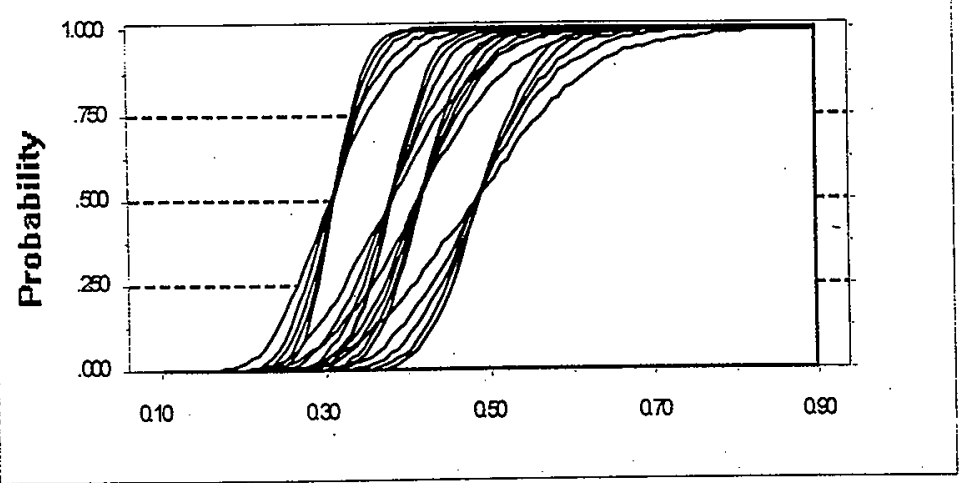


HNF-2234, Rev. 2

water_two_ovrly.xls

Crystal Ball Report

Simulation started on 9/24/98 at 9:54:08

Simulation stopped on $9 / 24 / 98$ at 10:00:57

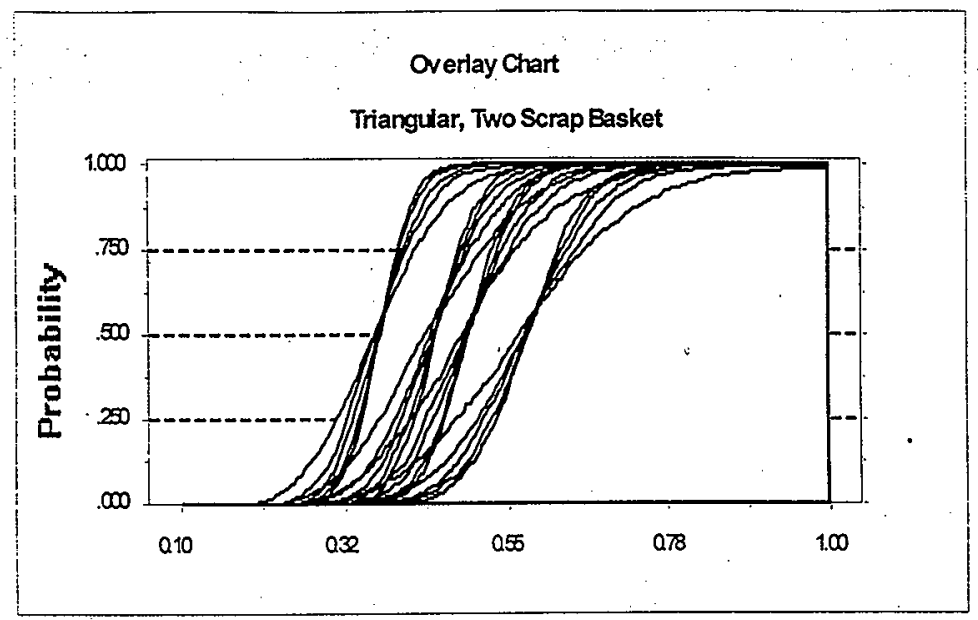


HNF-2234, Rev. 2

lognormal_rev3_zero_ovrly.xis

Crystal Ball Report

Simulation started on $9 / 25 / 98$ at $14: 24: 17$

Simulation stopped on $9 / 25 / 98$ at $14: 36: 02$

\section{Queray Chat}

Lognama, Nb Scrap Baskets

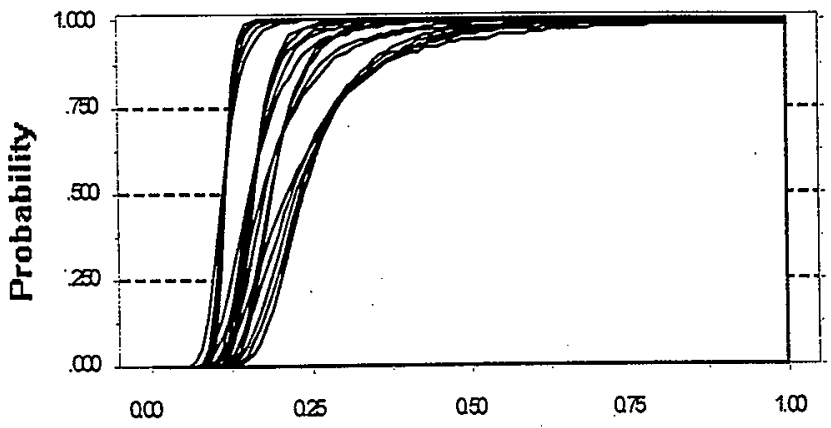


HNF-2234, Rev. 2

lognormal_rev3_one_ovrly.xls

Crystal Ball Report

Simulation started on $9 / 25 / 98$ at $14: 24: 17$

Simulation stopped on $9 / 25 / 98$ at $14: 36: 02$

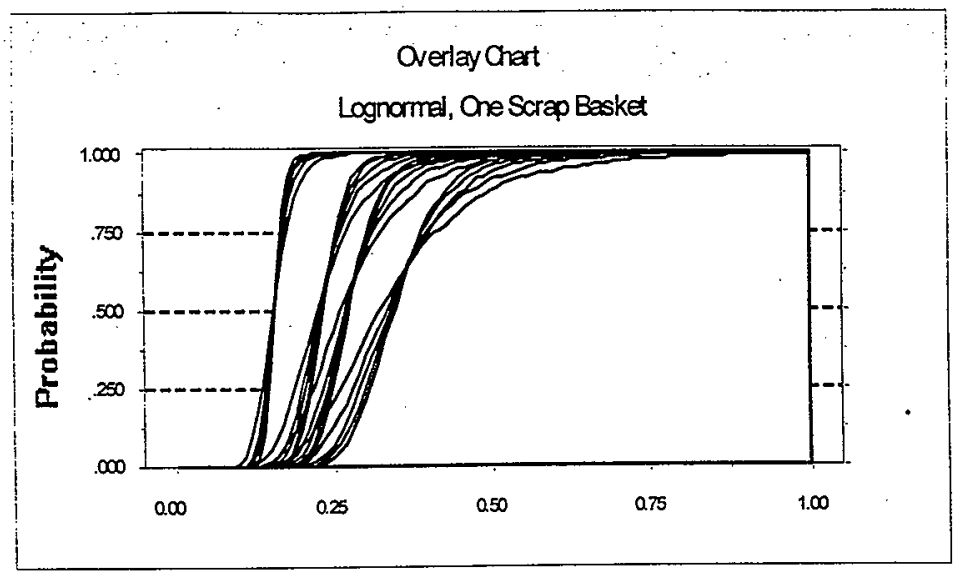


HNF-2234, Rev. 2

lognormal_rev3_two_ovrly.xis

Crystal Ball Report

Simulation started on 9/25/98 at 15:13:18

Simulation stopped on 9/25/98 at 15:19:04

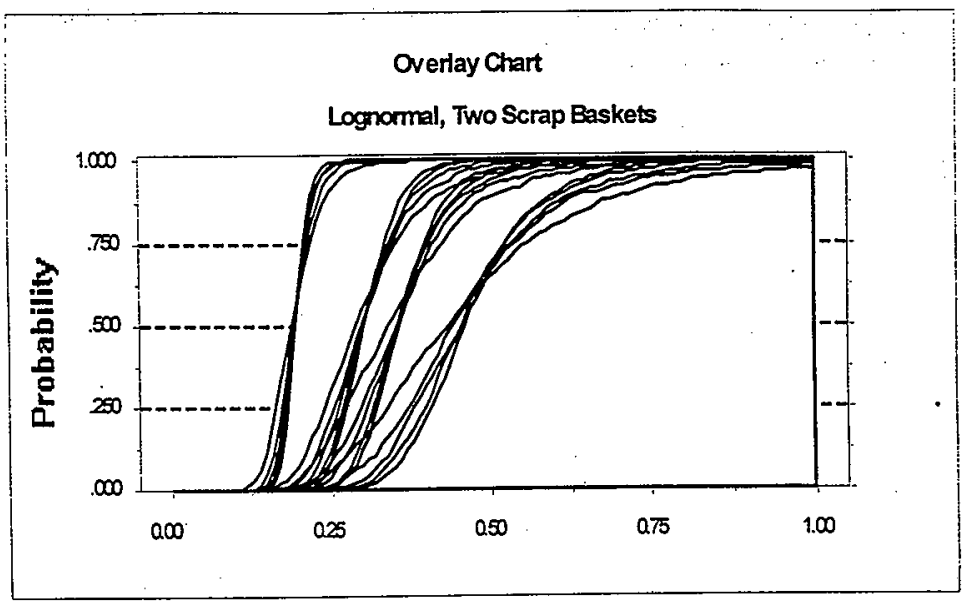


HNF-2234, Rev. 2

Weibull_zero_ovrly.xls

Crystal Ball Report

Simulation started on $9 / 25 / 98$ at $15: 36: 48$

Simulation stopped on $9 / 25 / 98$ at $15: 42: 28$

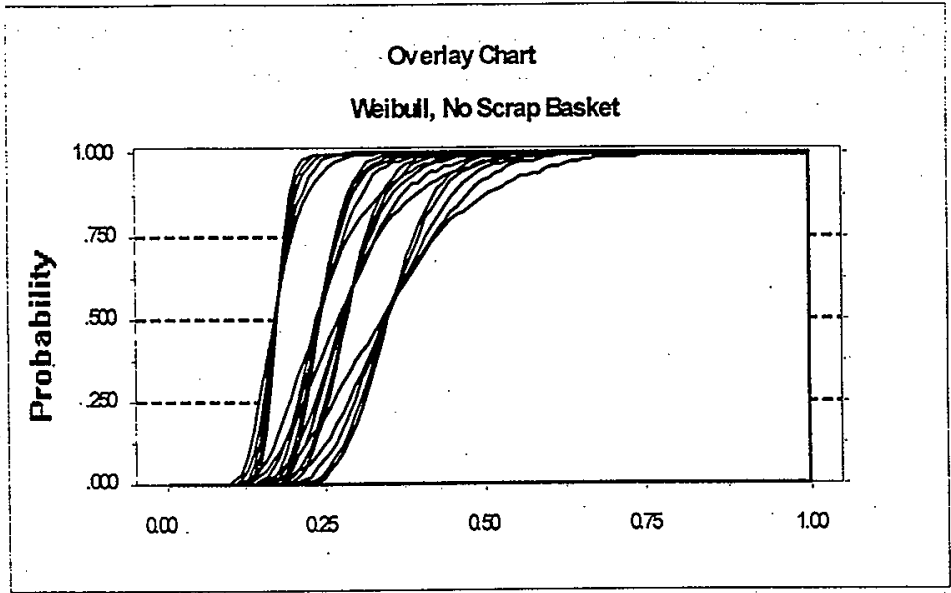


HNF-2234, Rev. 2

weibull_one_ovrly.xls

\section{Crystal Ball Report}

Simulation started on 9/24/98 at 11:32:22

Simulation stopped on $9 / 24 / 98$ at $11: 39: 11$

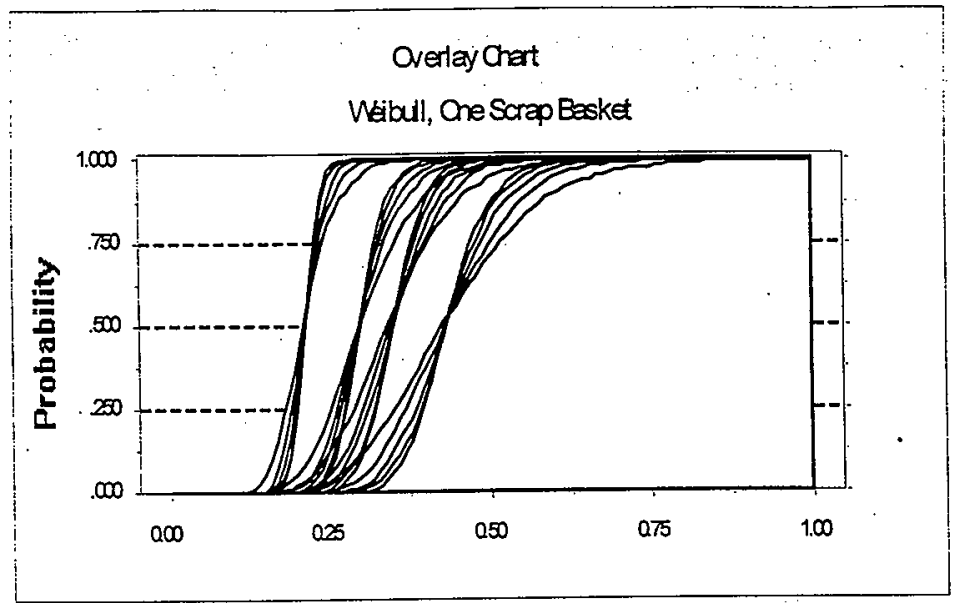


HNF-2234, Rev. 2

weibull_tow_ovrly.xis

Crystal Ball Report

Simulation started on 9/24/98 at $11: 46: 43$

Simulation stopped on $9 / 24 / 98$ at $11: 53: 48$

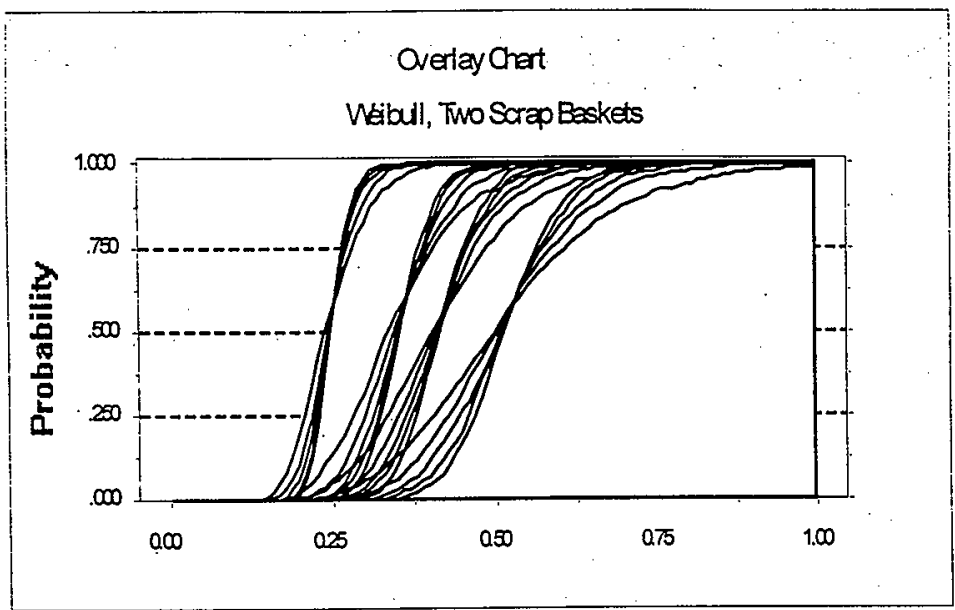


HNF-2234, Rev. 2

APPENDIX H

ANDERSON-DARLING STATISTIC SIGNIFICANCE LEVELS

\section{Table H-1:}

Anderson-Darling Statistic Distribution

$q=P\left(A^{2}<z\right)$ [D'Agostino and Stephens, 1986]

\begin{tabular}{|c|l|}
\hline$z$ & $q^{(1)}$ \\
\hline 0.100 & 0.0000 \\
0.200 & 0.0096 \\
0.300 & 0.0618 \\
0.400 & 0.1513 \\
0.500 & 0.2532 \\
0.600 & 0.3520 \\
0.700 & 0.4412 \\
0.800 & 0.5190 \\
0.900 & 0.5858 \\
1.000 & 0.6427 \\
1.100 & 0.6912 \\
1.200 & 0.7324 \\
1.300 & 0.7677 \\
1.400 & 0.7973 \\
1.500 & 0.8253 \\
\hline
\end{tabular}


HNF-2234, Rev. 2

\section{APPENDIX I \\ WATER CONTENT USING FINAL VALUE \\ FOR CANISTER PARTICULATE MASS}

A limited set of cases was re-run using the final nominal value for canister particulate mass per assembly ( 2.41 grams/assy). Recall that our method preserved the nominal value as the median of the log-normal distribution. For canister particulate mass/assembly, the median value was shifted from 2.22 grams to 2.41 grams, which shifted the mean value from 3.94 grams to 4.05 grams, which is a $2.8 \%$ increase in the mean. Of course, as the mean shifts upward slightly, the standard deviation must be reduced slightly to fit the percentile for the high value, be it $95 \%$ or $90 \%$.

Table I-1 shows results and comparisons for six cases:

1. Log-Normal, Zero Scrap Baskets, $95 \%, 10$ Groups

2. Log-Normal, Zero Scrap Baskets, $90 \%, 10$ Groups

3. Log-Normal, One Scrap Basket, 95\%, 10 Groups

4: Log-Normal, One Scrap Basket, 90\%, 10 Groups

5. Log-Normal, Two Scrap Baskets, $95 \%, 10$ Groups

6. Log-Normal, Two Scrap Baskets, 90\%, 10 Groups

Differences are noticeable only for the case with no scrap baskets. In cases with one or two scrap baskets, the adhering particulate contributes the preponderance of the total water mass, and slight changes in the canister particulate are not important. Given the nature of our Monte Carlo calculations, where slight deviations occur from one run to the next regardless of the input, a minor $(\sim 3 \%)$ change in one of several input variables does not produce significant change. 


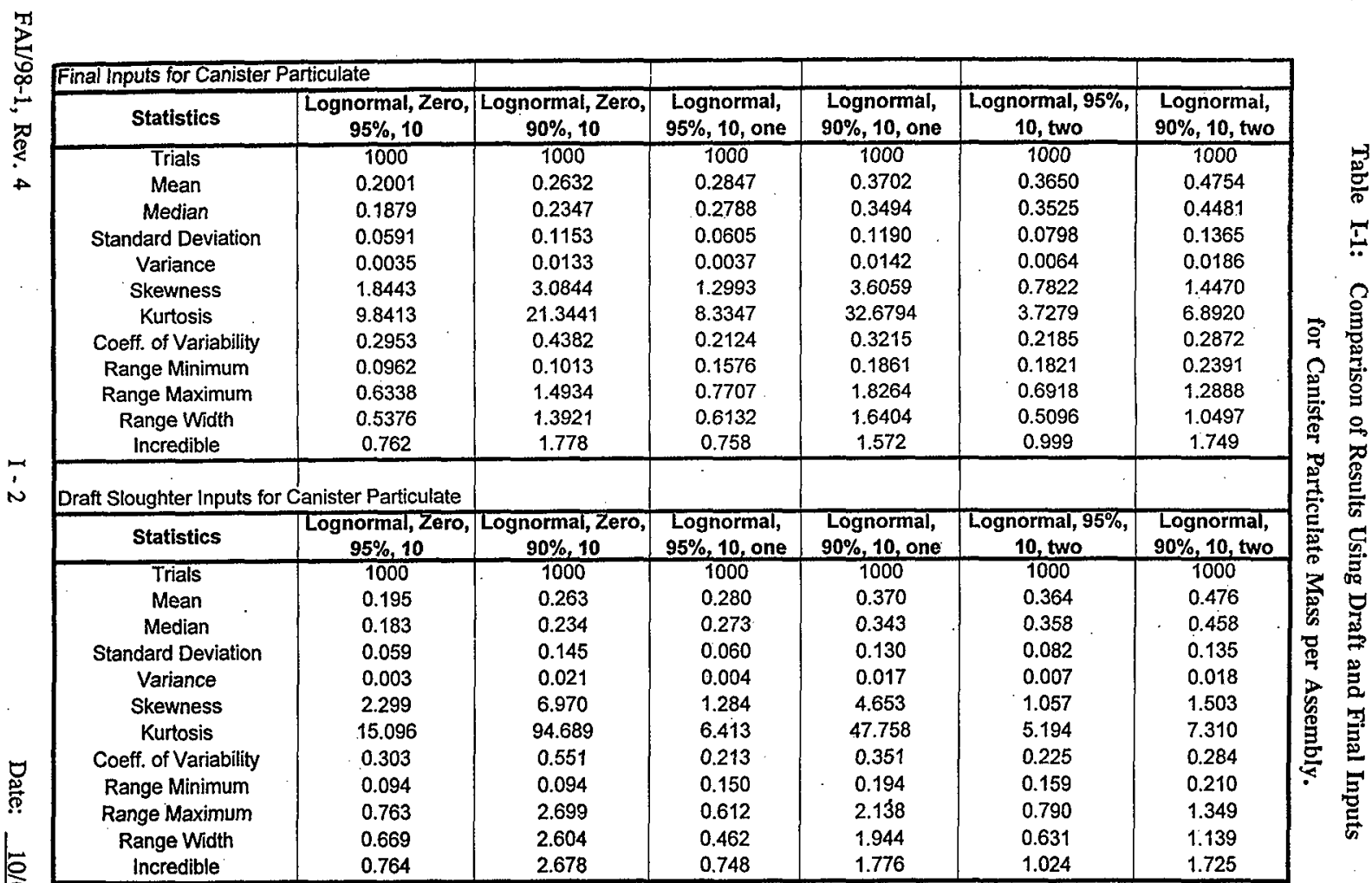


HNF-2234, Rev. 2

\section{APPENDIX $\mathrm{J}$ \\ QUALITY ASSURANCE DOCUMENTS}

Included here are:

1. Calculation Note Cover Sheet.

2. Calculation Note Methodology Checklist. 


\section{CalCulation Note COVER SHEET}

\section{SECTION TO BE COMPLETED BY AUTHOR(S):}

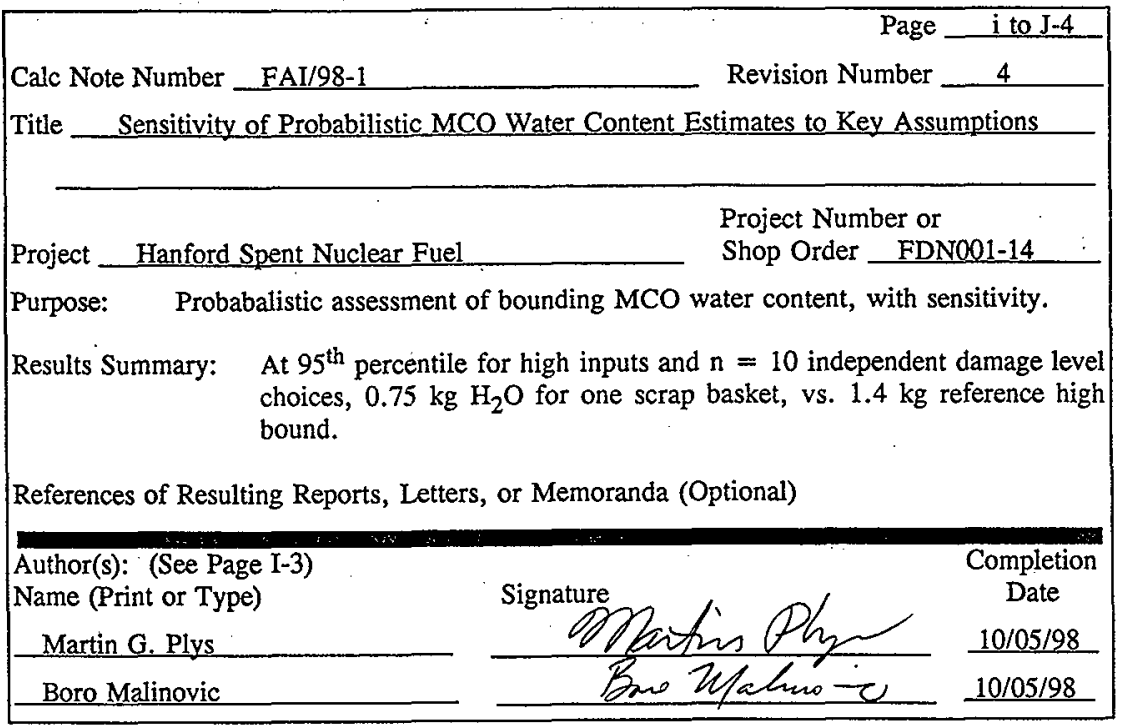

\section{SECTION TO BE COMPLETED BY VERIFIER(S):}

Verifier(s): (See Page I-3)

Name (Print or Type)

Martin G. Plys

Boro Malinovic

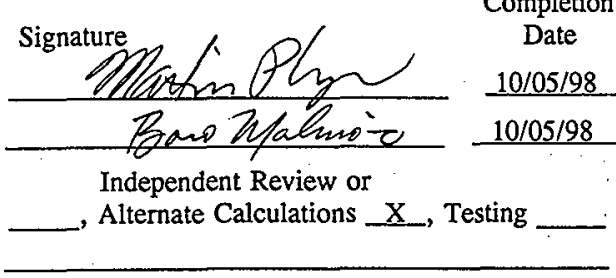

Completion

Shop Order FDNO01-14

Boro Malinovic

Method of Verification: Design Review Other (specify)

\section{SECTION TO BE COMPLETED BY MANAGER:}

Responsible Manager:

Name (Print or Type)

Martin G. Plys

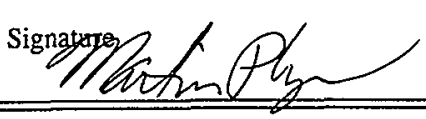

Approval

Date 
Authorship and Review of this Calculation Note is as Follows:

\begin{tabular}{|c|c|c|}
\hline Section & Author & Reviewer \\
\hline 1 & M.G. Plys & B. Malinovic \\
2 & M.G. Plys & B. Malinovic \\
4 & M.G. Plys & B. Malinovic \\
5.1 & M.G. Plys & B. Malinovic \\
5.2 & M.G. Plys & B. Malinovic \\
5.3 & B. Malinovic & M.G. Plys \\
5.4 & B. Malinovic & M.G. Plys \\
6 & B. Malinovic & M.G. Plys \\
App. A & M.G. Plys & B. Malinovic \\
App. B & B. Malinovic & M.G. Plys \\
App. C & B. Malinovic & M.G. Plys \\
App. D & B. Malinovic & M.G. Plys \\
App. E & M.G. Plys & B. Malinovic \\
App. F & B. Malinovic & M.G. Plys \\
App. G & B. Malinovic & M.G. Plys \\
App. H & B. Malinovic & M.G. Plys \\
App. I & B. Malinovic & M.G. Plys \\
App. J & N/A & M.G. Plys \\
\hline
\end{tabular}


CALC NOTE NUMBER _ FAI/98-1_REV. 4 PAGE i to J-4

\section{CALCULATION NOTE METHODOLOGY CHECKLIST}

\section{CHECKLIST TO BE COMPLETED BY AUTHOR(S) (CIRCLE APPROPRIATE RESPONSE)}

1. Is the subject and/or the purpose of the design analysis clearly stated? ....... NO

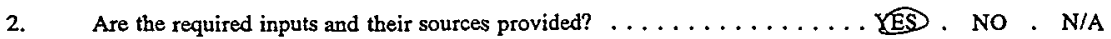

3. Are the assumptions clearly identified and justified? ..........ES . NO . N/A

4. Are the methods and units clearly identified? ............ES . NO . N/A

5. Have the limits of applicability been identified? ............ . NO . N/A (i.e., Is the analysis for a 3 or 4 loop plant or for a single application.)

6. Are the results of literature searches, if conducted; or other background data provided? ..................... N

7. Are all the pages sequentially numbered and identified by the calculation note number? $\ldots \ldots \ldots \ldots \ldots \ldots \ldots \ldots \ldots \ldots \ldots \ldots \ldots \ldots \ldots \ldots$ No

8. Is the project or shop order clearly identified? ...........

9. Has the required computer calculation information been provided? ....... N/A

10. Were the computer codes used under configuration control? ... . . . . YES . NO . M

11. Was the computer code(s) used applicable for modeling the physical and/or computational problems identified? $\ldots \ldots \ldots \ldots \ldots \ldots \ldots \ldots \ldots \ldots \ldots$. NO . N/A (i.e., Is the correct computer code being used for the intended purpose.)

12. Are the results and conclusions clearly stated? . . . NO

13. Are Open Items properly identified? ................ YES . No . NA

14. Were approved Design Control practices followed without exception? .....YES . NO * NA (Approved Design Control practices refers to guidance documents within NSD that state how the work is to be performed, such as how to perform a LOCA analysis.)

15. Have all related contract requirements been met?

ES. NO . N/A

NOTE: If NO to any of the above, Page Number containing justification 


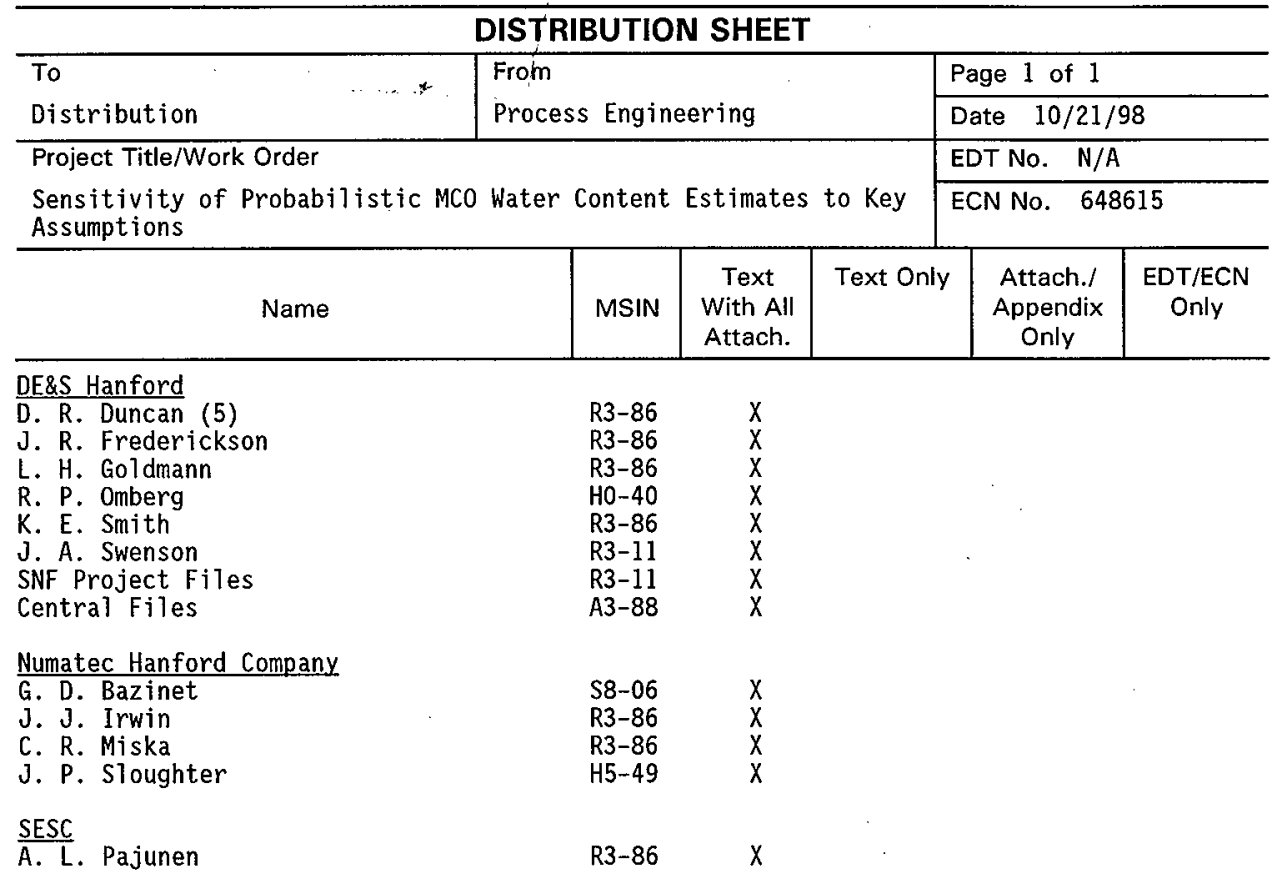

